\title{
Nanoaerosols Including Radon Decay Products in Outdoor and Indoor Air at a Suburban Site
}

\author{
Mateja Smerajec and Janja Vaupotič \\ Department of Environmental Sciences, Radon Center, Jožef Stefan Institute, Jamova cesta 39, 1000 Ljubljana, Slovenia \\ Correspondence should be addressed to Janja Vaupotič, janja.vaupotic@ijs.si
}

Received 26 July 2011; Revised 15 October 2011; Accepted 18 October 2011

Academic Editor: Laura Canesi

Copyright () 2012 M. Smerajec and J. Vaupotič. This is an open access article distributed under the Creative Commons Attribution License, which permits unrestricted use, distribution, and reproduction in any medium, provided the original work is properly cited.

\begin{abstract}
Nanoaerosols have been monitored inside a kitchen and in the courtyard of a suburban farmhouse. Total number concentration and number size distribution $(5-1000 \mathrm{~nm})$ of general aerosol particles, as measured with a Grimm Aerosol SMPS+C 5.400 instrument outdoors, were mainly influenced by solar radiation and use of farming equipment, while, indoors, they were drastically changed by human activity in the kitchen. In contrast, activity concentrations of the short-lived radon decay products ${ }^{218} \mathrm{Po},{ }^{214} \mathrm{~Pb}$, and ${ }^{214} \mathrm{Bi}$, both those attached to aerosol particles and those not attached, measured with a Sarad EQF3020-2 device, did not appear to be dependent on these activities, except on opening and closing of the kitchen window. Neither did a large increase in concentration of aerosol particles smaller than 10 or $20 \mathrm{~nm}$, with which the unattached radon products are associated, augment the fraction of the unattached decay products significantly.
\end{abstract}

\section{Introduction}

Air is an aerosol with suspended particulate matter. The particle size ranges from several $\mathrm{nm}$ for molecular clusters to about $100 \mu \mathrm{m}$ for fog droplets and dust particles. Particles larger than $100 \mu \mathrm{m}$ cannot remain suspended in air and may not therefore be considered as aerosols [1]. The particle size, structure, and chemical composition of aerosols are of key importance for climate and environmental health and are therefore of great interest to aerosol scientists, atmospheric chemists and physicists, and toxicologists and are of serious concern to the regulatory bodies responsible for public health [2-4].

Particulates are emitted by a number of various human activities. They are released by various industries, such as thermal power plants burning fossil fuel or biomass, incinerators, mineral mining and milling facilities, and others. In urban areas where an important or even major particle source is traffic [3-9], aerosol concentration is an order of magnitude higher than those in suburban or rural areas. Nanoparticles are also produced intentionally [10] to be used as constituents in electronics, medicines, pharmaceuticals, cosmetics, paints, and a variety of other consumers products.
Nanotechnology is increasing fast and so is the possibility for the nanoparticles to appear in the air of workplaces and be released into the outdoor atmosphere and subsequently enter living environments [11].

During breathing of air, aerosol particulates are partly deposited on the walls of the respiratory tract. Mathematical simulations have shown that their deposition strongly depends on the particle size [12-15]. Thus, for instance [16], about $90 \%$ of the inhaled $1 \mathrm{~nm}$ particles are deposited in the nasopharyngeal region and the rest in the tracheobronchial region, with no deposition in the alveolar region. Five nm particles are almost equally deposited in all three regions. On the other hand, half of the $20 \mathrm{~nm}$ particles are deposited in the alveolar region and the remaining half equally in the other two regions. Physical translocation and clearance in the respiratory tract are also size dependent. Aerosol particles enter the body also by ingestion and absorption through skin. This uptake is more efficient for smaller particles than for larger ones; nonetheless it is minor in comparison to inhalation. Because the ratio of the numbers of surface versus bulk atoms exponentially increases with reducing size, smaller particles are expected to be chemically and biochemically more reactive, and thus potentially more toxic, than larger 


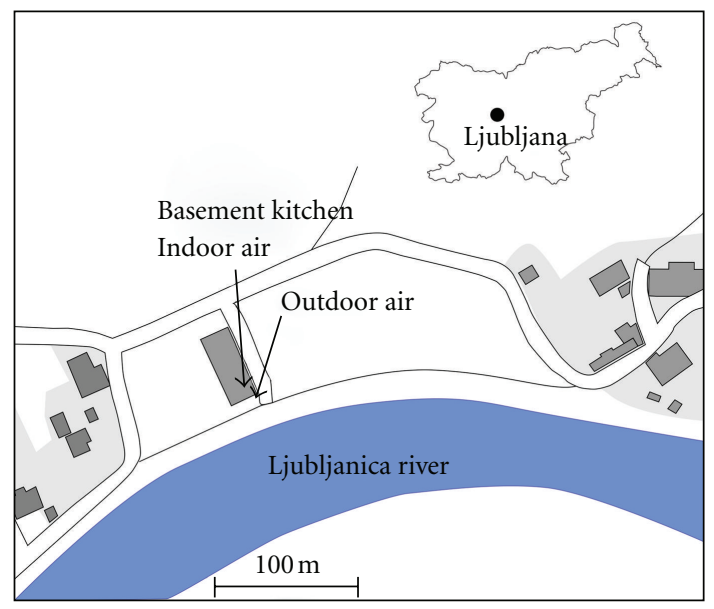

FIGURE 1: Layout of the measurement site.

ones [16]. It has been now recognised that nanoparticles cause oxidation stress, pulmonary inflammation, and cardiovascular events, although the mechanisms of these detrimental effects are not yet understood entirely $[4,16-$ 18]. Aerosols also have an indirect effect on human health because they serve as a carrier for the uptake of airborne radionuclides by inhalation, as explained below.

Three isotopes of radioactive noble gas radon are created by $\alpha$-transformation of radium within the primordial radioactive decay chains in the earth's crust [19]: ${ }^{220} \mathrm{Rn}$ (thoron, half-life $t_{1 / 2}=55.6 \mathrm{~s}$ ) from ${ }^{224} \mathrm{Ra}$ in the ${ }^{232} \mathrm{Th}$ chain, ${ }^{222} \mathrm{Rn}$ (radon, 3.82 days) from ${ }^{226} \mathrm{Ra}$ in the ${ }^{238} \mathrm{U}$ chain, and ${ }^{219} \mathrm{Rn}$ (actinon, 3.9 s) from ${ }^{223} \mathrm{Ra}$ in the ${ }^{235} \mathrm{U}$ chain. Due to its recoil energy, a fraction of radon atoms succeed in leaving the mineral grain and thus enter the void space. From there, radon travels through the medium either by diffusion or, more effectively and over longer distances, carried by gas or water [20]. On its way, it accumulates in underground rooms (mines, karst caves, fissures, basements) and eventually enters the atmosphere and appears in the air of living and working environments. Usually only ${ }^{222} \mathrm{Rn}$ appears at significant levels in the ambient air because of its very long half-life, as compared with the half-life of ${ }^{220} \mathrm{Rn}$ and especially that of ${ }^{219} \mathrm{Rn}$. We will deal here with ${ }^{222} \mathrm{Rn}$ and will call it hereafter radon or $\mathrm{Rn}$.

Radon $\left({ }^{222} \mathrm{Rn}\right) \quad \alpha$-transformation is followed by a radioactive chain of its successive short-lived decay products $(\mathrm{RnDP}):{ }^{218} \mathrm{Po}(\alpha, 3.05 \mathrm{~min}) \rightarrow{ }^{214} \mathrm{~Pb}(\beta$ and $\gamma, 26.8 \mathrm{~min}) \rightarrow$ ${ }^{214} \mathrm{Bi}(\beta$ and $\gamma, 19.7 \mathrm{~min}) \rightarrow{ }^{214} \mathrm{Po}(\alpha, 164 \mu \mathrm{s})$ [19]. Initially, the products appear mostly as positive ions [21-23], which react with molecules of trace gases and vapours (mostly water) in air, are partly oxidized, and form small charged clusters. Eventually, they become neutralised [22, 24]. These processes are accompanied and followed by attachment of clusters [23, 25-28], both charged and already neutralised, to background atmospheric aerosol particles. According to a review by Porstendörfer and Reineking [22], the activity median diameter (AMD) of the RnDP clusters falls into the range from $0.9 \mathrm{~nm}$ to $30 \mathrm{~nm}$, while the activity median aerodynamic diameter (AMAD) of the aerosol particles carrying RnDP attached falls in the range from $50 \mathrm{~nm}$ to $500 \mathrm{~nm}$. In a radon chamber containing carrier aerosol, AMD values of $0.82,0.79,1.70$, and $0.82 \mathrm{~nm}$ were obtained for the unattached ${ }^{218} \mathrm{Po},{ }^{214} \mathrm{~Pb},{ }^{214} \mathrm{Bi}$, and ${ }^{214} \mathrm{Po}$, respectively, [29]. The border between unattached and attached is not fixed. Thus, for indoor air, RnDP associated with particles smaller than $20 \mathrm{~nm}$, grouped around $5 \mathrm{~nm}$ [30], and particles in the $0.5-1.5 \mathrm{~nm}$ size range may be considered as unattached RnDP [31]. Measurements in indoor air also showed that within the unattached region of $<10 \mathrm{~nm}$, two (with AMD of 0.80 and $4.20 \mathrm{~nm}$ ) or even three activity size distribution peaks $(0.60,0.85$ and $1.25 \mathrm{~nm})$ may appear [32, 33]. In addition, RnDP appeared in the nucleation (attached to particles of $14-40 \mathrm{~nm})$, accumulation $(210-310 \mathrm{~nm})$, and coarse modes (3000-5000 nm) [32]. In an intercomparison experiment carried out in a test chamber, the AMD values of the unattached RnDP were found in the range from 0.53 to $1.76 \mathrm{~nm}$, followed by a gap until about $50 \mathrm{~nm}$ when the attached RnDP appeared [34].

Total concentration of $\mathrm{RnDP}$ in air is reported as equilibrium equivalent activity concentration $\left(C_{\mathrm{RnDP}}^{\mathrm{A}}, \mathrm{Bq} \mathrm{m}^{-3}\right)$, expressed as [19]

$$
C_{\mathrm{RnDP}}^{\mathrm{A}}=0.1065 C_{218 \mathrm{Po}}^{\mathrm{A}}+0.515 C_{214 \mathrm{~Pb}}^{\mathrm{A}}+0.379 C_{214 \mathrm{Bi}}^{\mathrm{A}},
$$

where $C^{\mathrm{A}}\left(\mathrm{Bq} \mathrm{m}^{-3}\right)$ stands for the individual activity concentrations of ${ }^{218} \mathrm{Po},{ }^{214} \mathrm{~Pb}$, and ${ }^{214} \mathrm{Bi}$. Because of its short half time, ${ }^{214} \mathrm{Po}$ activity is equal to the activity of ${ }^{214} \mathrm{Bi}$ and is therefore already included in the last term of (1). Due to air movement and deposition of RnDP on surfaces, individual activity concentrations of $\mathrm{RnDP}$ are always lower than that of radon $\left(C_{\mathrm{Rn}}^{\mathrm{A}}\right)$, and the secular equilibrium between radon and $\mathrm{RnDP}$ is never reached in the ambient air, its degree being described by the equilibrium factor defined as [19]

$$
F=\frac{C_{\mathrm{RnDP}}^{\mathrm{A}}}{C_{\mathrm{Rn}}^{\mathrm{A}}} .
$$




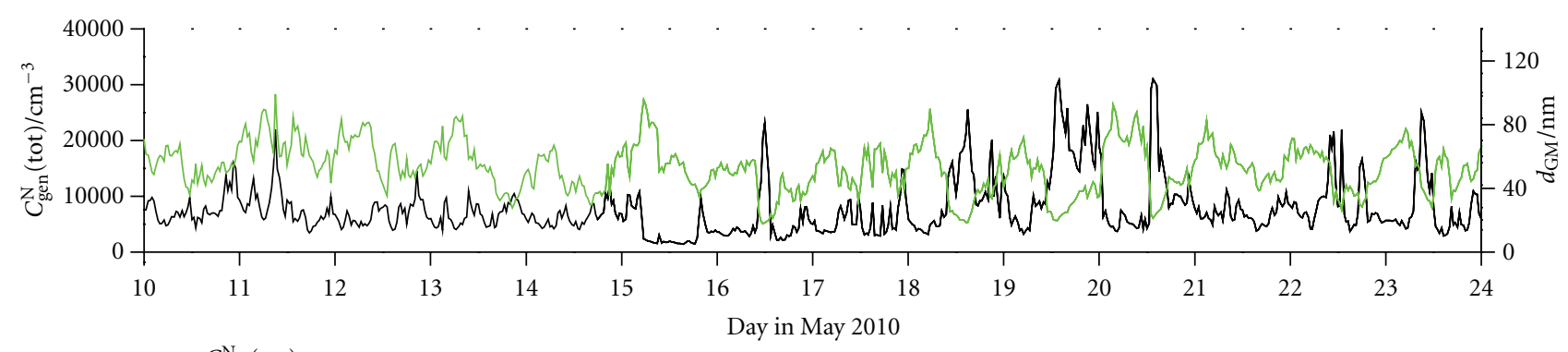

$$
-C_{\mathrm{gen}}^{\mathrm{N}}(\text { tot })
$$

(a)

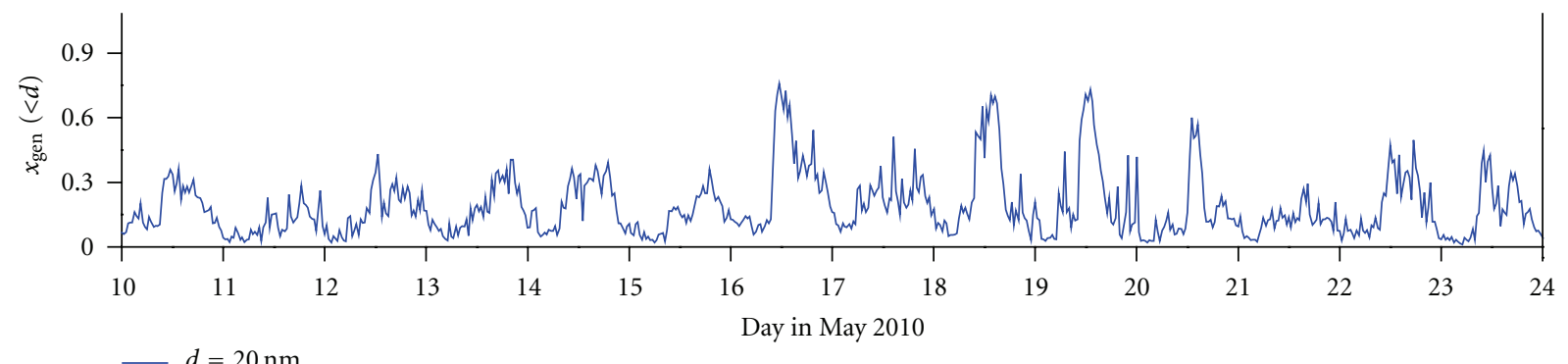

(b)

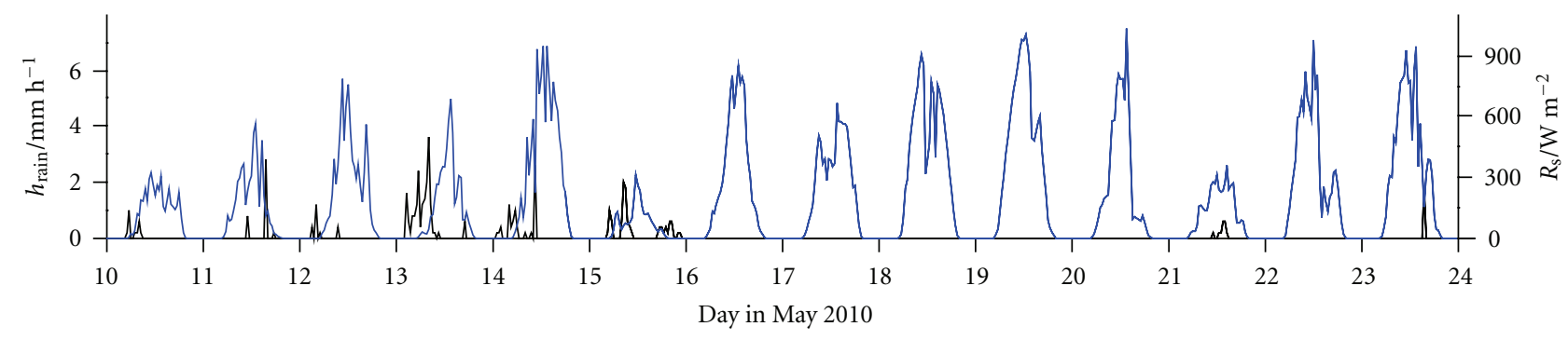

(c)

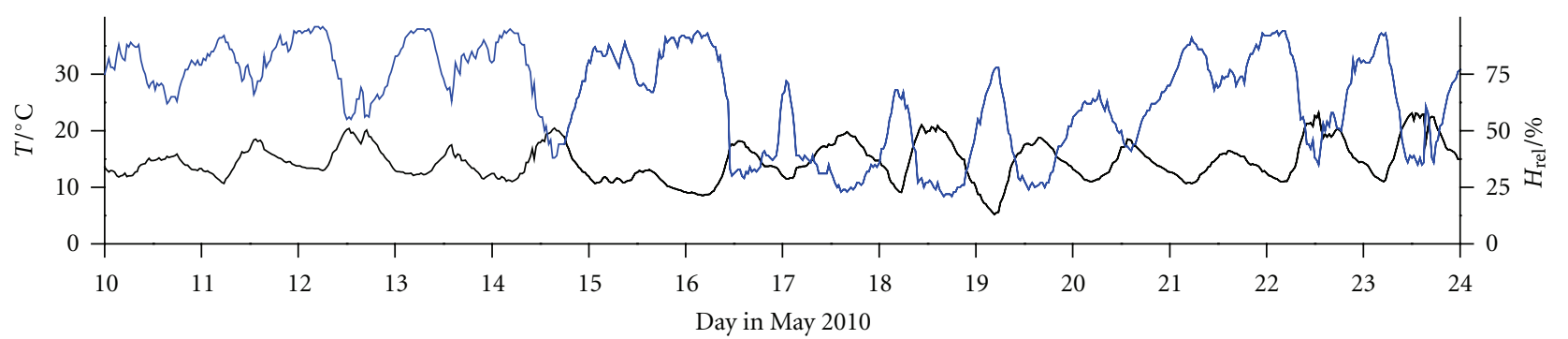

$T$
$-H_{\text {rel }}$

(d)

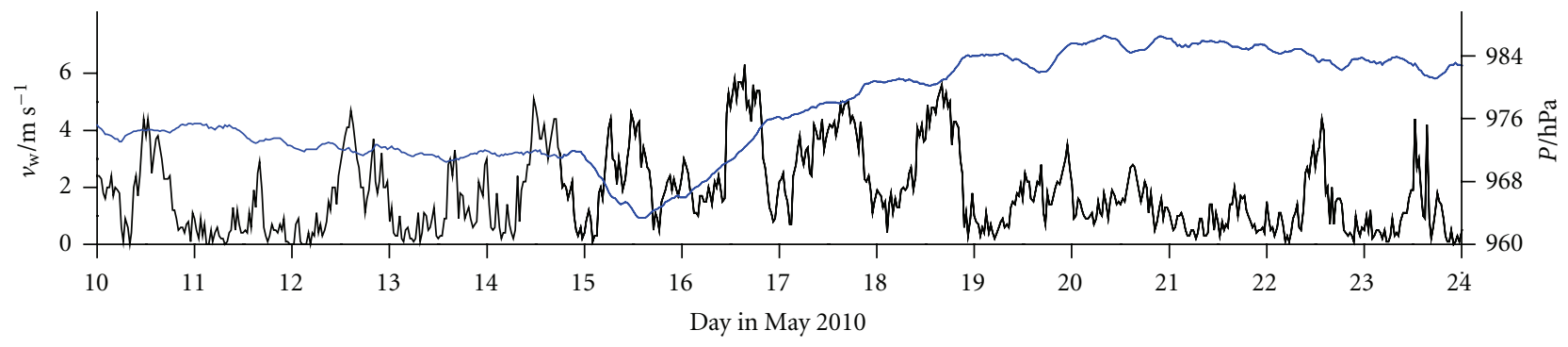

(e)

Figure 2: Continued. 


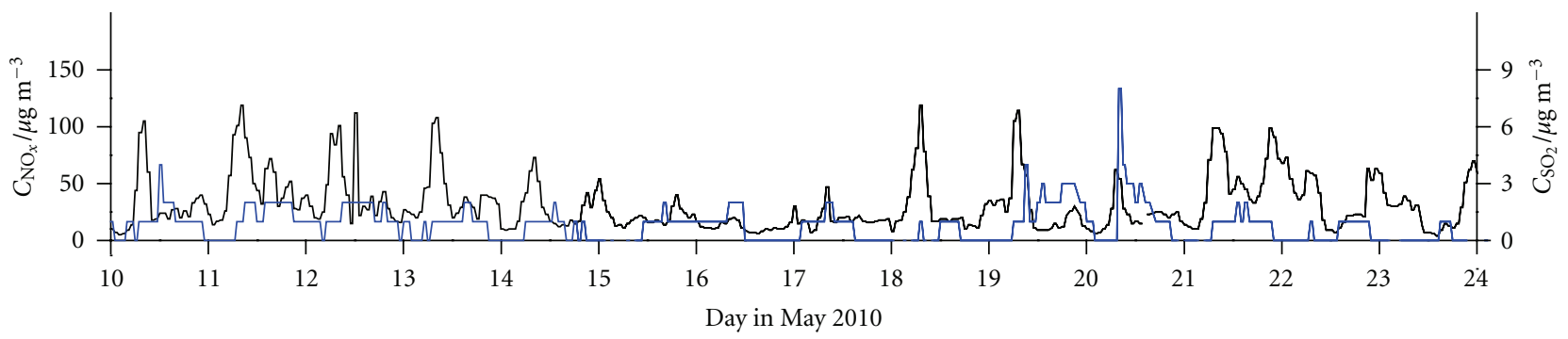

(f)

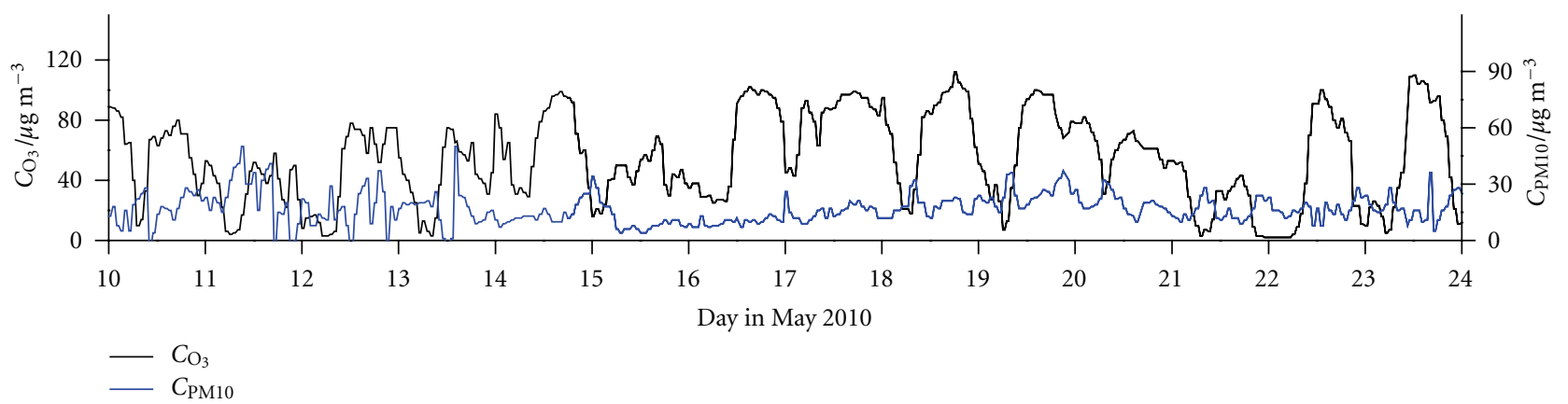

$(\mathrm{g})$

FIgURE 2: Time run of: (a) the total number concentration of general aerosol particles $\left(C_{\mathrm{gen}}^{\mathrm{N}}(\right.$ tot $\left.)\right)$ and geometric mean of their diameters $\left(d_{\mathrm{GM}}\right)$, (b) number fraction of particles smaller than $10 \mathrm{~nm}\left(x_{\text {gen }}(<10)\right)$ and smaller than $20 \mathrm{~nm}\left(x_{\text {gen }}(<20)\right)$, (c) precipitation $\left(h_{\text {rain }}\right)$ and solar radiation $\left(R_{s}\right),(\mathrm{d})$ air temperature $(T)$ and air relative humidity $\left(H_{\mathrm{rel}}\right),(\mathrm{e})$ wind velocity $\left(v_{\mathrm{w}}\right)$ and barometric pressure $(P)$, (f) concentration of $\mathrm{NO}_{x}\left(C_{\mathrm{NO}_{x}}\right)$ and $\mathrm{SO}_{2}\left(C_{\mathrm{SO}_{2}}\right)$, and $(\mathrm{g})$ concentrations of $\mathrm{O}_{3}\left(C_{\mathrm{O}_{3}}\right)$ and aerosol particles smaller than $10 \mu \mathrm{m}\left(C_{\mathrm{PM} 10}\right)$, in outdoor air in front of the dwelling for the period May 10-23, 2010.

Because on the world average, RnDP contribute about half (radon contribution is minor) to the effective dose that a member of the general public receives from all natural radioactivity [35] and are a major cause of lung cancer, second only to cigarette smoking [36], their levels in living and working environments are of serious social concern, and present a great scientific challenge.

For general purposes of radon dosimetry, the International Commission on Radiological Protection in its Publication 65 recommends a dose conversion factor $\left(D_{\text {CF-E }}\right)$ of $4 \mathrm{mSv} \mathrm{WLM}^{-1}$ and $5 \mathrm{mSv} \mathrm{WLM}^{-1}$ at home and in the workplace, respectively, [37], as the conventional values deduced from results of epidemiological studies. Above, 1WLM (working-level-month) is the exposure gained by 170 hour breathing air in which potential $\alpha$-energy concentration of $\operatorname{RnDP}\left(E_{\alpha \mathrm{RnDP}}\right)$ is $1.3 \times 10^{8} \mathrm{MeV} \mathrm{m}^{-3}$. $E_{\alpha \mathrm{RnDP}}\left(\mathrm{MeV} \mathrm{m}^{-3}\right)$ is expressed through the activity concentrations $\left(C^{\mathrm{A}}, \mathrm{Bq} \mathrm{m}^{-3}\right)$ of ${ }^{218} \mathrm{Po},{ }^{214} \mathrm{~Pb}$, and ${ }^{214} \mathrm{Bi}$, as [19]

$$
E_{\alpha \mathrm{RnDP}}=3690 C_{218 \mathrm{Po}}^{\mathrm{A}}+17830 C_{214 \mathrm{~Pb}}^{\mathrm{A}}+113120 C_{214 \mathrm{Bi}}^{\mathrm{A}} .
$$

On the other hand, dose conversion factors can be calculated by applying dosimetric models [12-15]. Following this approach, Birchall et al. $[38,39]$ elaborated the procedure for calculating dose conversion factor $\left(D_{\mathrm{CF}-\mathrm{D}}\right)$, which is used mainly for research purposes. They showed that the parameter most affecting $D_{\text {CF-D }}$, and thus the calculated effective dose, is the fraction $\left(f^{\mathrm{un}}\right)$ of the unattached RnDP, defined as [19]

$$
f^{\mathrm{un}}=\frac{C_{\mathrm{RnDP}}^{\mathrm{Aun}}}{C_{\mathrm{RnDP}}^{\mathrm{A} D}}
$$

Above, $C_{\mathrm{RnDP}}^{\mathrm{Aun}}$ is the equilibrium equivalent concentration of the unattached RnDP, obtained if activity concentrations of only the unattached ${ }^{218} \mathrm{Po},{ }^{214} \mathrm{~Pb}$, and ${ }^{214} \mathrm{Bi}$ are taken into (1). Further, they expressed $D_{\text {CF-D }}$ based on $f^{\text {un }}$ with an empirical formula:

$$
D_{\text {CF-D }}=11.35+43 f^{\text {un }} .
$$

As reviewed by Porstendörfer and Reineking [22], $f$ un differs substantially from environment to environment and place to place, and its value ranges from 0.006 to 0.83 . It appears to be inversely proportional to the number concentration of the background aerosol particles $[40,41]$ and thus to be very low in mines with high aerosol concentration [40] and high in karst caves with very clean air [40-45]. In indoor air, ventilation plays a dominant role in governing $F, C_{\mathrm{RnDP}}^{\mathrm{A}}$, and $f^{\text {un }}$, with latter being significantly lower when air condition is used than in places with electric fans or natural ventilation 


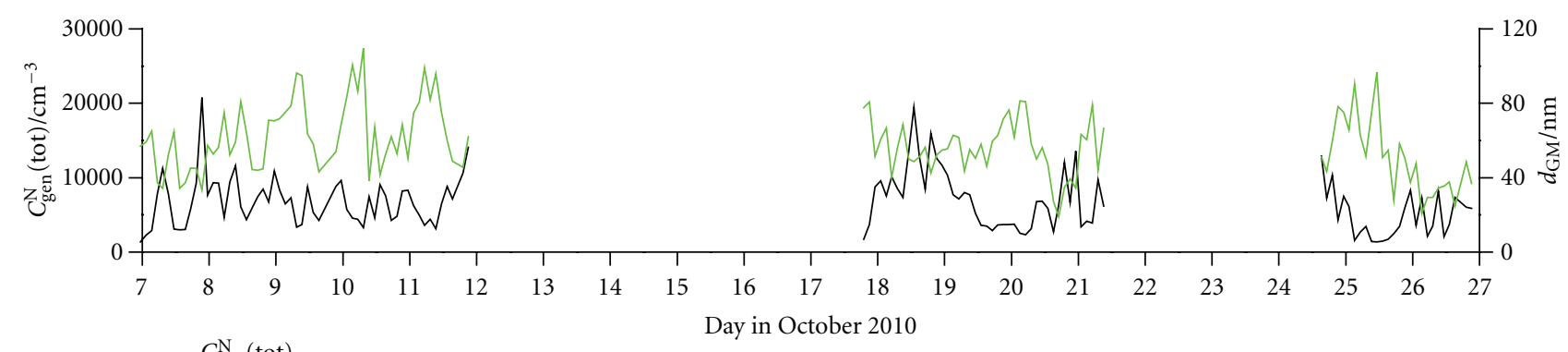

(a)

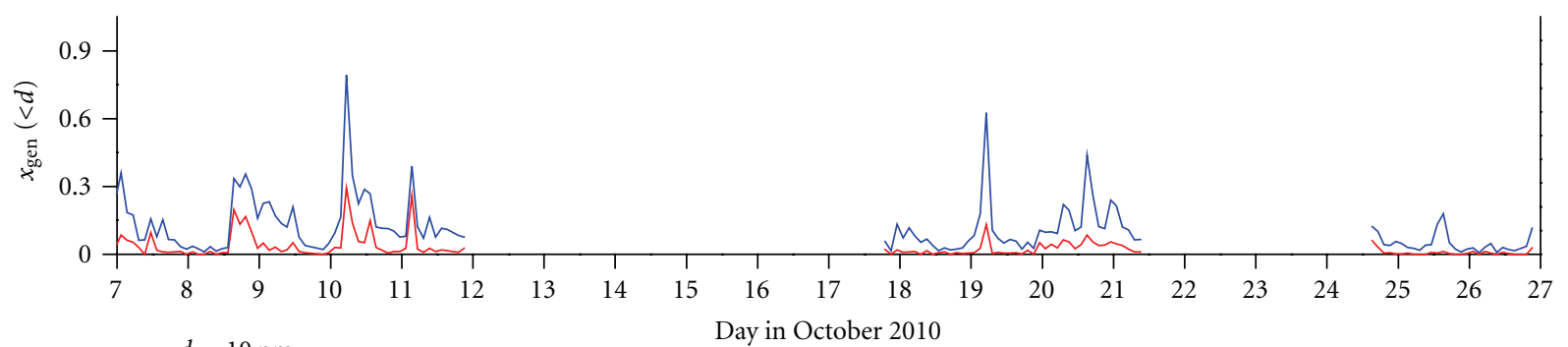

$d=10 \mathrm{~nm}$

$-d=20 \mathrm{~nm}$

(b)

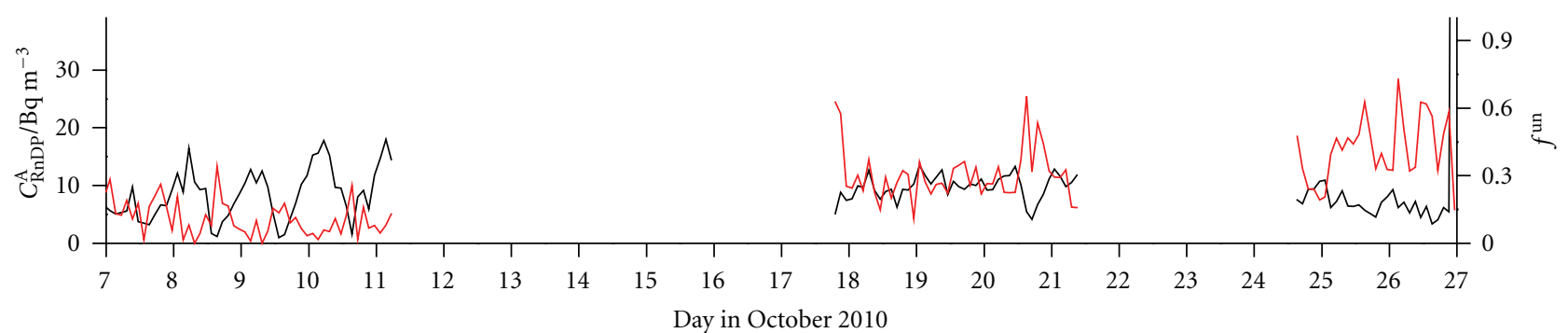

$-C_{\mathrm{RnDP}}^{\mathrm{A}}$
$-f^{\mathrm{un}}$

(c)

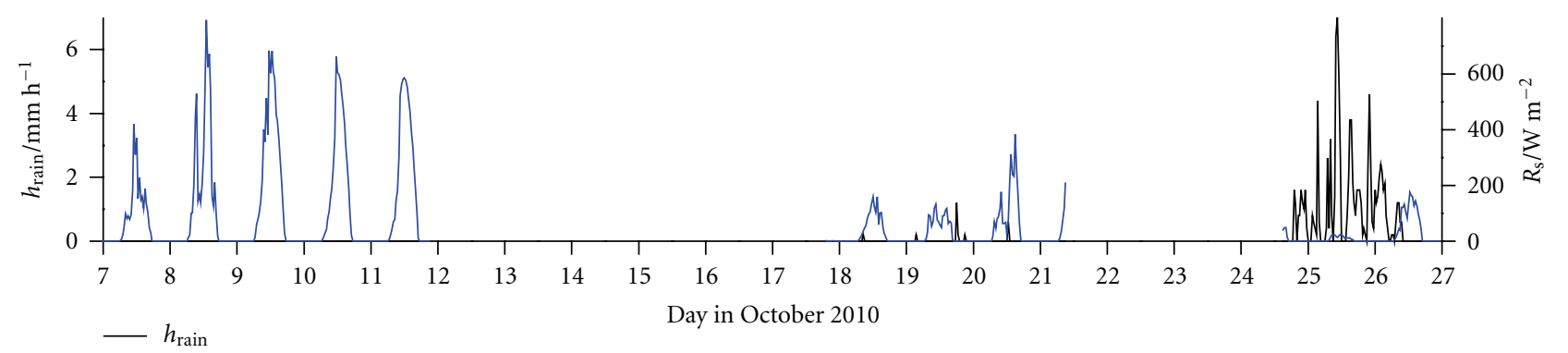

$-h_{\text {rain }}$
$-R_{\mathrm{s}}$

(d)
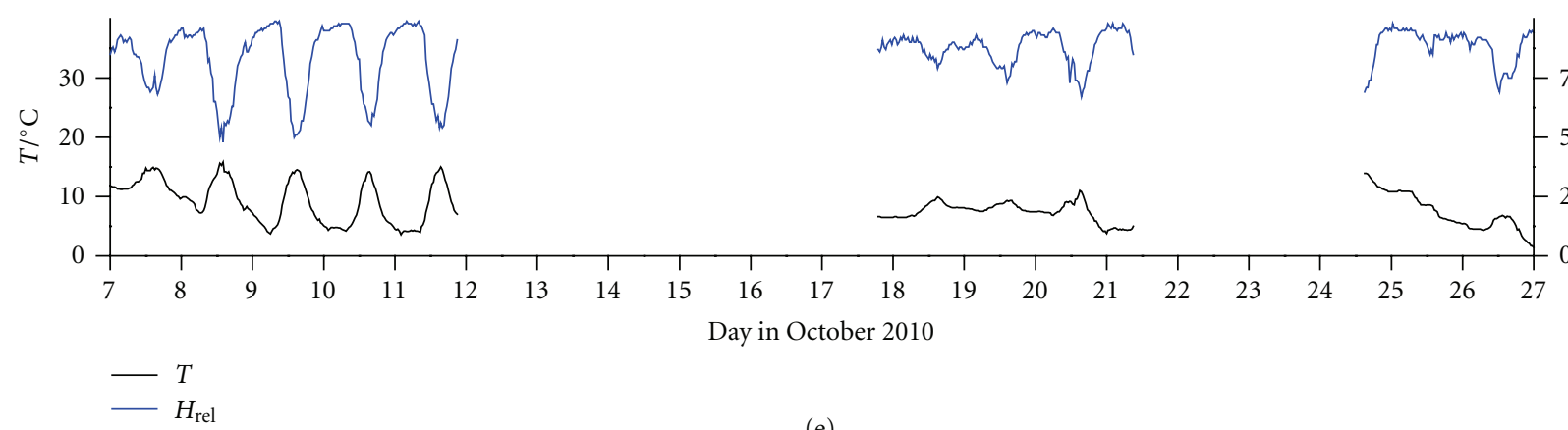


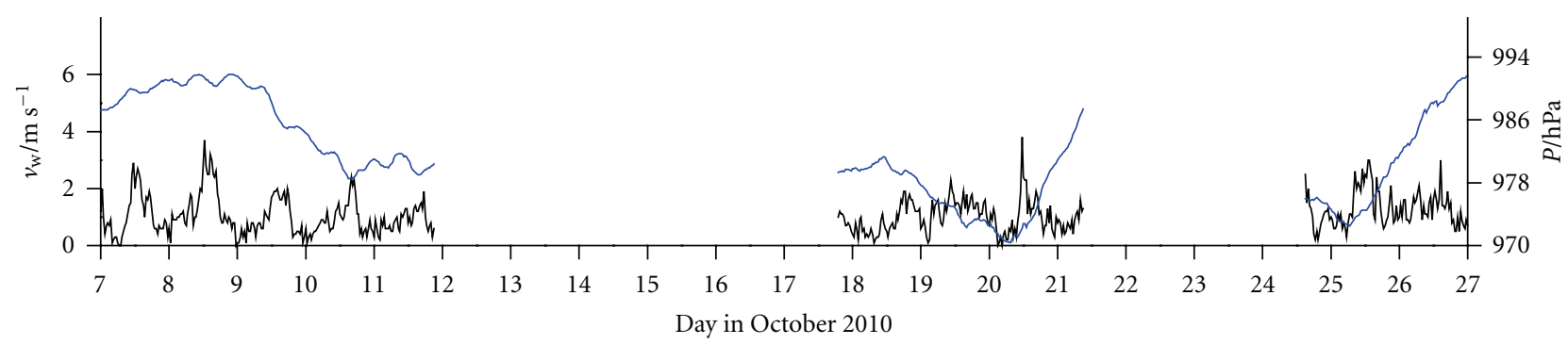

(f)

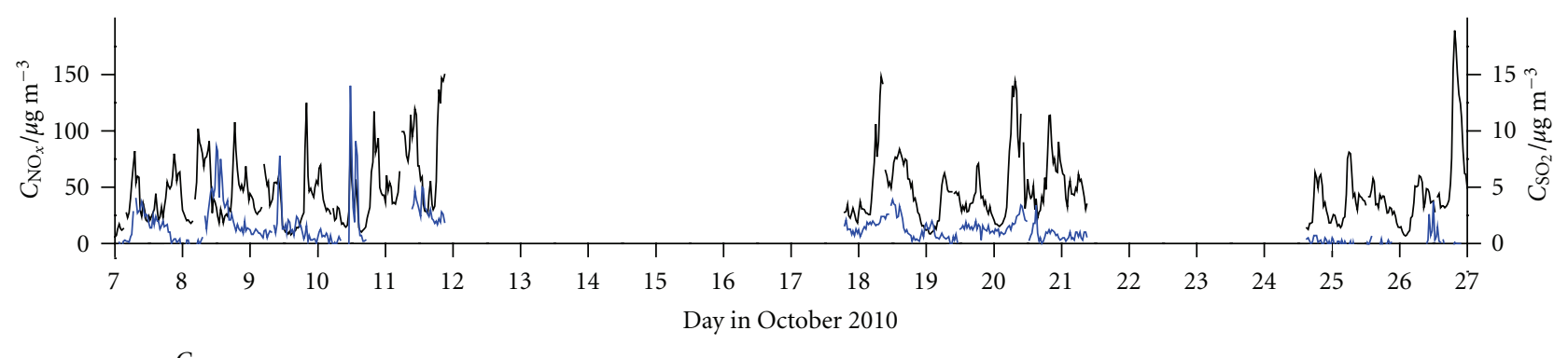
$-\mathrm{CNO}_{x}$
$-\mathrm{CSO}_{2}$

(g)

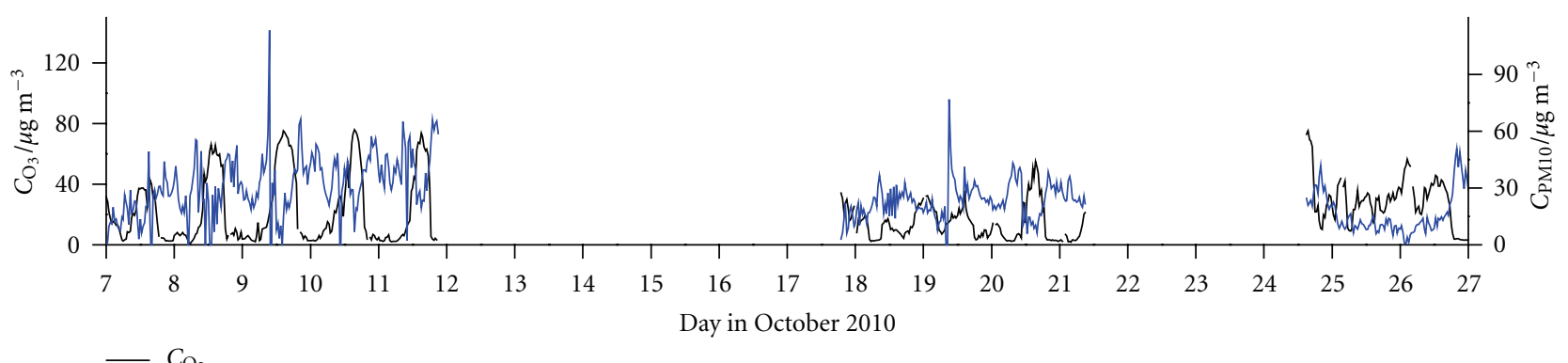

(h)

FIGURE 3: Time run of: (a) the total number concentration of general aerosol particles $\left(C_{\mathrm{gen}}^{\mathrm{N}}(\right.$ tot $\left.)\right)$ and geometric mean of their diameters $\left(d_{\mathrm{GM}}\right)$, (b) number fraction of particles smaller than $10 \mathrm{~nm}\left(x_{\mathrm{gen}}(<10)\right)$ and smaller than $20 \mathrm{~nm}\left(x_{\mathrm{gen}}(<20)\right)$, (c) precipitation $\left(h_{\mathrm{rain}}\right)$ and solar radiation $\left(R_{s}\right),(\mathrm{d})$ air temperature $(T)$ and air relative humidity $\left(H_{\text {rel }}\right),(\mathrm{e})$ wind velocity $\left(v_{\mathrm{w}}\right)$ and barometric pressure $(P)$, (f) concentration of $\mathrm{NO}_{x}\left(C_{\mathrm{NO}_{x}}\right)$ and $\mathrm{SO}_{2}\left(C_{\mathrm{SO}_{2}}\right)$, and $(\mathrm{g})$ concentrations of $\mathrm{O}_{3}\left(C_{\mathrm{O}_{3}}\right)$ and aerosol particles smaller than $10 \mu \mathrm{m}\left(C_{\mathrm{PM} 10}\right)$, in outdoor air in front of the dwelling for the period October 6-26, 2010.

(opening doors and windows) $[46,47]$. Important is also the outside environment as a source of particulate matter, such as proximity of, for example, other buildings, parks, roads, and so forth [47]. The influence of meteorological parameters (temperature, barometric pressure, air humidity, wind speed, and rainfall) [48] is less expressed in air-conditioned places $[47,49]$.

Therefore, knowledge of the number concentration and size distribution of aerosol particles, to which RnDP are associated, is a prerequisite to better understanding the $f^{\text {un }}$ values and their temporal variation in an environment [50]. In the present paper, monitoring of nano-aerosols including radon decay products in outdoor and indoor air at a suburban site is described, and results are presented and commented on.

\section{Experimental}

\subsection{Measuring Techniques}

2.1.1. Radon Decay Products. Individual activity concentrations $\left(C^{\mathrm{A}}, \mathrm{Bq} \mathrm{m}^{-3}\right)$ of ${ }^{222} \mathrm{Rn},{ }^{218} \mathrm{Po},{ }^{214} \mathrm{~Pb}$, and ${ }^{214} \mathrm{Bi} /{ }^{214} \mathrm{Po}$ were measured using the EQF3020-2 device (Sarad, Germany). Air is pumped for 6 minutes at a flow rate of $2.4 \mathrm{dm}^{3} \mathrm{~min}^{-1}$ over a metal mesh grid on which particles smaller than $5 \mathrm{~nm}$ (considered as associated with the unattached $\mathrm{RnDP}$ ) are separated from those above this size (considered as associated with the attached RnDP), and the two fractions are deposited electrostatically on two separate $150 \mathrm{~mm}^{2}$ silicon surface barrier detectors. Gross alpha activity is measured during three consecutive intervals within 110 minutes after the end of pumping, and, applying the Markov 

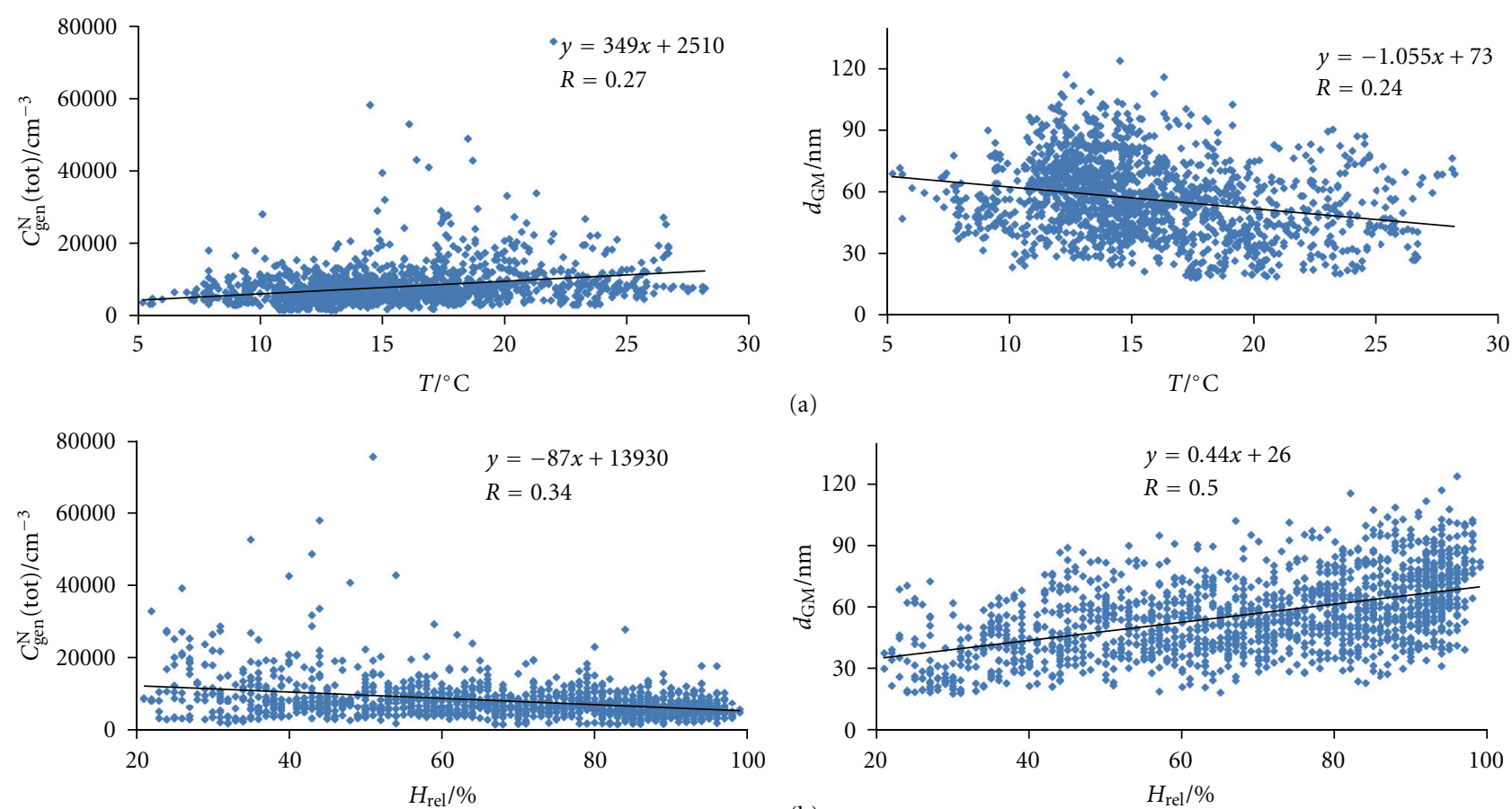

(a)
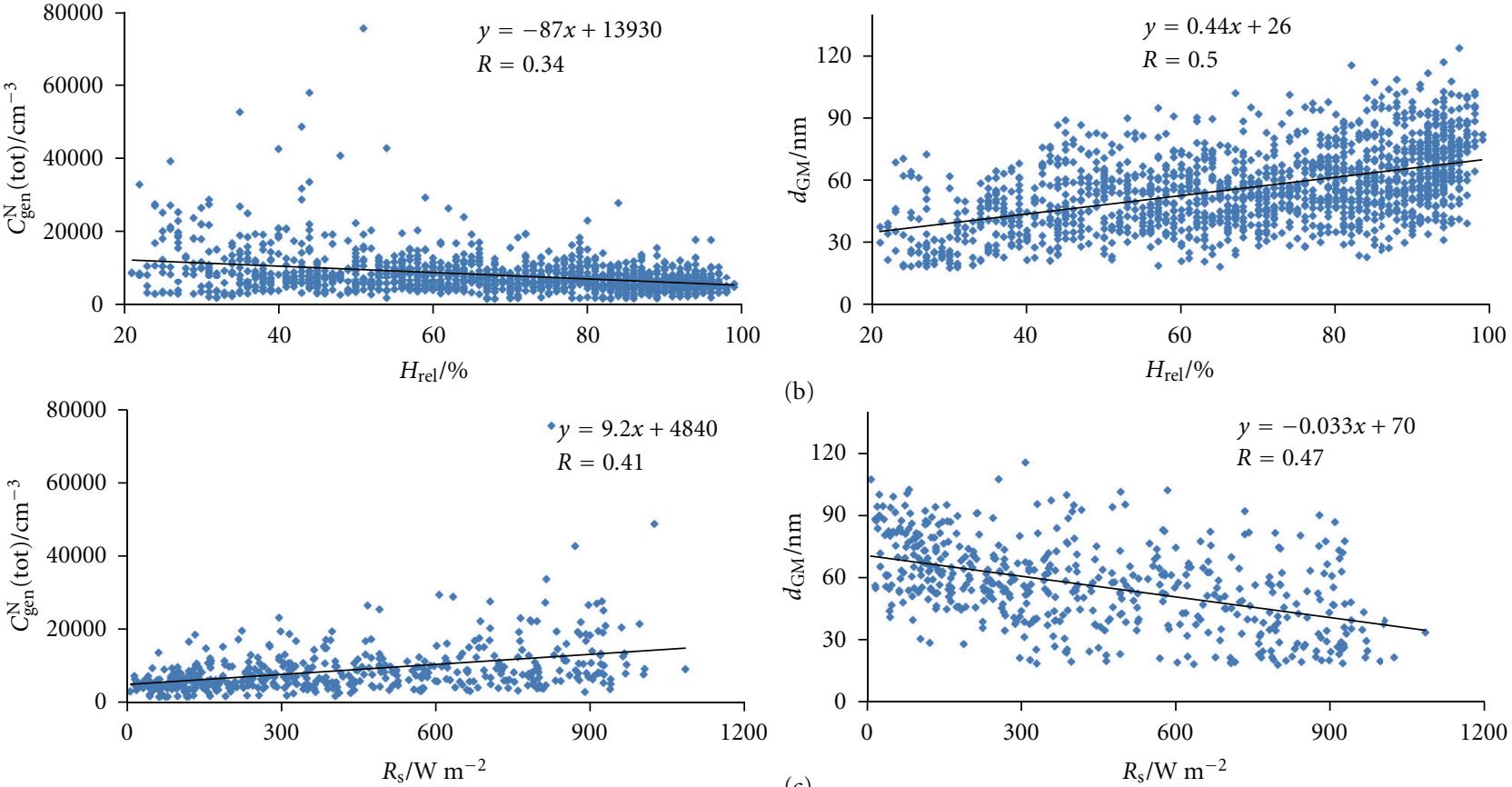

(b)
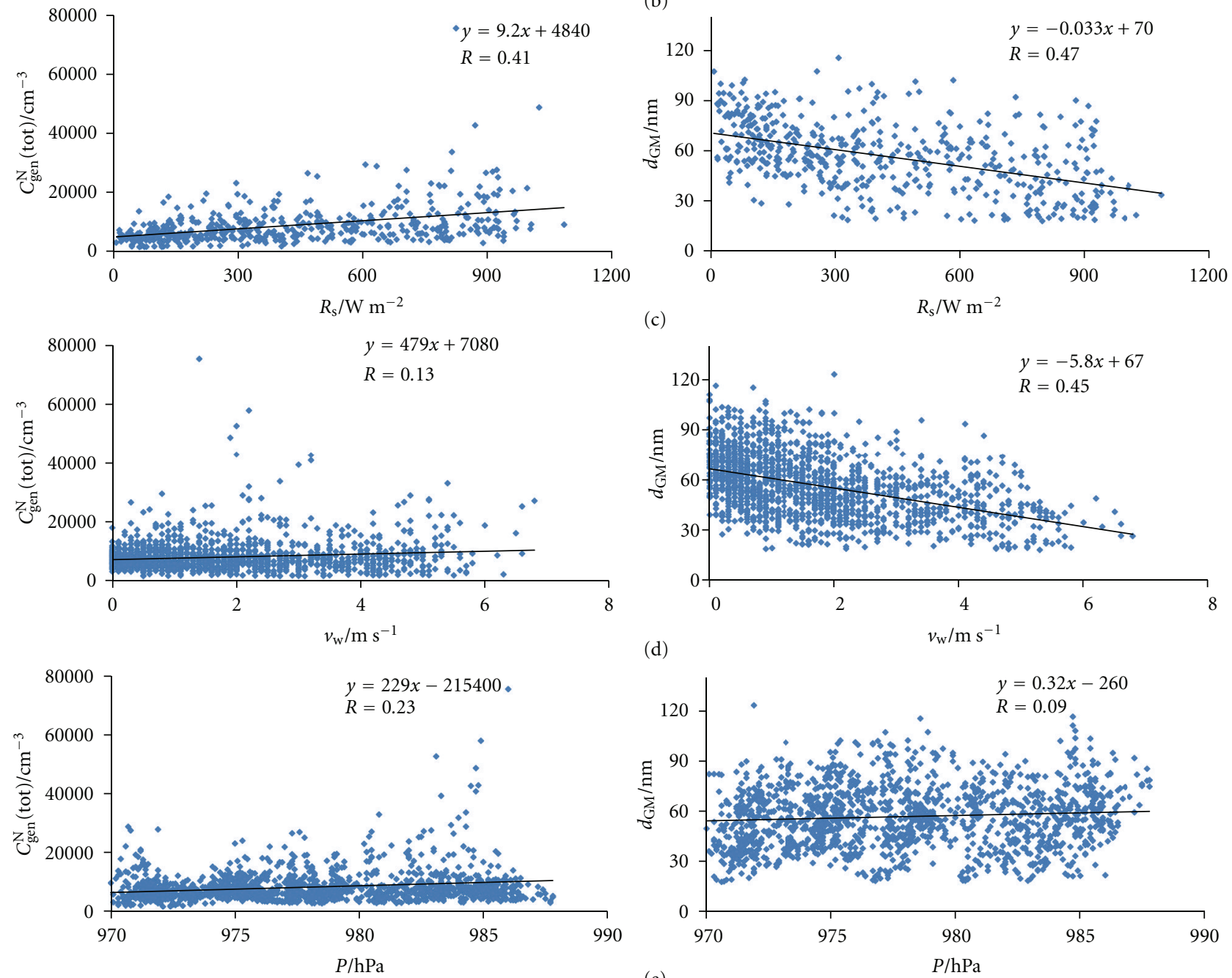

(e)

FIgURE 4: Continued. 

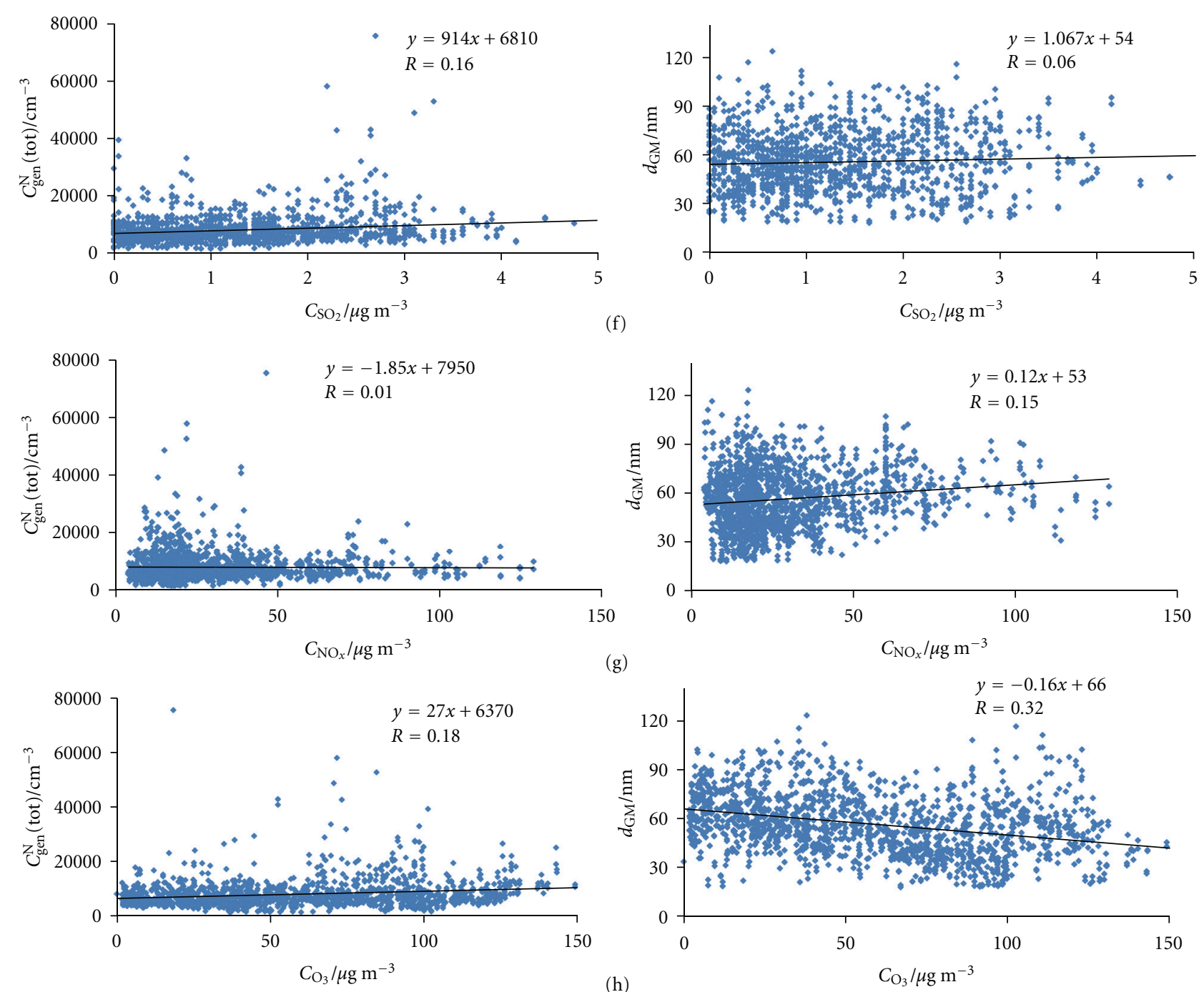

(g)
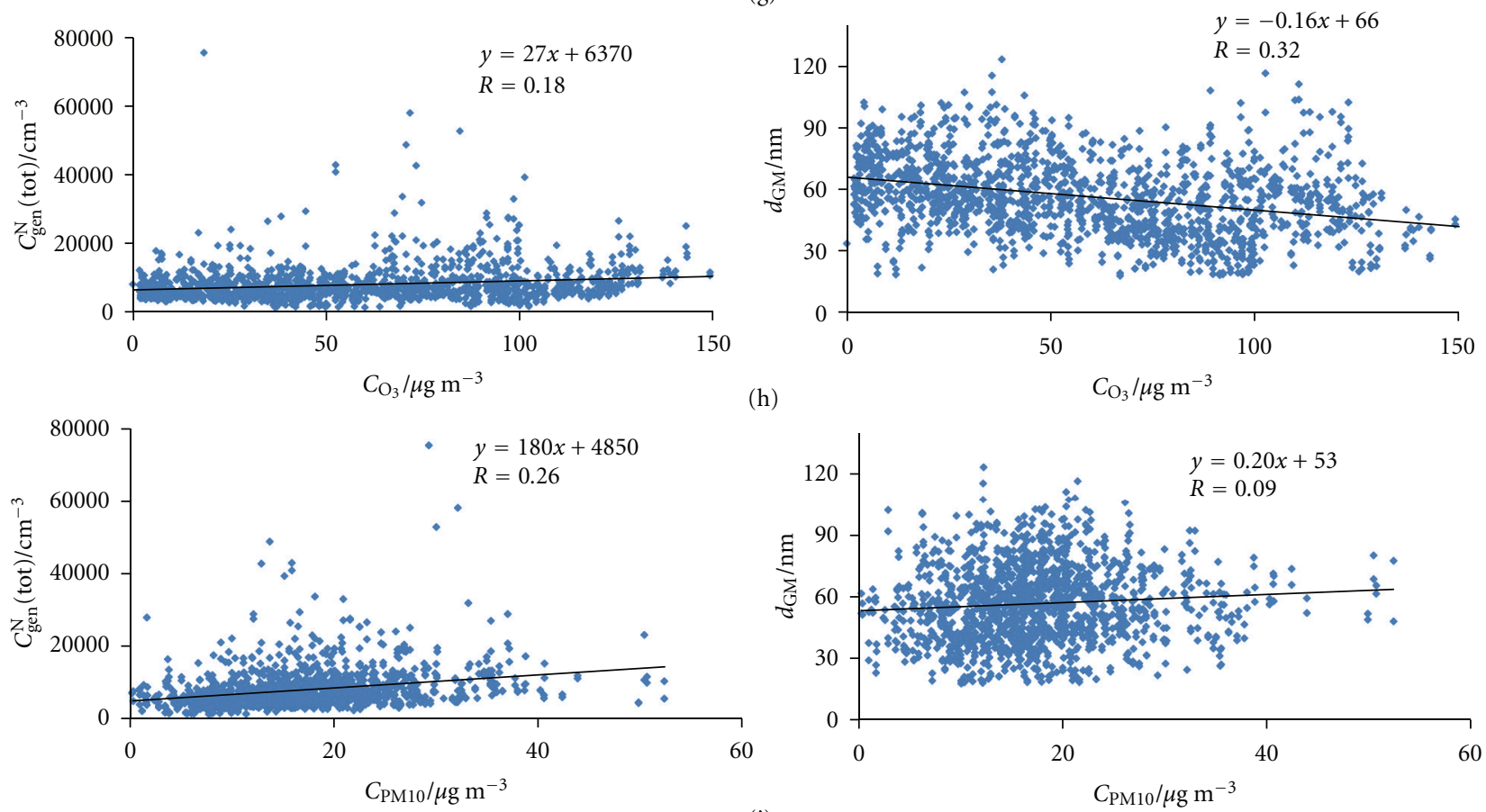

(i)

FIGURE 4: Correlations of the following relationships in outdoor air for the period May 3-June 6, 2010: (a) $C_{\mathrm{gen}}^{\mathrm{N}}\left(\right.$ tot)- $T$ and $d_{\mathrm{GM}}-T$, (b) $C_{\mathrm{gen}}^{\mathrm{N}}($ tot $)-H_{\mathrm{rel}}$ and $d_{\mathrm{GM}}-H_{\mathrm{rel}}$, (c) $C_{\mathrm{gen}}^{\mathrm{N}}(\mathrm{tot})-R_{s}$ and $d_{\mathrm{GM}}-R_{\mathrm{s}}$, (d) $C_{\mathrm{gen}}^{\mathrm{N}}($ tot $)-v_{\mathrm{w}}$ and $d_{\mathrm{GM}}-v_{\mathrm{w}}$, (e) $C_{\mathrm{gen}}^{\mathrm{N}}($ tot $)-P$ and $d_{\mathrm{GM}}-P$, (f) $C_{\mathrm{gen}}^{\mathrm{N}}$ (tot) $-C_{\mathrm{SO}}$ and $d_{\mathrm{GM}}-C_{\mathrm{SO}_{2}}$, (g) $C_{\mathrm{gen}}^{\mathrm{N}}$ (tot) $-C_{\mathrm{NO}_{x}}$ and $d_{\mathrm{GM}}-C_{\mathrm{NO}_{x}}$, (h) $C_{\mathrm{gen}}^{\mathrm{N}}($ tot $)-C_{\mathrm{O}_{3}}$ and $d_{\mathrm{GM}}-C_{\mathrm{O}_{3}}$, and (i) $C_{\mathrm{gen}}^{\mathrm{N}}$ (tot) $-C_{\mathrm{PM} 10}$ and $d_{\mathrm{GM}}-C_{\mathrm{PM} 10}$.

method [51, 52], individual activity concentrations of ${ }^{218} \mathrm{Po}$, ${ }^{214} \mathrm{~Pb}$, and ${ }^{214} \mathrm{Bi}$ in the unattached $\left(C_{218}^{\mathrm{Aun}} \mathrm{Po}_{2}, C_{214}^{\mathrm{Aun}} \mathrm{Pb}\right.$, and $\left.C_{214 \mathrm{Bi}}^{\mathrm{Aun}}\right)$ and attached $\left(C_{218 \mathrm{Po}}^{\mathrm{Aatt}}, C_{214 \mathrm{~Pb}}^{\mathrm{Aatt}}\right.$, and $\left.C_{214 \mathrm{Bi}}^{\mathrm{Aatt}}\right)$ fractions are obtained. The device also gives radon activity concentration $\left(C_{\mathrm{Rn}}^{\mathrm{A}}\right)$, equilibrium equivalent activity concentration of $\operatorname{RnDP}\left(C_{\mathrm{RnDP}}^{\mathrm{A}}\right)$, equilibrium factor between $\mathrm{Rn}$ and $\mathrm{RnDP}$ $(F)$, fraction of the unattached $\operatorname{RnDP}\left(f^{\text {un }}\right)$, and potential $\alpha$-energy concentration of $\mathrm{RnDP}\left(E_{\alpha \mathrm{RnDP}}\right)$, as well as air temperature and relative humidity.

The activity concentrations $\left(C^{\mathrm{A}}\right)$ of radionuclides are converted into their atom number concentrations $\left(C^{\mathrm{N}}\right)$, by applying the radioactivity law equation [19]:

$$
C^{\mathrm{A}}=\lambda \times C^{\mathrm{N}},
$$



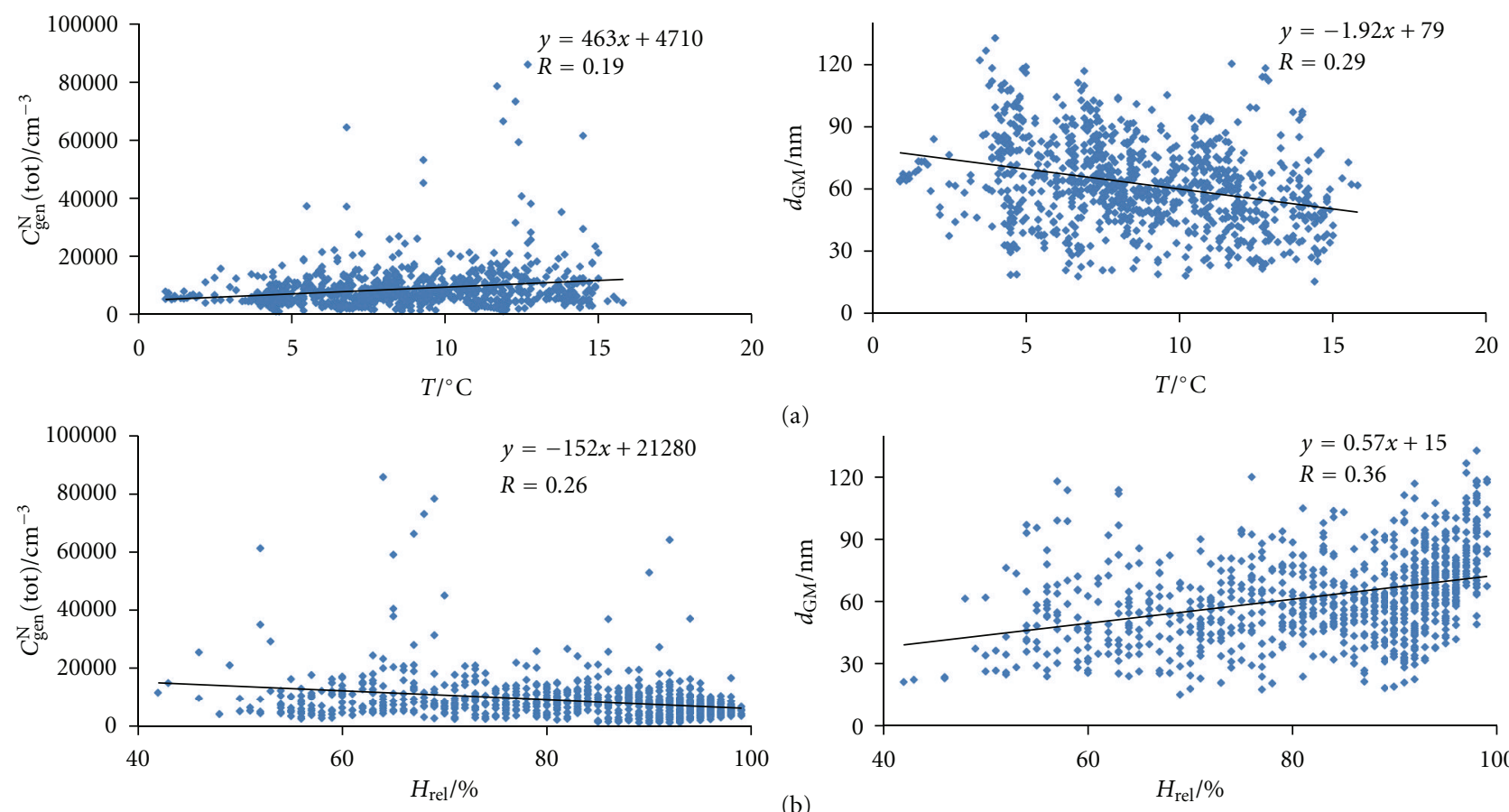

(a)
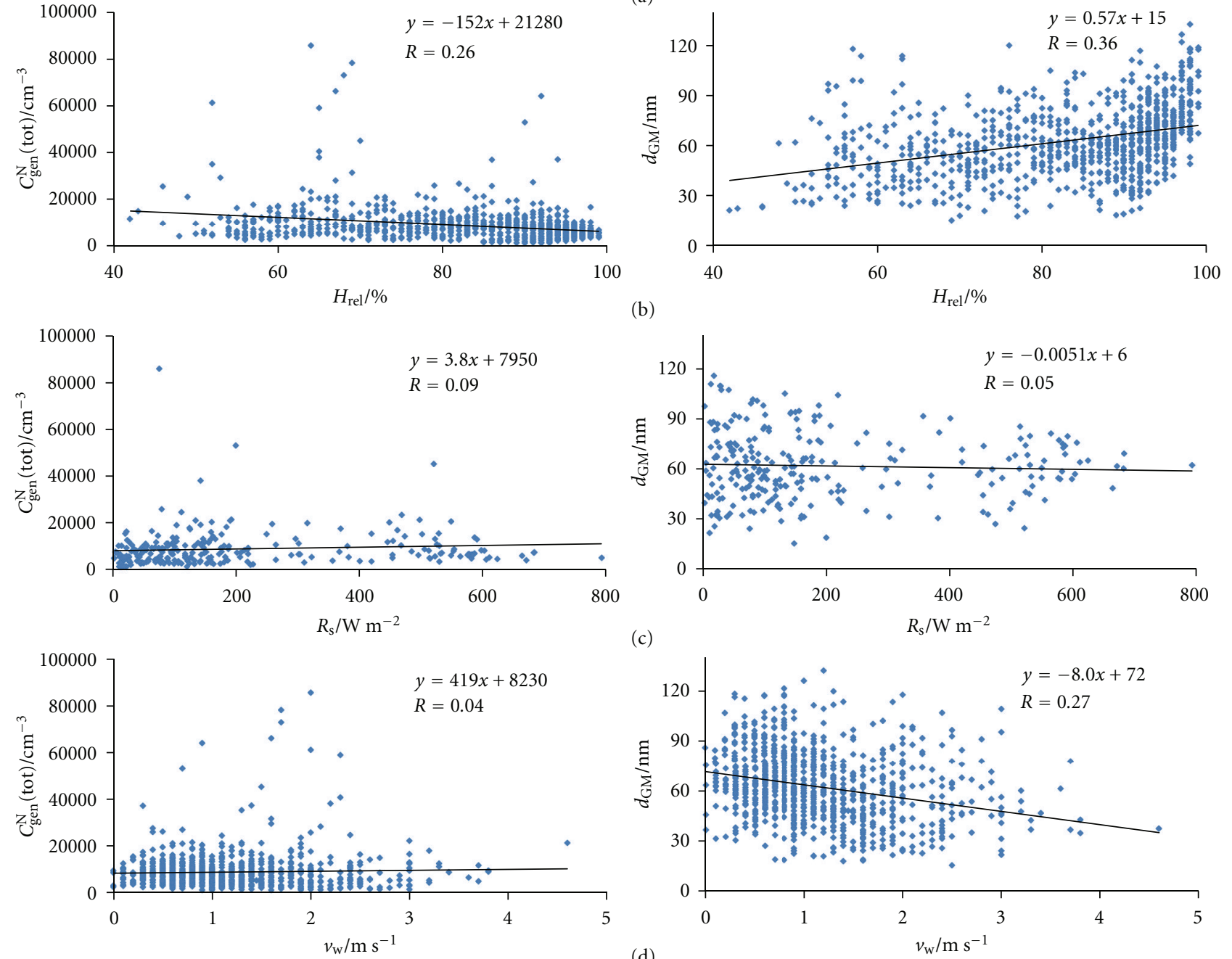

(c)
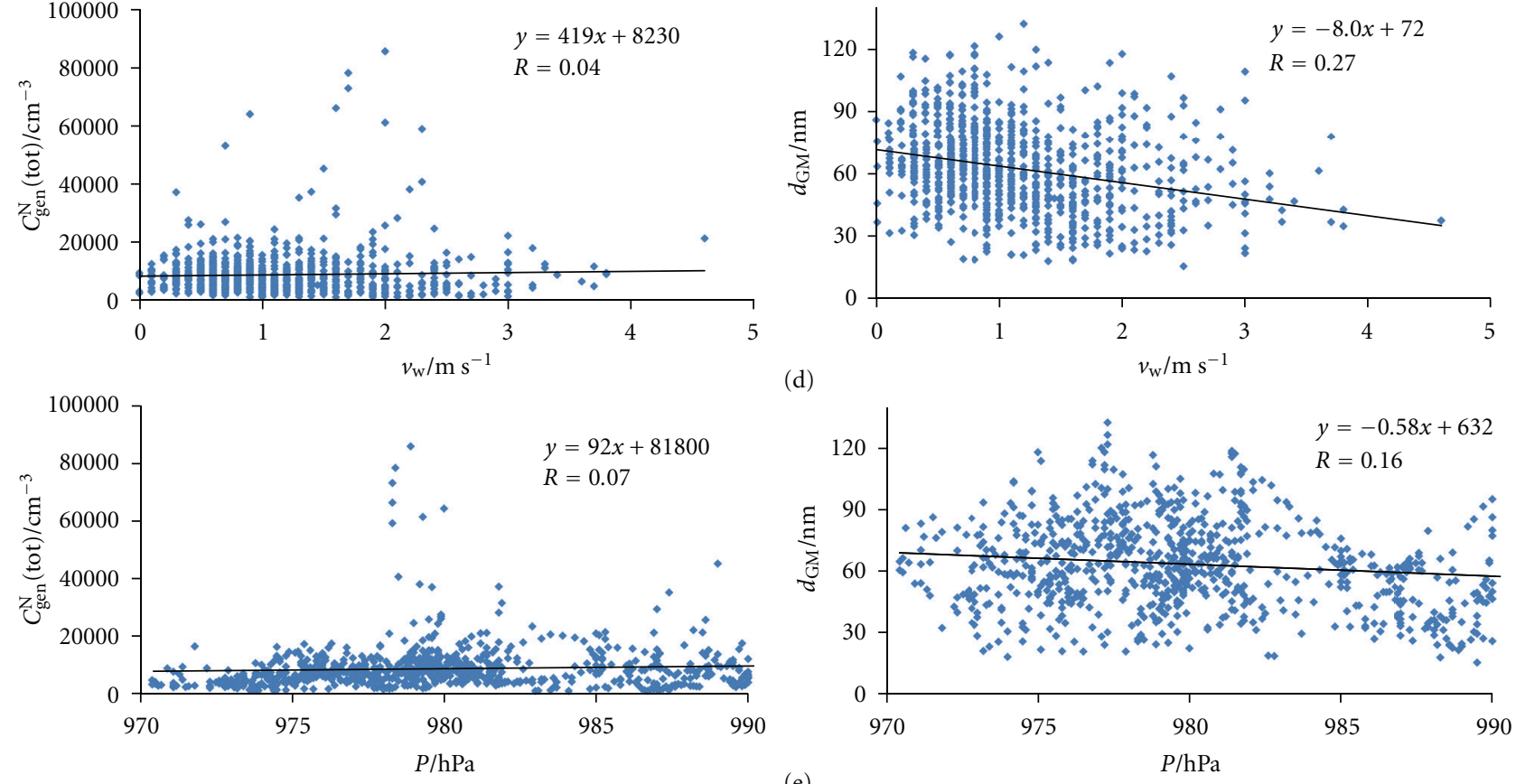

(e)

Figure 5: Continued. 

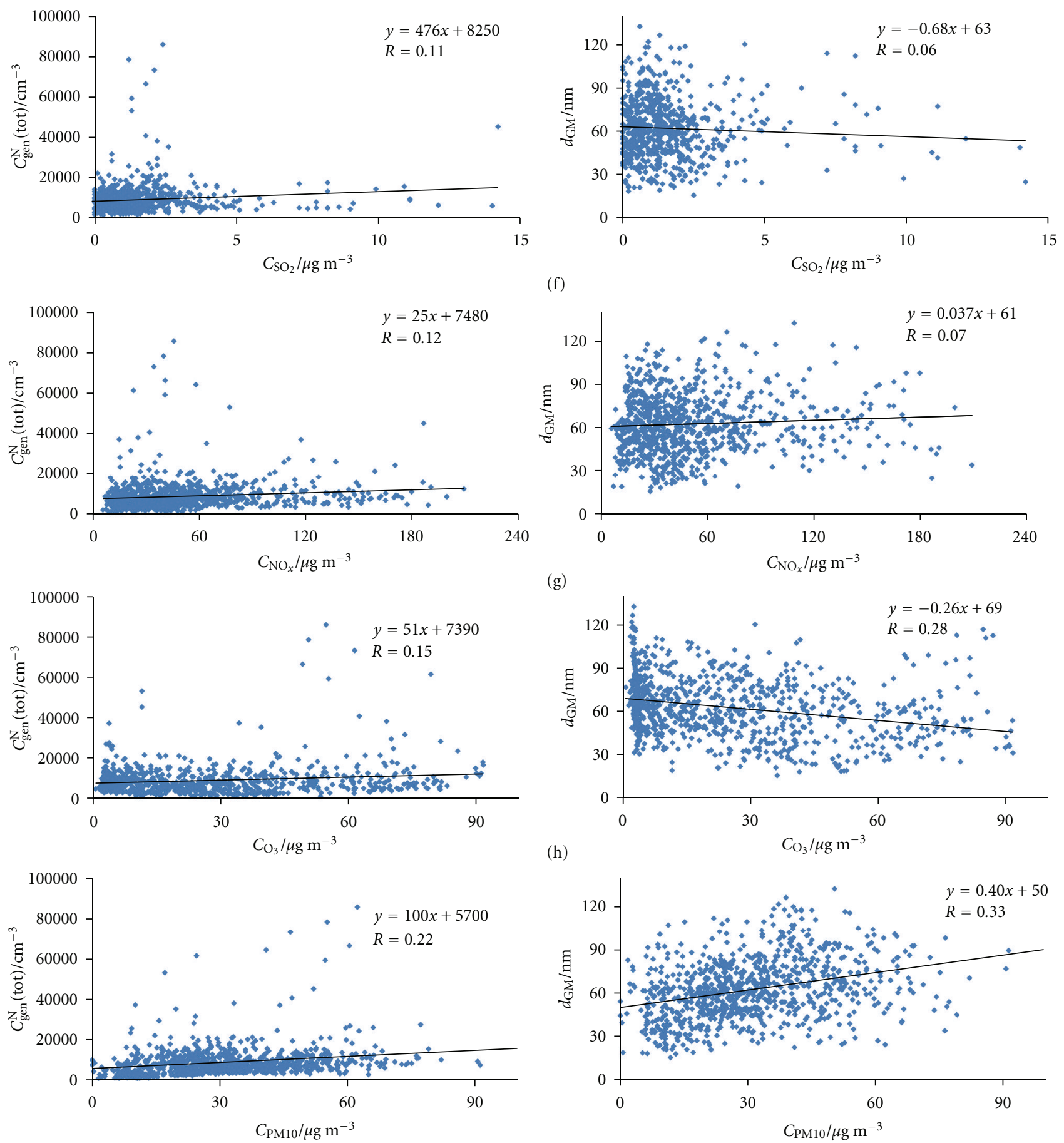

(h)

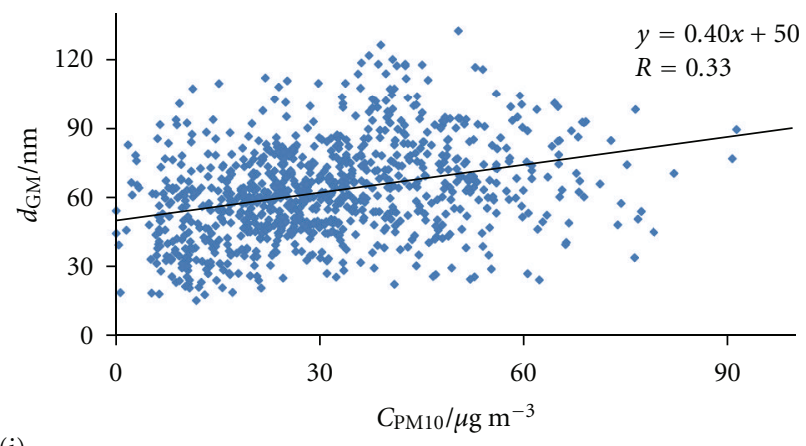

(i)

FIGURE 5: Correlations of the following relationships in outdoor air for the period October 6-26, 2010: (a) $C_{\mathrm{gen}}^{\mathrm{N}}\left(\right.$ tot) $-T$ and $d_{\mathrm{GM}}-T$, (b) $C_{\text {gen }}^{\mathrm{N}}$ (tot) $-H_{\text {rel }}$ and $d_{\mathrm{GM}}-H_{\text {rel }}$, (c) $C_{\text {gen }}^{\mathrm{N}}($ tot $)-R_{\mathrm{s}}$ and $d_{\mathrm{GM}}-R_{\mathrm{s}}$, (d) $C_{\mathrm{gen}}^{\mathrm{N}}($ tot $)-v_{\mathrm{w}}$ and $d_{\mathrm{GM}}-v_{\mathrm{w}}$, (e) $C_{\mathrm{gen}}^{\mathrm{N}}$ (tot) $-P$ and $d_{\mathrm{GM}}-P$, (f) $C_{\text {gen }}^{\mathrm{N}}$ (tot) $-C_{\mathrm{SO}}$ and $d_{\mathrm{GM}}-C_{\mathrm{SO}_{2}},(\mathrm{~g}) C_{\mathrm{gen}}^{\mathrm{N}}($ tot $)-C_{\mathrm{NO}_{x}}$ and $d_{\mathrm{GM}}-C_{\mathrm{NO}_{x}}$, (h) $C_{\mathrm{gen}}^{\mathrm{N}}($ tot $)-C_{\mathrm{O}_{3}}$ and $d_{\mathrm{GM}}-C_{\mathrm{O}_{3}}$, and (i) $C_{\mathrm{gen}}^{\mathrm{N}}$ (tot) $-C_{\mathrm{PM} 10}$ and $d_{\mathrm{GM}}-C_{\mathrm{PM} 10}$.

with $\lambda$ equalling the rate constant of radioactive transformation $\left(\lambda=\ln 2 / t_{1 / 2}\right)$. The obtained number concentrations of ${ }^{218} \mathrm{Po},{ }^{214} \mathrm{~Pb}$, and ${ }^{214} \mathrm{Bi}$ atoms $\left(\mathrm{cm}^{-3}\right)$ are denoted by $C_{218 \mathrm{Po}}^{\mathrm{Nun}}, C_{214 \mathrm{~Pb}}^{\mathrm{Nun}}$ and $C_{214 \mathrm{Bi}}^{\mathrm{Nun}}$, respectively, for the unattached form, and $C_{218}^{\mathrm{Natt}} \mathrm{Po}_{0}, C_{214 \mathrm{~Pb}}^{\mathrm{Natt}}$, and $C_{214 \mathrm{Bi}}^{\mathrm{Natt}}$, respectively, for the attached form. Also calculated was the fraction $x^{\text {un }}$ of the unattached RnDP, expressed by

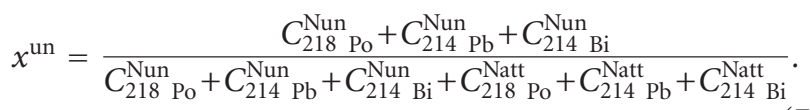




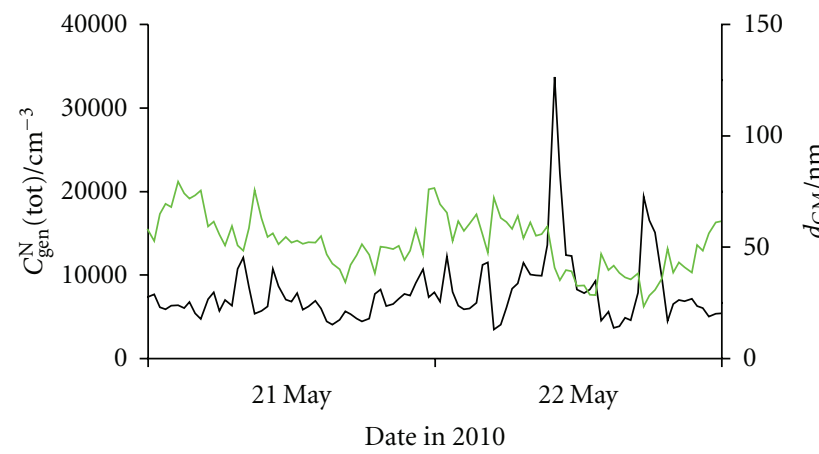

(a)

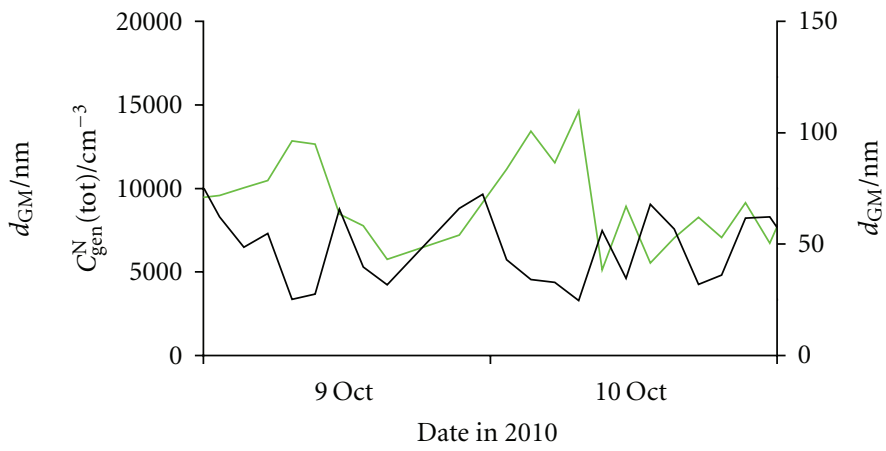

$-C_{\mathrm{gen}}^{\mathrm{N}}($ tot $)$
$-d_{\mathrm{GM}}$

(b)

FigURE 6: Diurnal variations of the total number concentration of general aerosol $\left(C_{\mathrm{gen}}^{\mathrm{N}}(\right.$ tot $\left.)\right)$ and geometric mean of their diameters $\left(d_{\mathrm{GM}}\right)$ in outdoor air for (a) May 21-22 and (b) October 9-10.

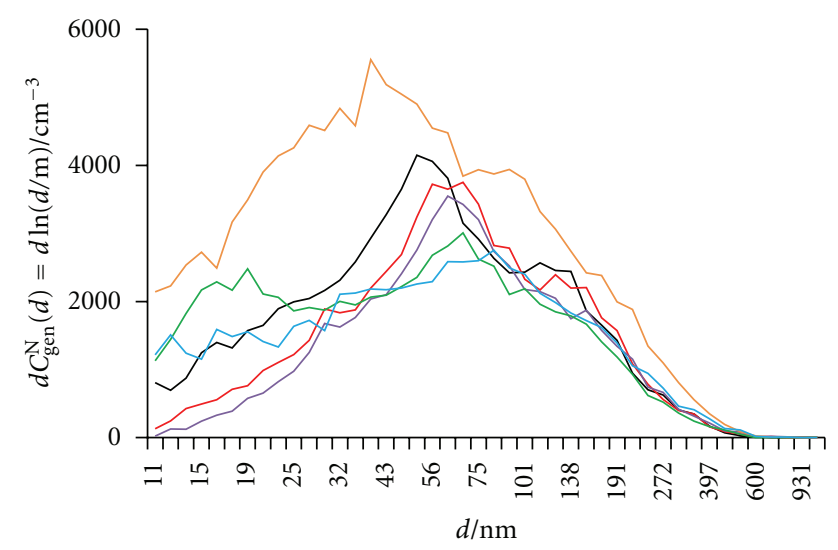

(a)

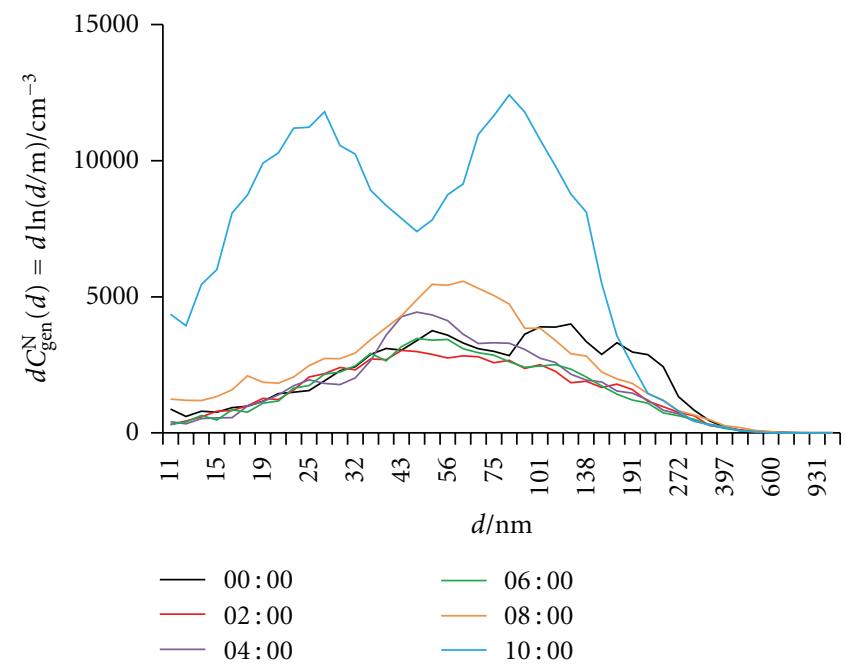

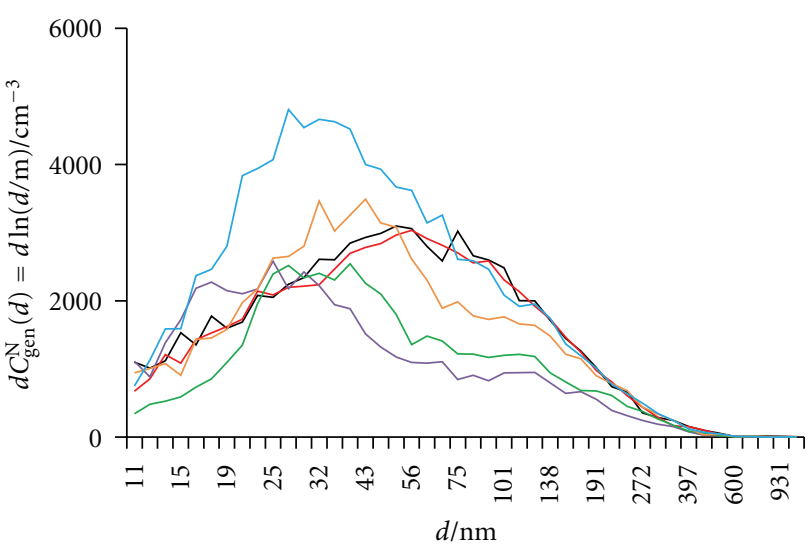

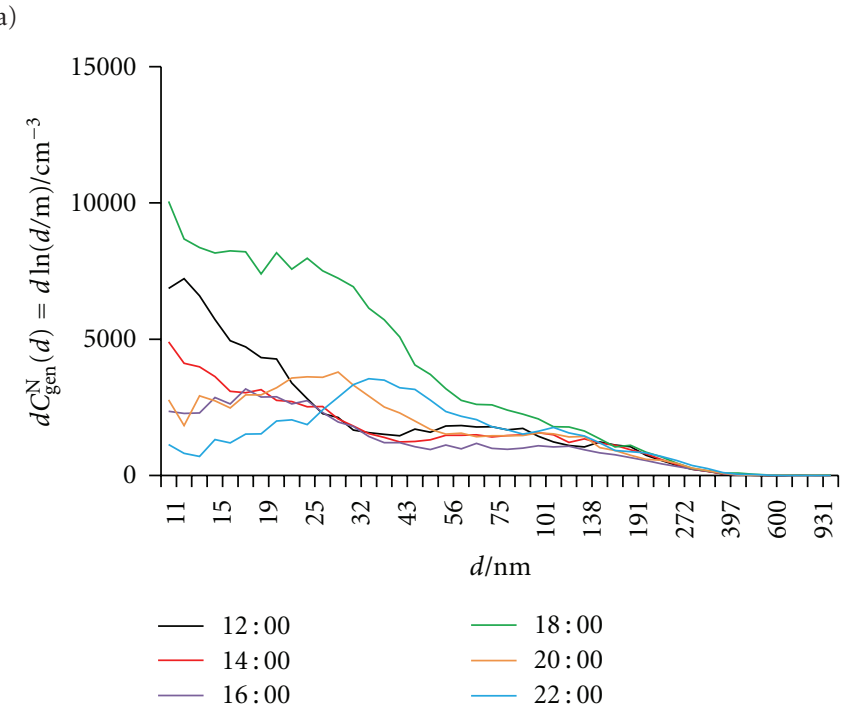

(b)

FIGURE 7: Number particle size distribution $\left(\mathrm{d} C_{\mathrm{gen}}^{\mathrm{N}}(\mathrm{d})=\mathrm{d} \ln (d / \mathrm{m})\right)$ in outdoor air recorded every two hours on: (a) May 21 and (b) May 22. 

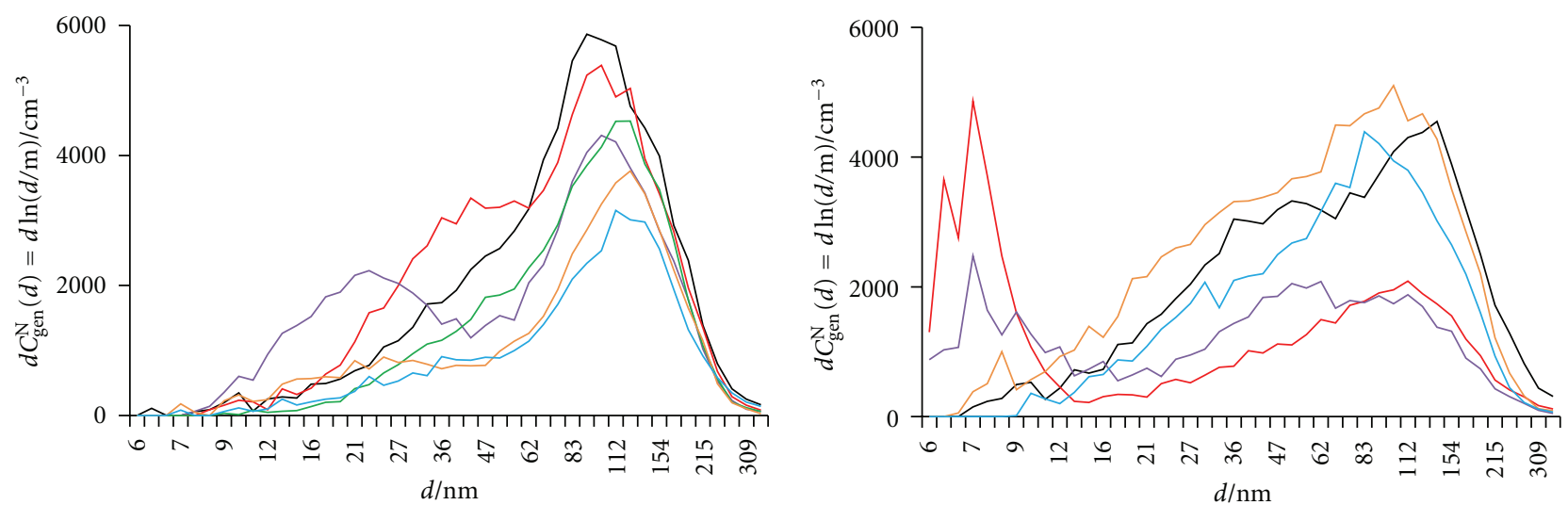

(a)
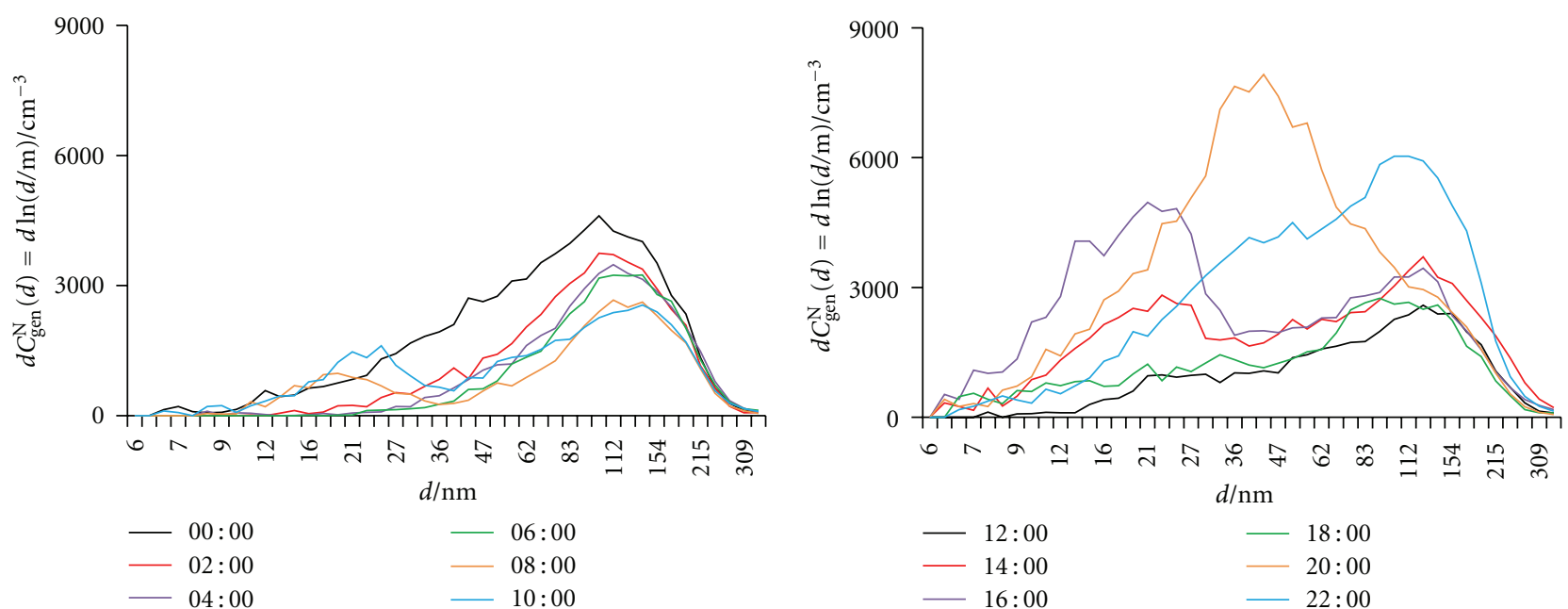

(b)

Figure 8: Number particle size distribution $\left(\mathrm{d} C_{\text {gen }}^{\mathrm{N}}(d)=\mathrm{d} \ln (d / \mathrm{m})\right)$ in outdoor air recorded every two hours on: (a) October 9 and (b) October 10.

In order to avoid confusion, hereafter, $f$ un will be referred to as the activity fraction of the unattached RnDP, and $x^{\text {un }}$ as the number fraction of the unattached RnDP.

2.1.2. General Aerosols. Number concentration and size distribution of aerosol particles were measured with a Grimm Aerosol SMPS+C instrument, Series 5.400 (Germany). Its long Vienna DMA unit is designed for $10-1100 \mathrm{~nm}$ and a medium DMA unit, for the $5-350 \mathrm{~nm}$ size range. The DMA unit separates charged particles into 44 channels based on their electrical mobility, which depends on the particle size and electrical charge. Particles enter the CPC unit containing a heater saturator in which alcohol vapour molecules condense onto the entering particles, thus causing them to grow into droplets. The droplets are then detected with a laser beam (DLS detection) and counted. The frequency of measurement is one in seven minutes for the long unit and one in four minutes for the medium unit. The instrument detects and analyses all the particles, both carrying and not carrying RnDP (although the contribution of the latter is minimal, as will be seen later) therefore the term background aerosol could be misleading, and general aerosol will be used instead. The instrument gives the total number concentration of general aerosol particles $C_{\text {gen }}^{\mathrm{N}}($ tot $)$, the geometric mean of their diameters $d_{\mathrm{GM}}$, and the number size distribution $\mathrm{d} C_{\mathrm{gen}}^{\mathrm{N}}(\mathrm{d}) / \mathrm{d} \ln d$ [53], with $d$ being the electrical mobility equivalent particle diameter. Because the instrument is designed for $>5 \mathrm{~nm}$ sizes, the number size distribution of the unattached RnDP below this size could not be evaluated. Therefore, it was adopted $[29,30,54]$ that the attached RnDP in indoor air are associated with particles larger than either $10 \mathrm{~nm}$ or $20 \mathrm{~nm}$, and the fraction of the general aerosol particles related to the unattached $\mathrm{RnDP}$ was expressed by both $x_{\text {gen }}(<10)=C_{\text {gen }}^{\mathrm{N}}(<10) / C_{\text {gen }}^{\mathrm{N}}($ tot $)$ and $x_{\text {gen }}(<20)=C_{\text {gen }}^{\mathrm{N}}(<20) / C_{\text {gen }}^{\mathrm{N}}($ tot $)$.

2.1.3. Environmental Parameters. The $1 / 2$ hourly average values of the following environmental parameters for outdoor air were obtained from the Slovenian Environment Agency for the Ljubljana Bežigrad meteorological station, 


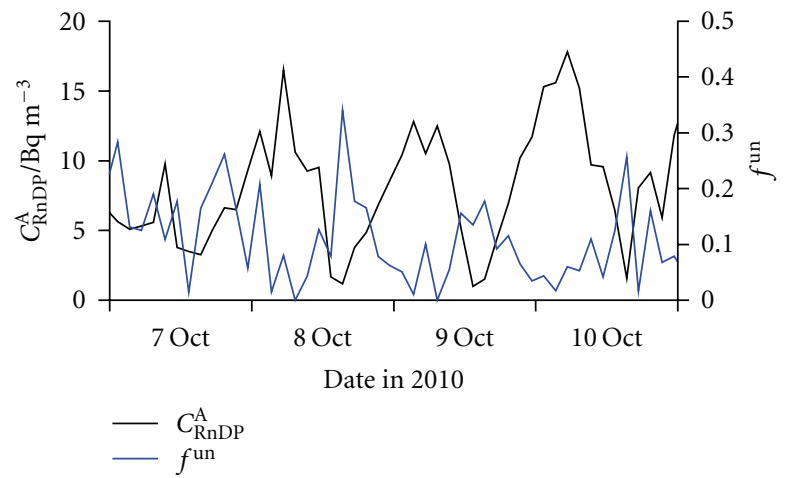

FIGURE 9: Diurnal variations of the equilibrium equivalent activity concentration of radon decay products $\left(C_{\mathrm{RnDP}}^{\mathrm{A}}\right)$ and fraction of the unattached decay products $\left(f^{\text {un }}\right)$, in outdoor air for the period October 7-10.

approximately $10 \mathrm{~km}$ away from our measurement site: air temperature $(T)$, barometric pressure $(P)$, relative air humidity $\left(H_{\text {rel }}\right)$, height of precipitation $\left(h_{\text {rain }}\right)$, solar radiation $\left(R_{s}\right)$, concentrations of $\mathrm{NO}_{x}\left(C_{\mathrm{NO}_{x}}\right), \mathrm{SO}_{2}\left(C_{\mathrm{SO}_{2}}\right), \mathrm{O}_{3}$ $\left(C_{\mathrm{O}_{3}}\right)$, and PM10 ( $\left.C_{\mathrm{PM} 10}\right)$ (aerosol particles smaller than $10 \mu \mathrm{m})$, and wind velocity $\left(v_{\mathrm{w}}\right)$.

2.2. Site Description. Our experiment was carried out in the farm village of Zalog, a suburb of Ljubljana (Slovenia's capital with 370,000 inhabitants). Of the total five farms, the last one at the furthest end of the road was selected, composed of a residential house and several accompanying buildings (Figure 1). They were built in 1987 of concrete and brick. The family lives in the ground floor of the residential house. One person lives temporarily in a small $20 \mathrm{~m}^{2}$ flat in the basement, its floor lying $1.2 \mathrm{~m}$ below the courtyard level. The flat consists of a kitchen, living room, bathroom, and corridor. A door and a window of the kitchen face the courtyard in front of the house, while the other door connects it to other rooms. Central heating using hot water radiators is based on burning wood. There is no air conditioning. The Ljubljanica river flows at a distance of about $20 \mathrm{~m}$ and the nearest neighbour lies about $50 \mathrm{~m}$ away. The village is surrounded by fields. Across the river at a distance of about $500 \mathrm{~m}$, the main railway Ljubljana-Maribor runs along a hill covered by forest. The Ljubljana wastewater treatment plant is about $400 \mathrm{~m}$ outside the village, and there are some small industrial plants several kilometres away.

Indoor measurements were performed in the kitchen of the basement flat, and outdoor measurements in the courtyard in front of it. Preliminary radon survey had shown elevated radon activity concentration in indoor air, ranging from $300 \mathrm{~Bq} \mathrm{~m}^{-3}$ to $1000 \mathrm{~Bq} \mathrm{~m}^{-3}$, as compared with the national average in winter of $121 \mathrm{~Bq} \mathrm{~m}^{-3}$ for one thousand randomly selected dwellings [55]. With some interruptions because of other measurements, outside measurements were carried out in May 2010 using the long Vienna DMA unit, and in October 2010 using the medium Vienna DMA unit, and indoor measurements were performed from October 2010 to January 2011, also using the medium Vienna DMA unit.

\section{Results and Discussion}

3.1. Outdoor Air. Figures 2 and 3 show the total number concentration of general aerosols $\left(C_{\text {gen }}^{\mathrm{N}}(\right.$ tot $\left.)\right)$ and geometric mean of particle diameter $\left(d_{\mathrm{GM}}\right)$, together with environmental parameters, for the outdoor measurements carried out in the periods of May 10-23 and October 7-26, respectively. Minimum and maximum values, geometric means and geometric standard deviations are shown in Table 1. Figures 4 and 5 show relationships between $C_{\text {gen }}^{\mathrm{N}}$ (tot) and $d_{\mathrm{GM}}$ with the environmental parameters for the May and October measurements, respectively. All correlation coefficients $(R)$ are far below 0.50, and hence the dependence of both $C_{\text {gen }}^{\mathrm{N}}$ (tot) and $d_{\mathrm{GM}}$ on these parameters is weak. The values of the environmental data taken from the meteorological station $10 \mathrm{~km}$ away may not show the actual situation at our measurement site, and the correlations shown are not necessarily realistic. Exceptions could be temperature and solar radiation, whose values may not change markedly in several kilometres. Nonetheless, based on $R$ values neither of their effects are evidenced.

Figure 6 shows diurnal variations of $C_{\text {gen }}^{\mathrm{N}}($ tot $)$ and $d_{\mathrm{GM}}$ only for two selected days in May and October. For these days, the following correlation coefficients for $R_{s}$ were obtained: 0.51 for $C_{\text {gen }}^{\mathrm{N}}$ (tot) and 0.60 for $d_{\mathrm{GM}}$ in May, and 0.69 for $C_{\text {gen }}^{\mathrm{N}}$ (tot) and 0.65 for $d_{\mathrm{GM}}$ in October; hence, solar radiation may be taken into account in data interpretation. In both urban $[8,56,57]$ and semirural areas [58], two daily $C_{\text {gen }}^{\mathrm{N}}$ (tot) peaks were found, one in the morning and the other in late afternoon, coinciding with the traffic rush hours. In our case, no periodicity is seen for May, and changes seem to appear sporadically. Diurnal variation in size distribution differs considerably from day to day, as seen for every two hours in Figure 7. In October, two maxima appear, one at around midnight, and the other at around noon. In this period of the year, farming activities (e.g., running cars, tractors, and other farming equipment) are highest from late morning to early afternoon, with a concomitant strongest solar radiation $[56,59,60]$, thus causing the first increase in $C_{\mathrm{gen}}^{\mathrm{N}}$ (tot), accompanied by a decrease in $d_{\mathrm{GM}}$. The late afternoon simultaneous rising of both $C_{\text {gen }}^{\mathrm{N}}$ (tot) and $d_{\mathrm{GM}}$ is presumably related to farming activities, traffic 

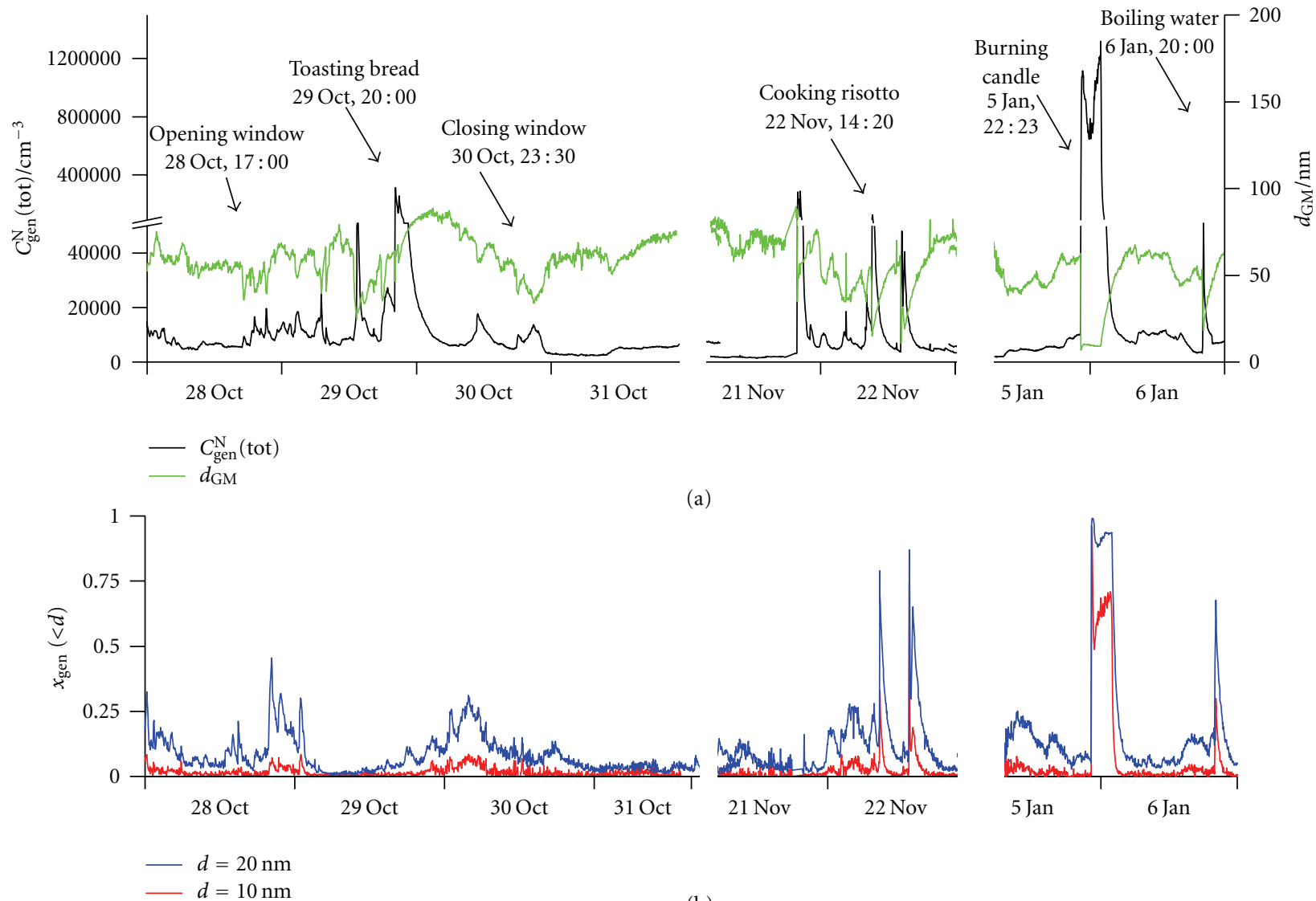

(a)

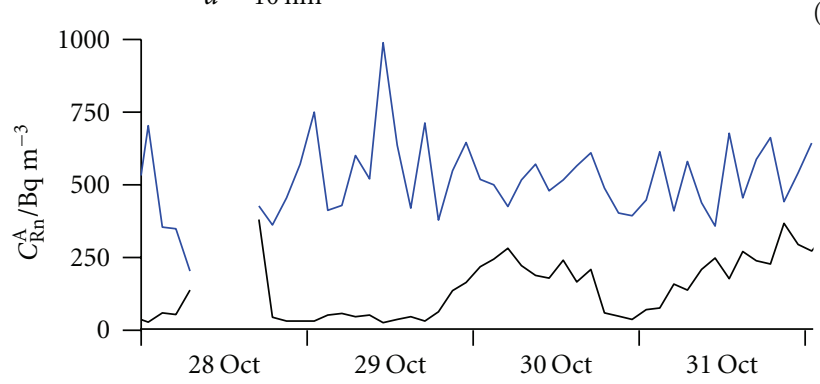

(b)
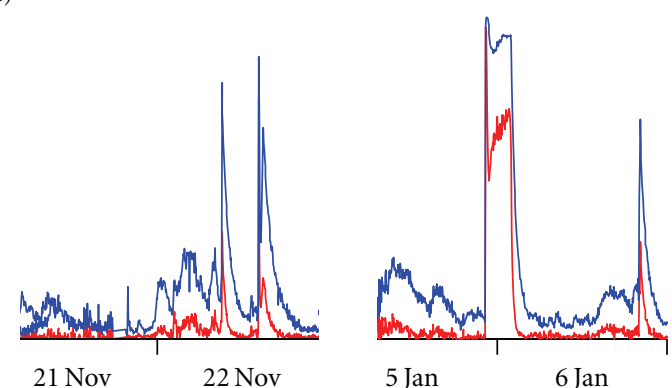

5 Jan

6 Jan
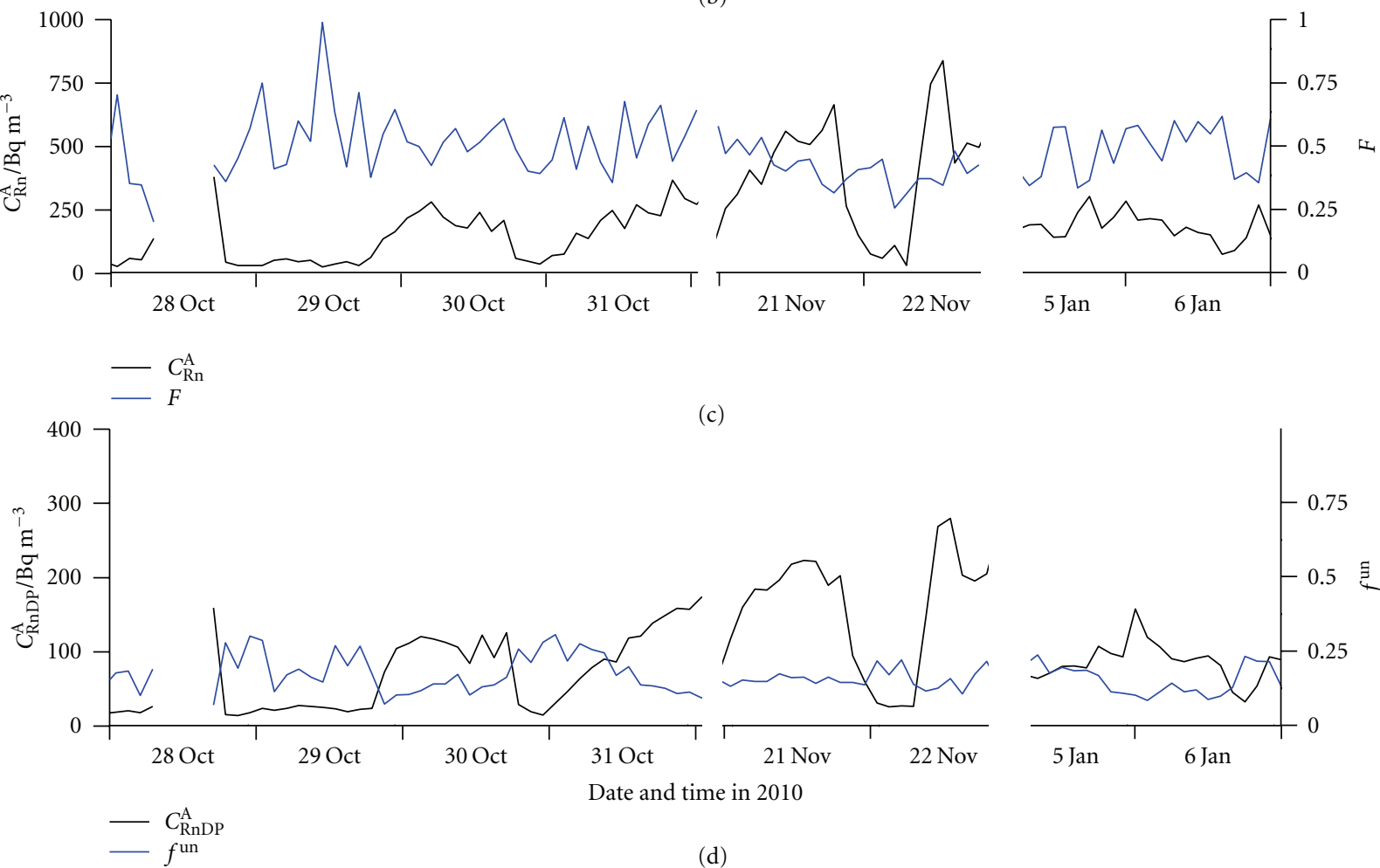

(c)

FIGURE 10: Time run of: (a) total number concentration of general aerosol particles $\left(C_{\mathrm{gen}}^{\mathrm{N}}(\right.$ tot $\left.)\right)$ and geometric mean values of their diameters $\left(d_{\mathrm{GM}}\right)$, (b) number fraction of particles smaller than $10 \mathrm{~nm}\left(x_{\text {gen }}(<10)\right)$ and smaller than $20 \mathrm{~nm}\left(x_{\text {gen }}(<20)\right)$, (c) activity concentration of radon $\left(C_{\mathrm{Rn}}^{\mathrm{A}}\right)$ and equilibrium factor between $\mathrm{Rn}$ and $\mathrm{RnDP}(F)$, and (d) equilibrium equivalent activity concentration of radon decay products $\left(C_{\mathrm{RnDP}}^{\mathrm{A}}\right)$ and activity fraction of the unattached $\operatorname{RnDP}\left(f^{\mathrm{un}}\right)$, in indoor air from October 28 to January 6. 


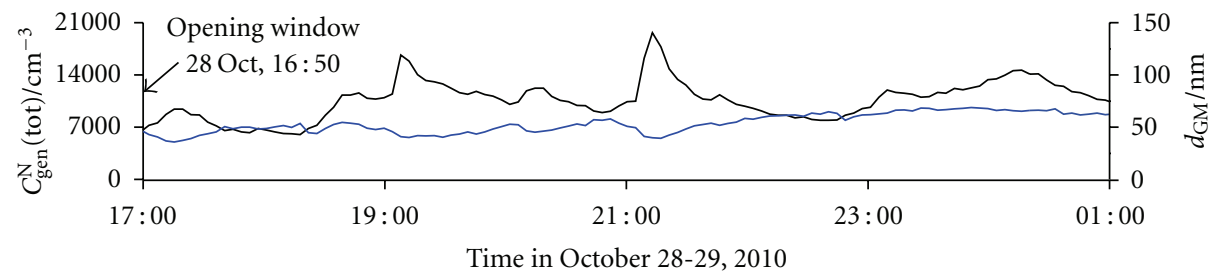

$$
\begin{aligned}
& -C_{\mathrm{gen}}^{\mathrm{N}}(\mathrm{tot}) \\
& -d_{\mathrm{GM}}
\end{aligned}
$$

(a)

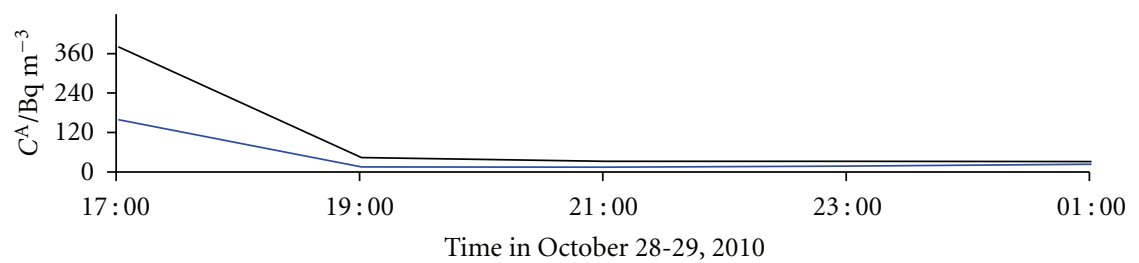

$-C_{\mathrm{Rn}}^{\mathrm{A}}$

(b)

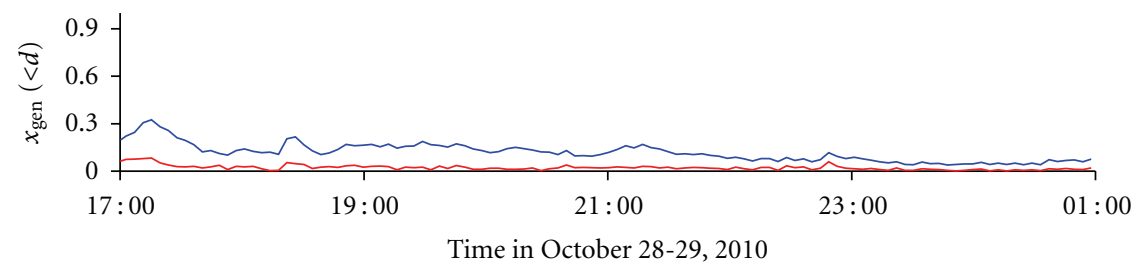

$-d=10 \mathrm{~nm}$

$-d=20 \mathrm{~nm}$

(c)

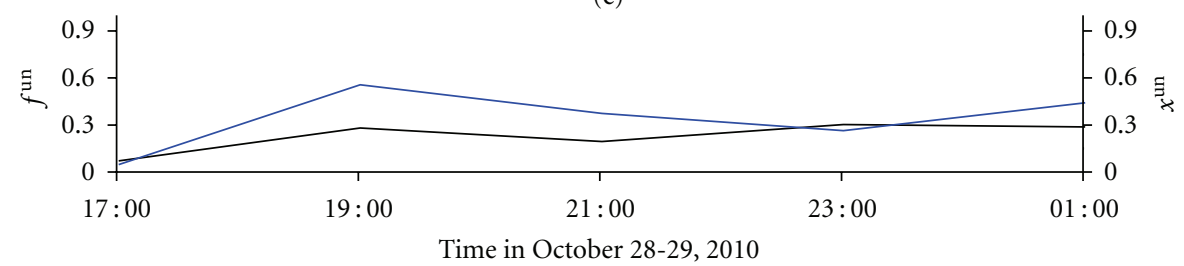

$f^{\text {un }}$

(d)

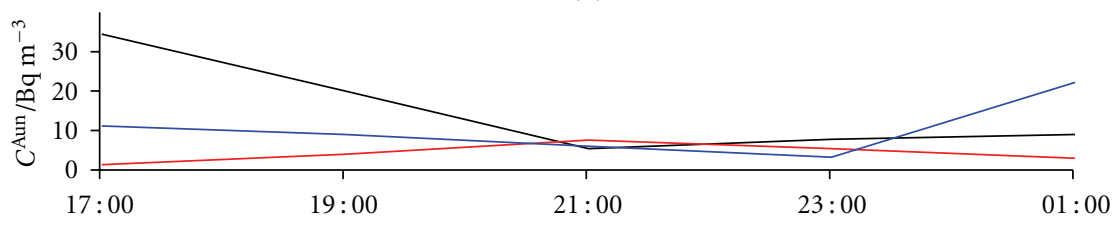

Time in October 28-29, 2010

$-C_{218 \mathrm{Po}}$

- $C_{214 \mathrm{~Pb}}$

$-C_{214 \mathrm{Bi}}$

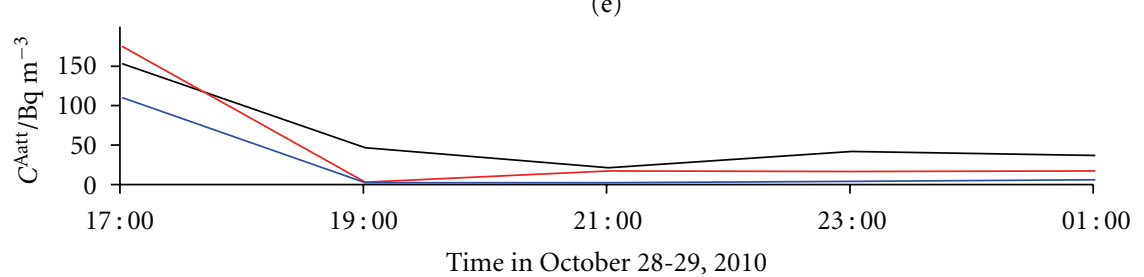

(f)

Figure 11: Continued. 


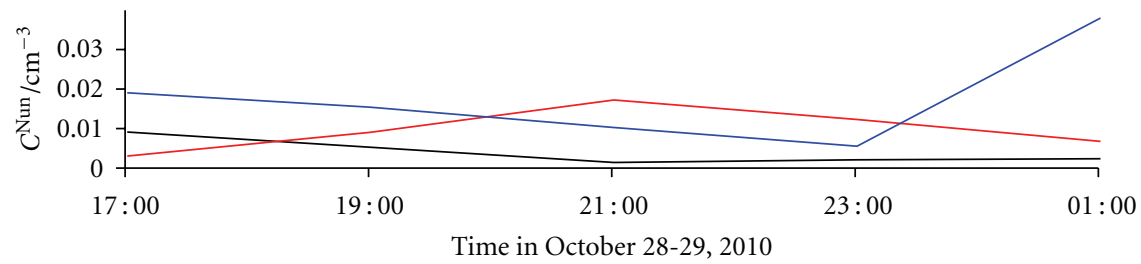

(g)

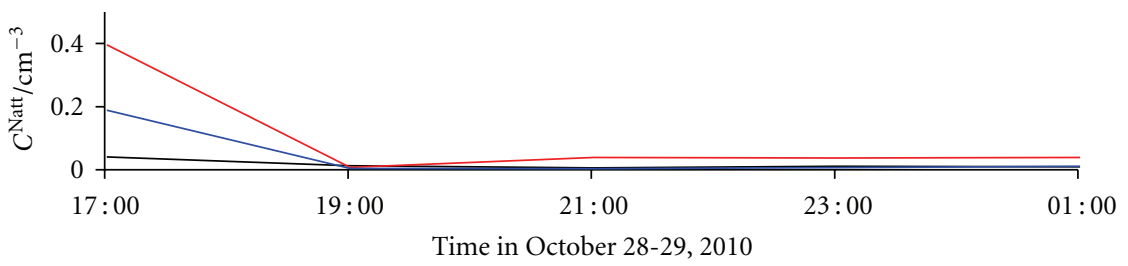

(h)

FIGURE 11: Time run of: (a) total number concentration of general aerosol particles $\left(C_{\mathrm{gen}}^{\mathrm{N}}(\right.$ tot $\left.)\right)$ and geometric mean values of their diameters $\left(d_{\mathrm{GM}}\right)$, (b) activity concentration of radon $\left(C_{\mathrm{Rn}}^{\mathrm{A}}\right)$ and equilibrium equivalent activity concentration of radon decay products $\left(C_{\mathrm{RnDP}}^{\mathrm{A}}\right)$, (c) number fraction of particles smaller than $10 \mathrm{~nm}\left(x_{\text {gen }}(<10)\right)$ and smaller than $20 \mathrm{~nm}\left(x_{\text {gen }}(<20)\right)$, (d) activity fraction of the unattached RnDP $\left(f^{\mathrm{un}}\right)$ and number fraction of the unattached $\mathrm{RnDP}\left(x^{\mathrm{un}}\right)$, (e) activity concentrations of the unattached $\mathrm{RnDP}$ atoms $\left(C_{218}^{\mathrm{Aun}} \mathrm{Po}, C_{214}^{\mathrm{Aun}} \mathrm{Pb}\right.$, and $\left.C_{214 \mathrm{Bi}}^{\mathrm{Aun}}\right)$, (f) activity concentrations of the attached RnDP atoms $\left(C_{218 \mathrm{Po}}^{\mathrm{Aatt}}, C_{214 \mathrm{~Pb}}^{\mathrm{Aatt}}\right.$, and $\left.C_{214 \mathrm{Bi}}^{\mathrm{Aatt}}\right)$, $(\mathrm{g})$ number concentrations of the unattached $\mathrm{RnDP}$ atoms $\left(C_{218}^{\mathrm{Nun}} \mathrm{Po}_{0}, C_{214 \mathrm{~Pb}}^{\mathrm{Nun}}\right.$, and $\left.C_{214 \mathrm{Bi}}^{\mathrm{Nun}}\right)$, and $(\mathrm{h})$ number concentrations of the attached $\mathrm{RnDP}$ atoms $\left(C_{218 \mathrm{Po}}^{\mathrm{Natt}}, C_{214}^{\mathrm{Natt}} \mathrm{Pb}\right.$, and $\left.C_{214}^{\mathrm{Natt}}{ }_{\mathrm{Bi}}\right)$, in indoor air for the period October 28-29 (with opening of the window in the kitchen at 16:50 on October 28).

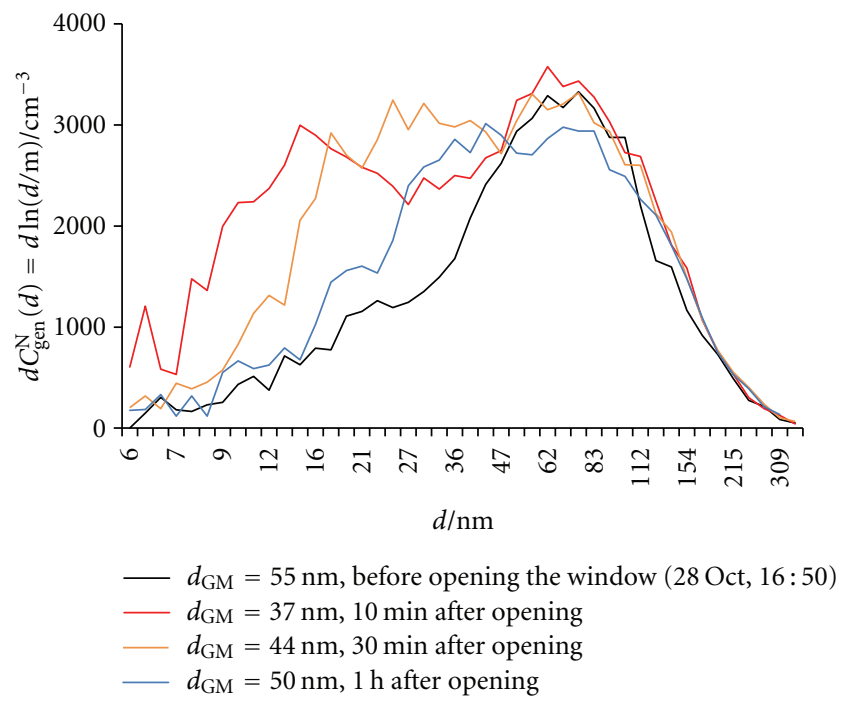

Figure 12: Number size distributions $\left(\mathrm{d} C_{\mathrm{gen}}^{\mathrm{N}}(d)=\mathrm{d} \ln (d / \mathrm{m})\right)$ of general aerosol particles in indoor air before and during opening of the window in the kitchen.

on a nearby road, and particle growth by coagulation [4, 61]. Decrease in $C_{\mathrm{gen}}^{\mathrm{N}}$ (tot) after its midnight maximum is ascribed to faster deposition of smaller particles, caused by growing air humidity and appearance of dew [62], thus resulting in increasing $d_{\mathrm{GM}}$. Figure 8 shows particle size distribution every two hours on these two days. While larger particles (around $100 \mathrm{~nm}$ ) prevail in the morning hours, the contribution of smaller ones (smaller than $30 \mathrm{~nm}$ ) becomes significant when using diesel engines.

Radioactive aerosol particles in outdoor air were monitored only in the periods of October 7-11 (Figure 9) and
October 17-26. Diurnal variation in $C_{\mathrm{RnDP}}^{\mathrm{A}}$, with maxima overnight and minima at noon, is well pronounced. An expected $[40,41,63]$, though only approximate, coincidence of $f$ un minima and $C_{\mathrm{RnDP}}^{\mathrm{A}}$ maxima is seen.

3.2. Indoor Air. Figure 10 shows the time series of (a) $C_{\text {gen }}^{\mathrm{N}}($ tot $)$ and $d_{\mathrm{GM}},(\mathrm{b}) x_{\mathrm{gen}}(<10)$ and $x_{\mathrm{gen}}(<20),(\mathrm{c}) C_{\mathrm{Rn}}^{\mathrm{A}}$ and $F$, and (d) $C_{\mathrm{RnDP}}^{\mathrm{A}}$ and $f^{\mathrm{un}}$, in indoor air of the basement kitchen, from October 28, 2010 to January 6, 2011, with some interruptions because of other measurements. During this 

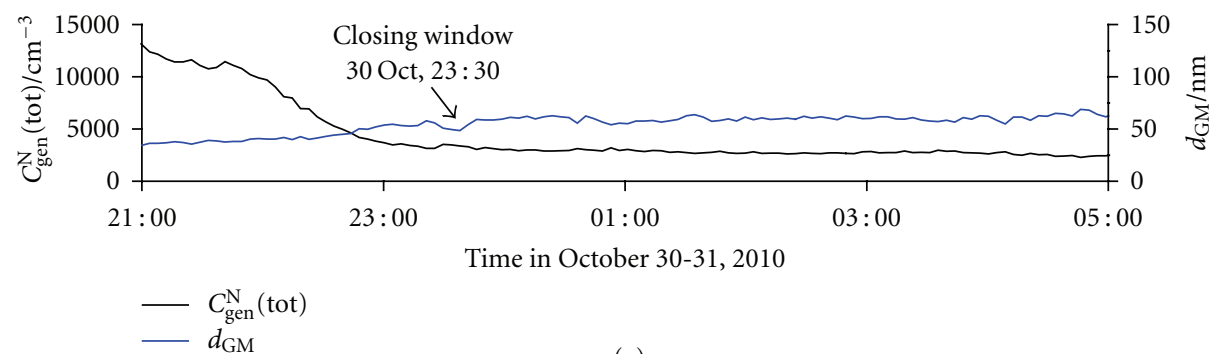

(a)
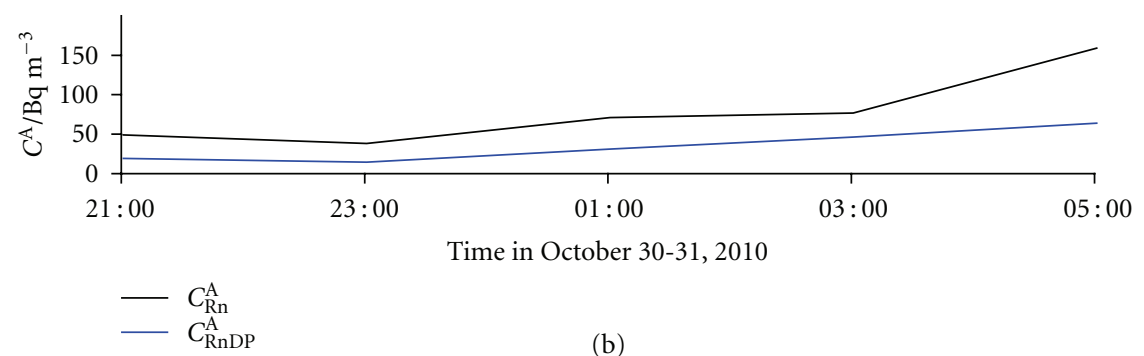

(b)

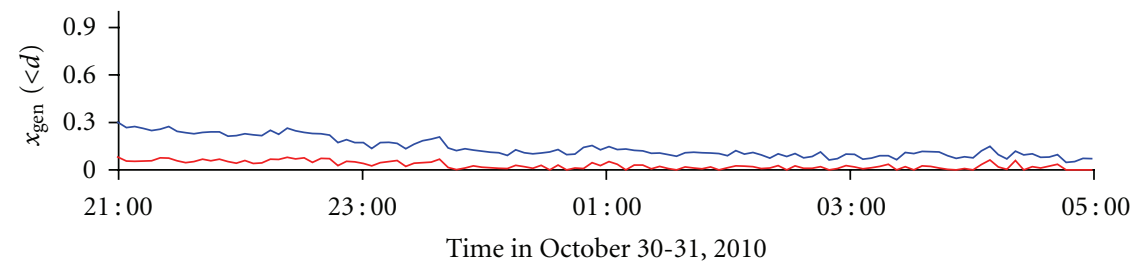

$-d=10 \mathrm{~nm}$

$-d=20 \mathrm{~nm}$

(c)
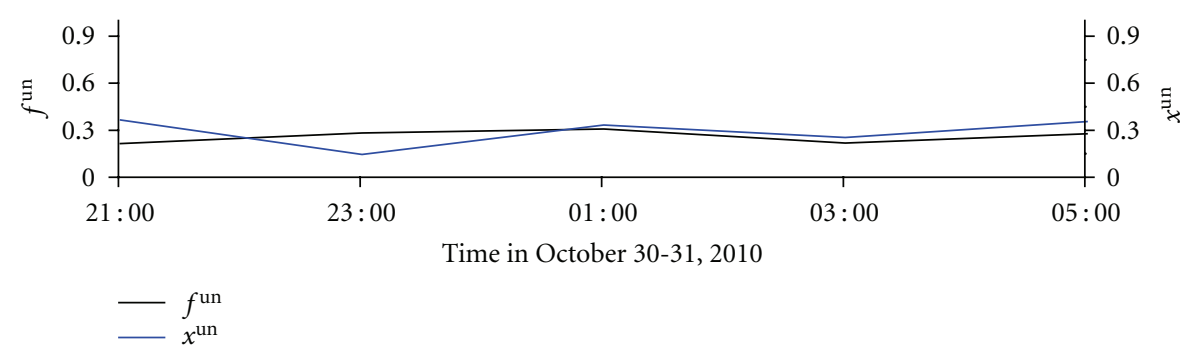

(d)

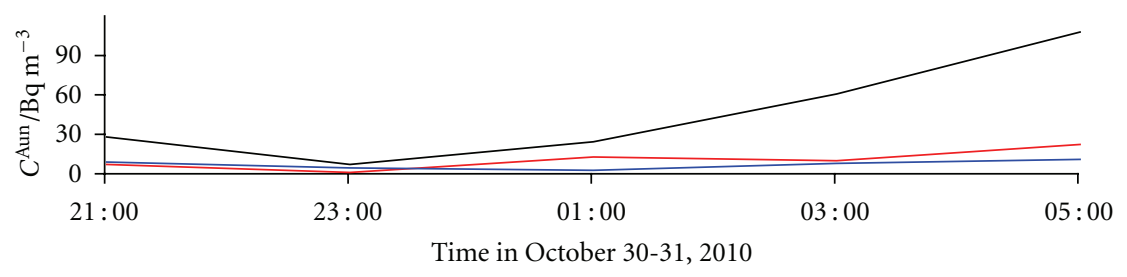

$-C_{218 \mathrm{Po}}$

$-C_{214 \mathrm{~Pb}}$

$-C_{214 \mathrm{Bi}}$

(e)

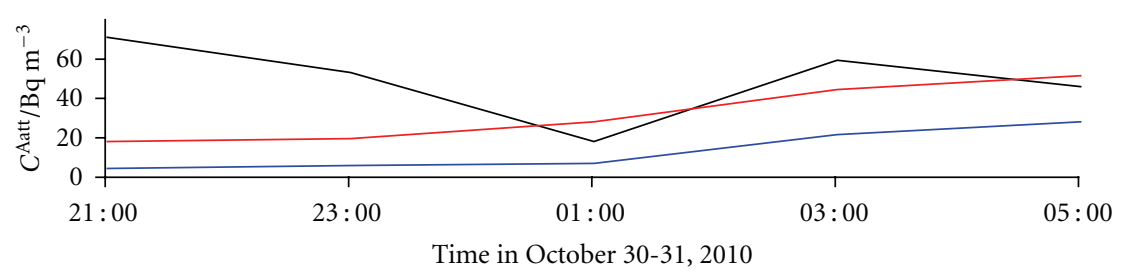

(f)

Figure 13: Continued. 


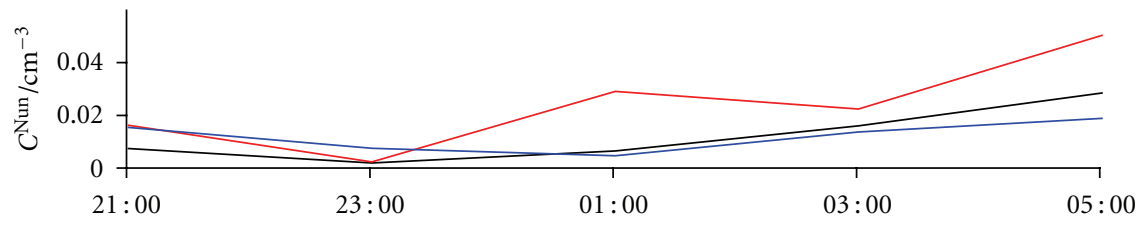

Time in October 30-31, 2010

(g)

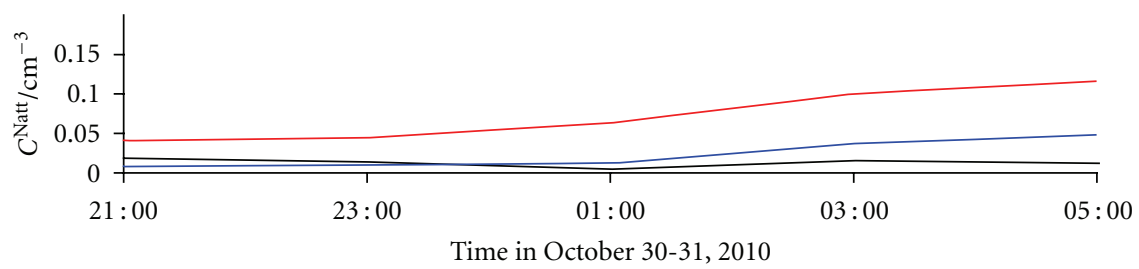

(h)

FIGURE 13: Time run of: (a) total number concentration of general aerosol particles $\left(C_{\mathrm{gen}}^{\mathrm{N}}(\right.$ tot $\left.)\right)$ and geometric mean values of their diameters $\left(d_{\mathrm{GM}}\right)$, (b) activity concentration of radon $\left(C_{\mathrm{Rn}}^{\mathrm{A}}\right)$ and equilibrium equivalent activity concentration of radon decay products $\left(C_{\mathrm{RnDP}}^{\mathrm{A}}\right)$, (c) number fraction of particles smaller than $10 \mathrm{~nm}\left(x_{\text {gen }}(<10)\right)$ and smaller than $20 \mathrm{~nm}\left(x_{\text {gen }}(<20)\right)$, (d) activity fraction of the unattached RnDP $\left(f^{\mathrm{un}}\right)$ and number fraction of the unattached $\operatorname{RnDP}\left(x^{\mathrm{un}}\right),(\mathrm{e})$ activity concentrations of the unattached $\mathrm{RnDP}$ atoms $\left(C_{218}^{\mathrm{Aun}} \mathrm{Po}, C_{214}^{\mathrm{Aun}} \mathrm{Pb}\right.$, and $\left.C_{214 \mathrm{Bi}}^{\mathrm{Aun}}\right)$, (f) activity concentrations of the attached RnDP atoms $\left(C_{218 \mathrm{Po}}^{\text {Aatt }}, C_{214 \mathrm{~Pb}}^{\mathrm{Aatt}}\right.$, and $\left.C_{214 \mathrm{Bi}}^{\mathrm{Aatt}}\right)$, (g) number concentrations of the unattached $\mathrm{RnDP}$ atoms $\left(C_{218 \mathrm{Po}}^{\mathrm{Nun}}, C_{214 \mathrm{~Pb}}^{\mathrm{Nun}}\right.$, and $\left.C_{214}^{\mathrm{Nun}}\right)$, and $(\mathrm{h})$ number concentrations of the attached $\mathrm{RnDP}$ atoms $\left(C_{218 \mathrm{Po}}^{\mathrm{Natt}}, C_{214}^{\mathrm{Natt}} \mathrm{Pb}\right.$, and $\left.C_{214}^{\mathrm{Natt}}{ }_{\mathrm{Bi}}\right)$, in indoor air for the period October 30-31 (with closing of the window in the kitchen at 23:30 on October 30).

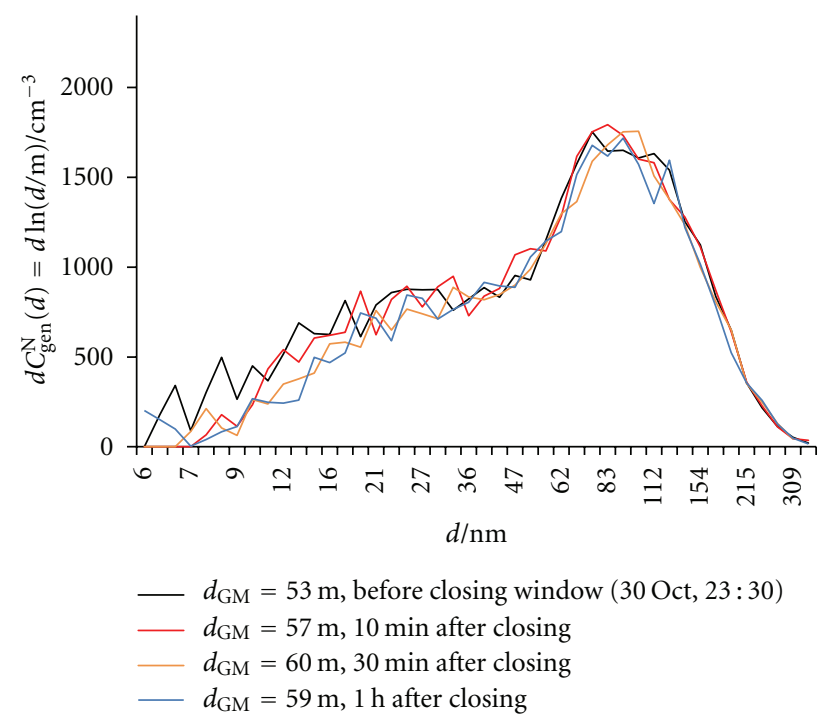

FIGURE 14: Number size distributions $\left(\mathrm{d} C_{\text {gen }}^{\mathrm{N}}(d)=\mathrm{d} \ln (d / \mathrm{m})\right)$ of general aerosol particles in indoor air before and after closing of the window in the kitchen.

period, the basement flat was normally inhabited, and all main activities were recorded, such as opening and closing windows, cleaning, preparing food, and other activities presumed to be sources of particulate matter. In the following, only events potentially influenced by human activity will be presented and discussed.

Table 2 shows minimum and maximum values, geometric means, and geometric standard deviations of the parameters monitored in the kitchen of the basement flat from October 28, 2010 to January 6, 2011, only during periods with the door and window closed and without human activity.

3.2.1. Opening the Window. The window in the kitchen was opened at 16:50 on October 28. As expected, both $C_{\mathrm{Rn}}^{\mathrm{A}}$ and $C_{\mathrm{RnDP}}^{\mathrm{A}}$ decreased suddenly (Figure 11(b)). Because $d_{\mathrm{GM}}$ in outdoor air is low in the afternoon, the inflow of outdoor air shifted the size distribution towards lower values (Figure 12), thus reducing $d_{\mathrm{GM}}$ and increasing $x_{\mathrm{gen}}(<20)$ 


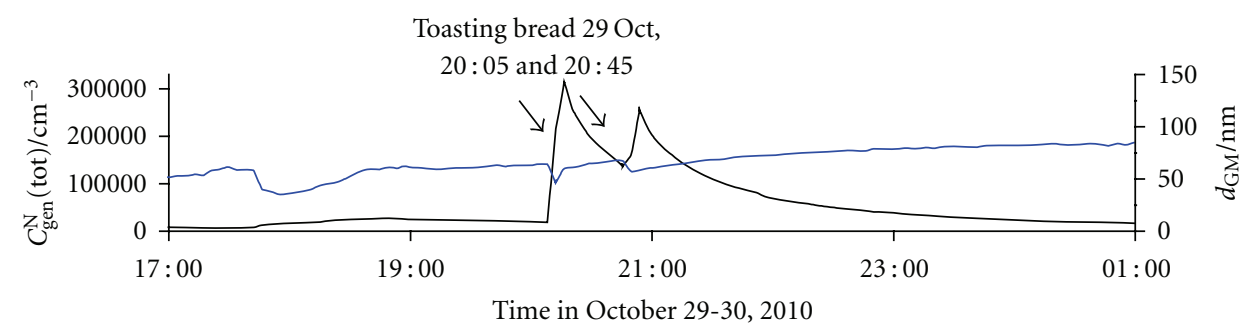

$-C_{\mathrm{gen}}^{\mathrm{N}}($ tot $)$
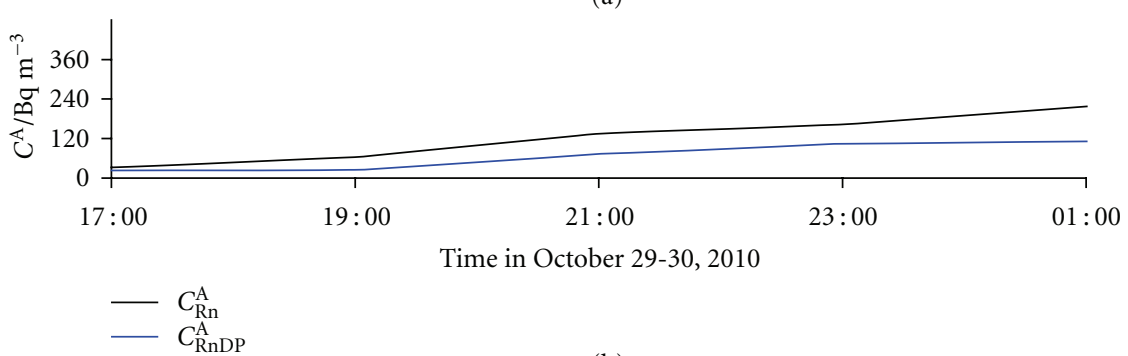

(b)

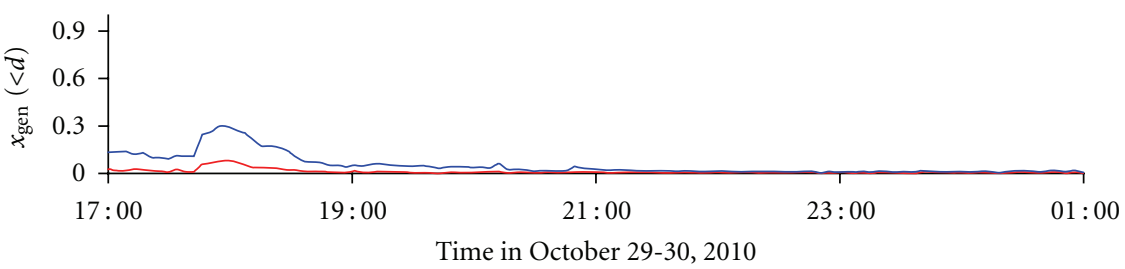

$\begin{aligned} d & =10 \mathrm{~nm} \\ -d & =20 \mathrm{~nm}\end{aligned}$

(c)

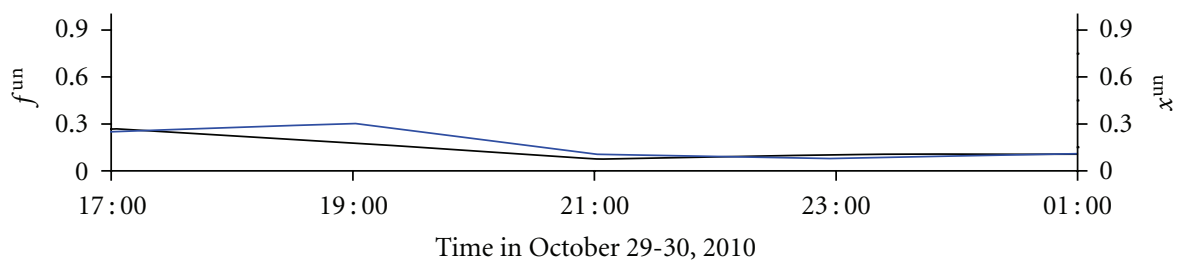

$f^{\text {un }}$
$-x^{\text {un }}$

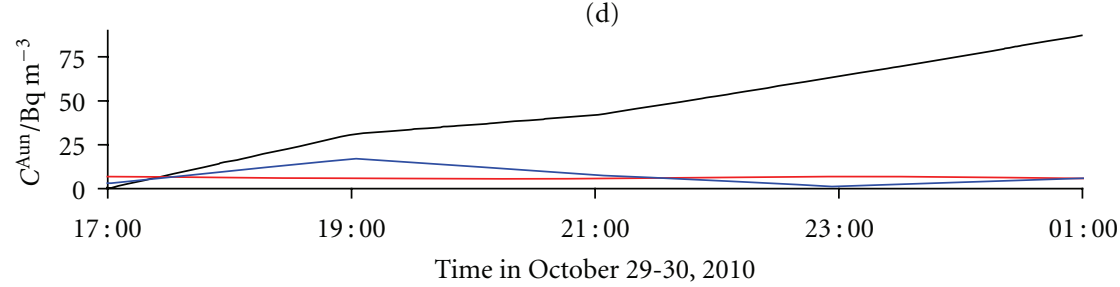

$-C_{218 \mathrm{Po}}$
$-C_{214 \mathrm{~Pb}}$
$-C_{214 \mathrm{Bi}}$

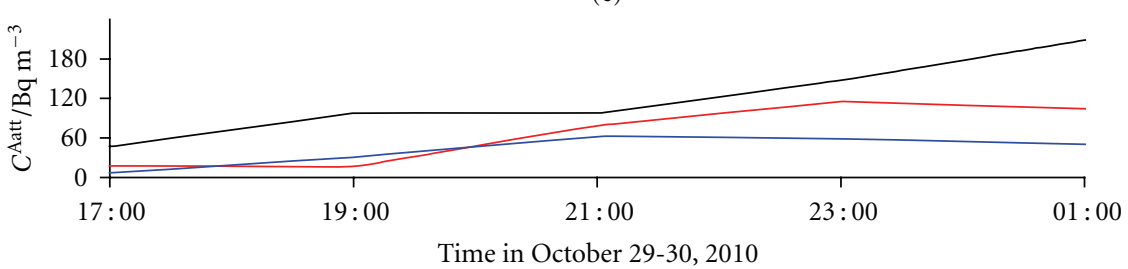

(f)

FIgURe 15: Continued. 


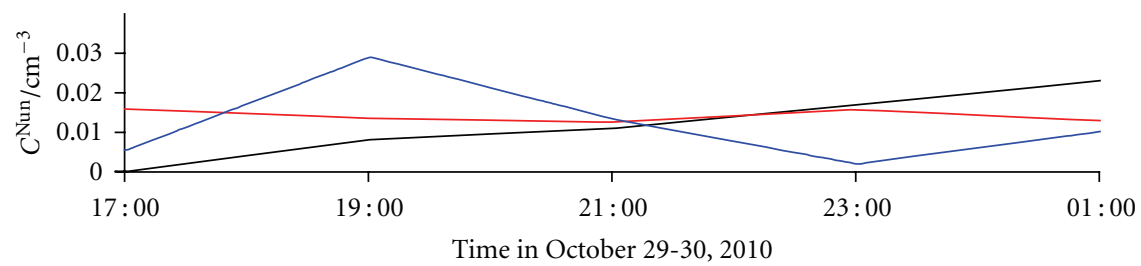

(g)

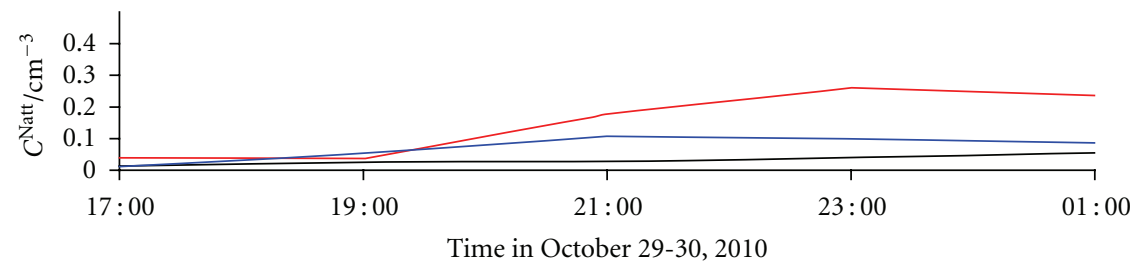

(h)

FIGURE 15: Time run of: (a) total number concentration of general aerosol particles $\left(C_{\text {gen }}^{\mathrm{N}}(\right.$ tot $\left.)\right)$ and geometric mean values of their diameters $\left(d_{\mathrm{GM}}\right)$, (b) activity concentration of radon $\left(C_{\mathrm{Rn}}^{\mathrm{A}}\right)$ and equilibrium equivalent activity concentration of radon decay products $\left(C_{\mathrm{RnDP}}^{\mathrm{A}}\right)$, (c) number fraction of particles smaller than $10 \mathrm{~nm}\left(x_{\text {gen }}(<10)\right)$ and smaller than $20 \mathrm{~nm}\left(x_{\text {gen }}(<20)\right)$, (d) activity fraction of the unattached $\operatorname{RnDP}\left(f^{\mathrm{un}}\right)$ and number fraction of the unattached $\mathrm{RnDP}\left(x^{\mathrm{un}}\right),(\mathrm{e})$ activity concentrations of the unattached $\mathrm{RnDP}$ atoms $\left(C_{218}^{\mathrm{Aun}}\right.$ Po $C_{214 \mathrm{~Pb}}^{\mathrm{Aun}}$, and $\left.C_{214 \mathrm{Bi}}^{\mathrm{Aun}}\right),(\mathrm{f})$ activity concentrations of the attached $\mathrm{RnDP}$ atoms $\left(C_{218}^{\text {Aatt } \mathrm{Po}}, C_{214 \mathrm{~Pb}}^{\text {Aatt }}\right.$, and $\left.C_{214 \mathrm{Bi}}^{\text {Aatt }}\right)$, (g) number concentrations of

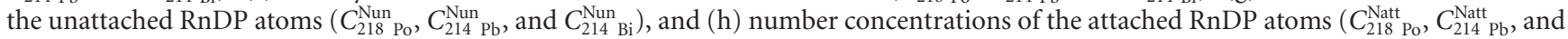
$C_{214}^{\mathrm{Natt}}$ Bi ), in indoor air for the period October 29-30 (periods of toasting bread in the kitchen from 20:05 to 20:15 and from 20:45 to 20:55 on October 29).

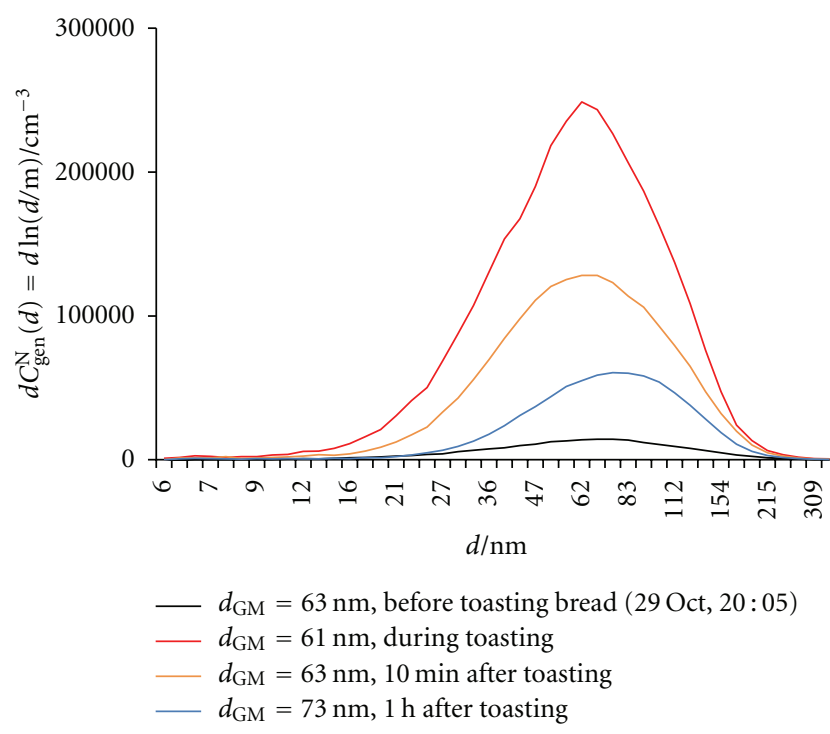

FIGURE 16: Number size distributions $\left(\mathrm{d} C_{\mathrm{gen}}^{\mathrm{N}}(d)=\mathrm{d} \ln (d / \mathrm{m})\right)$ of general aerosol particles in indoor air in the kitchen during toasting of bread.

indoors (Figure 11(c)). As a consequence, the probability of RnDP atoms meeting smaller particles is enhanced, and both $f^{\text {un }}$ and $x^{\text {un }}$ are increased, though not markedly (Figure 11(d)). Nonetheless, the frequency of EQF measurement is too low to follow such abrupt changes, and therefore the calculated $f$ un and $x^{\text {un }}$ responses are not necessarily correct. The decrease in number concentrations of all three $\mathrm{RnDP}$ in the attached form (Figure $11(\mathrm{~h})$ ) is a consequence of the decrease in $C_{\mathrm{RnDP}}^{\mathrm{A}}$ (Figure 11(b)).
3.2.2. Closing the Window. Upon closing the window at 23:30 on October 30 , only a slight and slow increase in $d_{\mathrm{GM}}$ was observed (Figure 13(a)), as shown also in Figure 14. A steady increase in $d_{\mathrm{GM}}$ and thus decrease in $x_{\text {gen }}(<10)$ and $x_{\text {gen }}(<20)$ follow (Figure 13(c)). Increase in $C_{\mathrm{RnDP}}^{\mathrm{A}}$ (Figure 13(b)) is a result of increasing the individual number concentrations of $\mathrm{RnDP}$, both in the unattached and attached forms (Figures $13(\mathrm{~g})$ and $13(\mathrm{~h}))$. Both $f^{\text {un }}$ and $x^{\text {un }}$ show a slight increase (Figure 13(d)). 


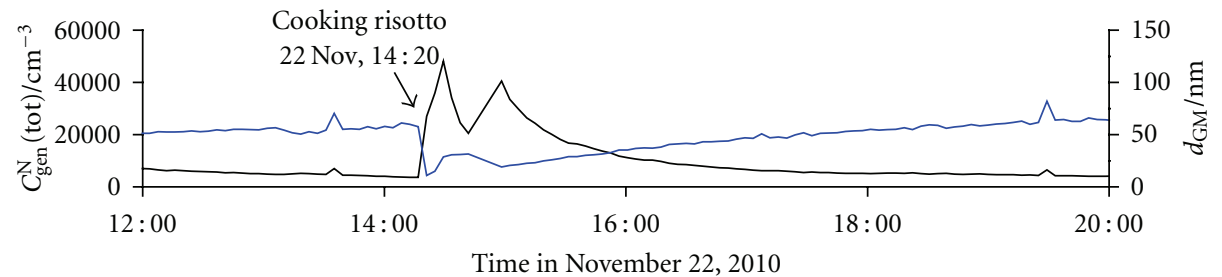$$
\begin{aligned}
& -C_{\mathrm{gen}}^{\mathrm{N}}(\text { tot }) \\
& -d_{\mathrm{GM}}
\end{aligned}
$$

(a)

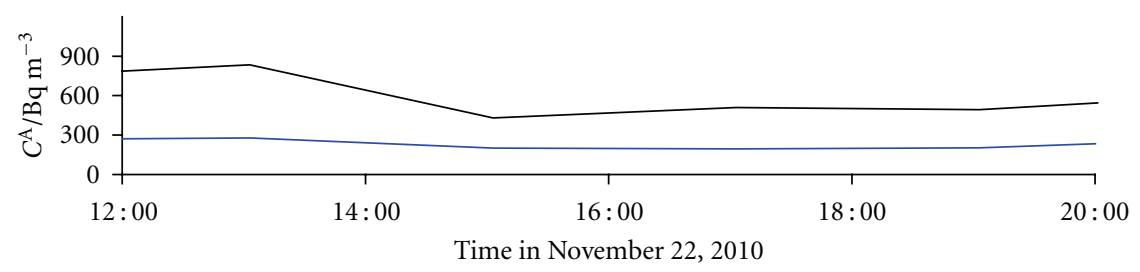

$-C_{\mathrm{Rn}}^{\mathrm{A}}$

$-C_{\mathrm{RnDP}}^{\mathrm{A}}$

(b)

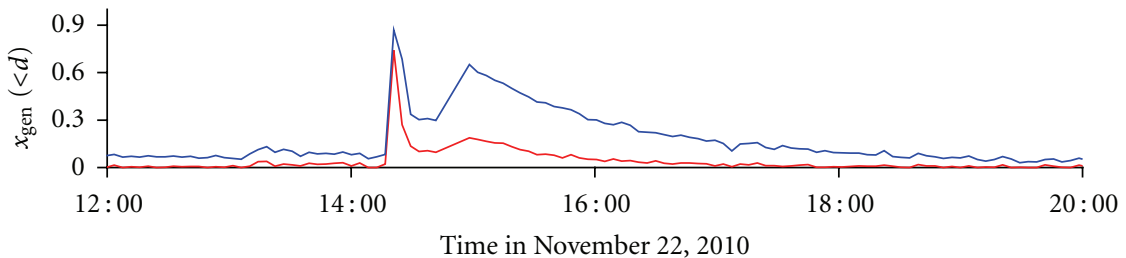

$-d=10 \mathrm{~nm}$

$-d=20 \mathrm{~nm}$

(c)

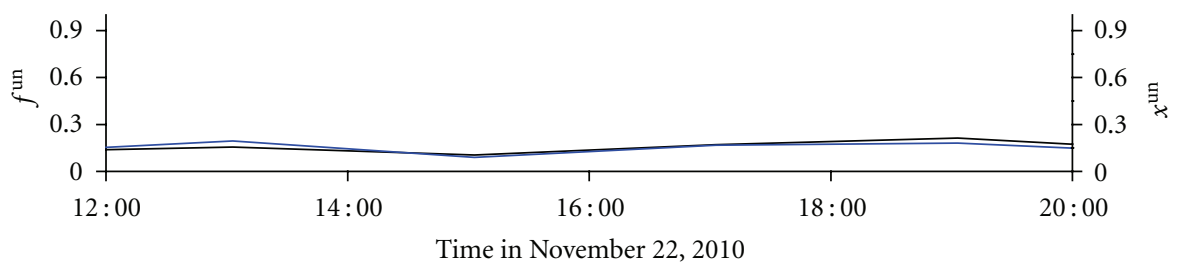

$-f^{\text {un }}$

(d)

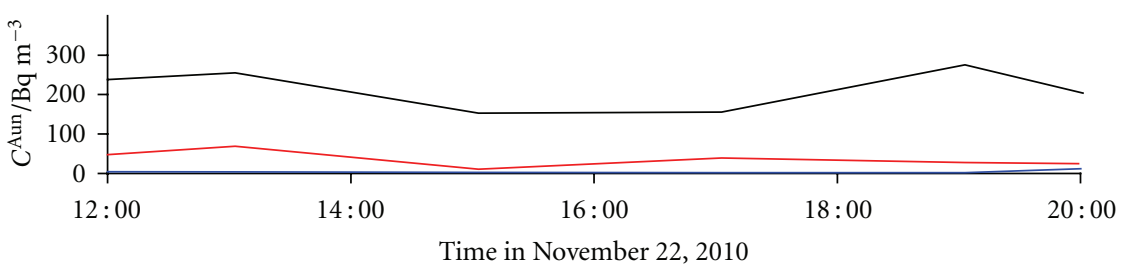

$-C_{218 \mathrm{Po}}$

$-C_{214 \mathrm{~Pb}}$

$-C_{214 \mathrm{Bi}}$

(e)

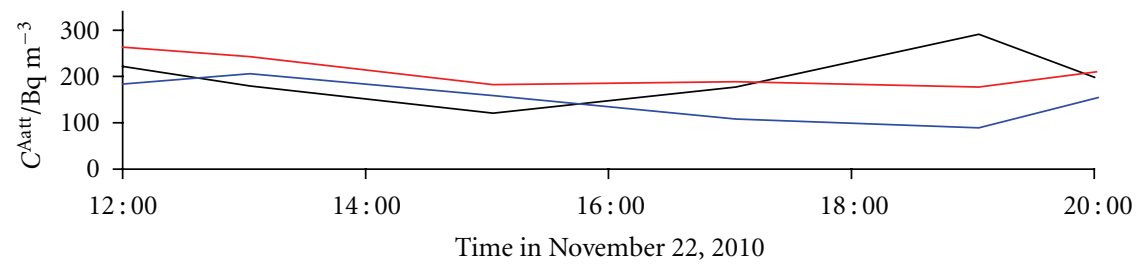

(f)

FIgure 17: Continued. 


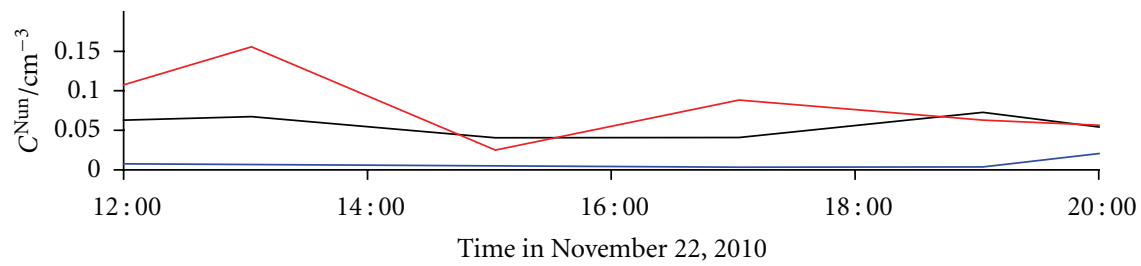

(g)

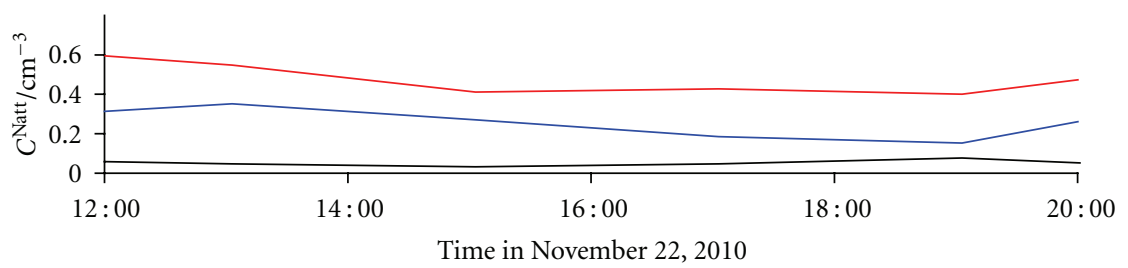

(h)

FIgURE 17: Time run of: (a) total number concentration of general aerosol particles $\left(C_{\mathrm{gen}}^{\mathrm{N}}(\right.$ tot $\left.)\right)$ and geometric mean values of their diameters $\left(d_{\mathrm{GM}}\right)$, (b) activity concentration of radon $\left(C_{\mathrm{Rn}}^{\mathrm{A}}\right)$ and equilibrium equivalent activity concentration of radon decay products $\left(C_{\mathrm{RnDP}}^{\mathrm{A}}\right)$, (c) number fraction of particles smaller than $10 \mathrm{~nm}\left(x_{\text {gen }}(<10)\right)$ and smaller than $20 \mathrm{~nm}\left(x_{\mathrm{gen}}(<20)\right)$, (d) activity fraction of the unattached RnDP $\left(f^{\mathrm{un}}\right)$ and number fraction of the unattached $\mathrm{RnDP}\left(x^{\mathrm{un}}\right)$, (e) activity concentrations of the unattached $\mathrm{RnDP}$ atoms $\left(C_{218}^{\mathrm{Aun}} \mathrm{Po}, C_{214}^{\mathrm{Aun}} \mathrm{Pb}\right.$, and $\left.C_{214 \mathrm{Bi}}^{\mathrm{Aun}}\right)$, (f) activity concentrations of the attached RnDP atoms $\left(C_{218 \mathrm{Po}}^{\text {Aatt }}, C_{214 \mathrm{~Pb}}^{\mathrm{Aatt}}\right.$, and $\left.C_{214 \mathrm{Bi}}^{\mathrm{Aatt}}\right),(\mathrm{g})$ number concentrations of the unattached RnDP atoms $\left(C_{218 \text { Po }}^{\mathrm{Nun}}, C_{214 \mathrm{~Pb}}^{\mathrm{Nun}}\right.$, and $\left.C_{214}^{\mathrm{Nun}} \mathrm{Bi}\right)$, and (h) number concentrations of the attached $\mathrm{RnDP}$ atoms $\left(C_{218 \mathrm{Po}}^{\mathrm{Natt}}, C_{214}^{\mathrm{Natt}} \mathrm{Pb}\right.$, and $\left.C_{214}^{\mathrm{Natt}}{ }_{\mathrm{Bi}}\right)$, in indoor air on November 22 (cooking a "risotto" dish from 14:20 to 15:00).

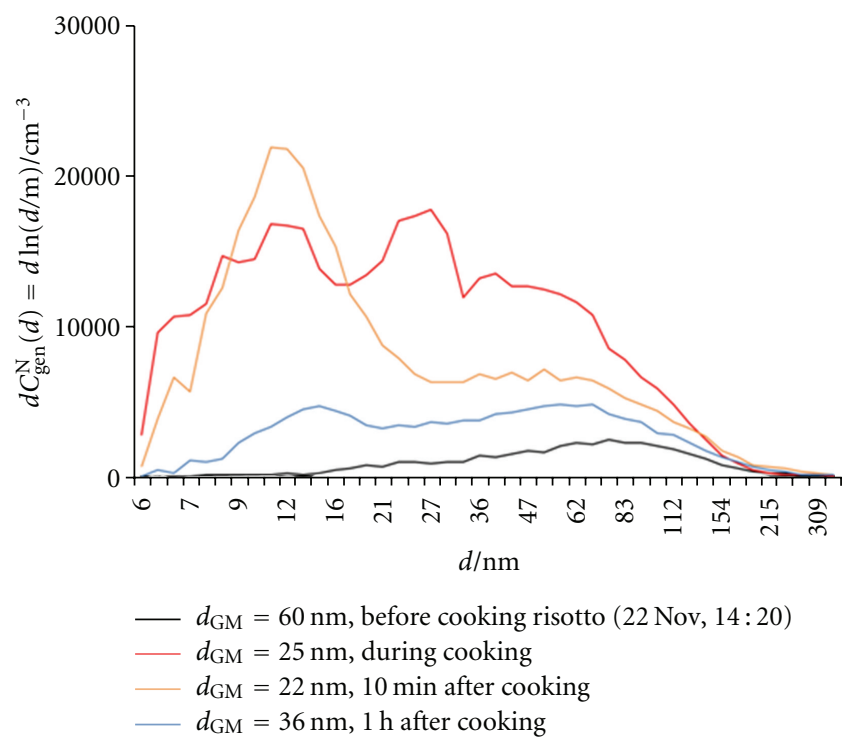

Figure 18: Number size distributions $\left(\mathrm{d} C_{\mathrm{gen}}^{\mathrm{N}}(d)=\mathrm{d} \ln (d / \mathrm{m})\right)$ of general aerosol particles in indoor air in the kitchen during cooking a "risotto" dish.

3.2.3. Using a Toaster. An abrupt and very large increase in $C_{\text {gen }}^{\mathrm{N}}$ (tot) (reaching $300,000 \mathrm{~cm}^{-3}$ ) on October 29 was caused by using a bread toaster (Figure $15(\mathrm{a})$ ). The $C_{\text {gen }}^{\mathrm{N}}$ (tot) peak is split into two because of two consecutive uses of the toaster for $10 \mathrm{~min}$ each, at 20:05 and 20:45. The size distribution of particles did not change significantly during toasting (Figure 16) and was only slightly shifted towards higher sizes afterwards. Decrease in $f^{\text {un }}$ and $x^{\text {un }}$ is mainly a consequence of decrease in the number concentration of the unattached ${ }^{214} \mathrm{Bi}$ (Figure $15(\mathrm{~g})$ ) and increase in the number concentration of the attached ${ }^{214} \mathrm{~Pb}$ (Figure $15(\mathrm{~h})$ ). After toasting was finished, $d_{\mathrm{GM}}$ started to increase continuously, presumably because of particle growth, estimated to be 2$3 \mathrm{~nm} \mathrm{~h}^{-1}$ for urban areas in this season of the year $[61,64]$.

3.2.4. Cooking a "Risotto" Dish. Figure 17 shows the effect of preparation of an Italian "risotto" dish, including boiling rice and frying rice, vegetables, and additives. $C_{\mathrm{gen}}^{\mathrm{N}}($ tot $)$ increased suddenly up to about $50,000 \mathrm{~cm}^{-3}$. Particles emitted were 


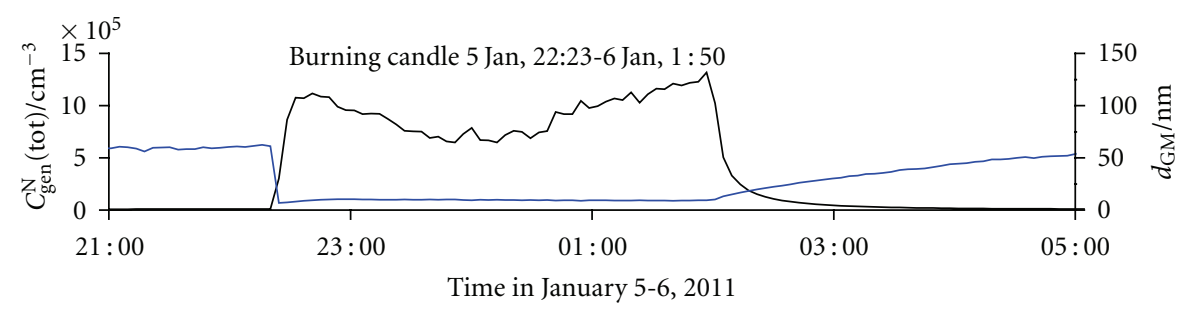

$-d_{\mathrm{gM}}^{\mathrm{N}}($ tot $)$

(a)

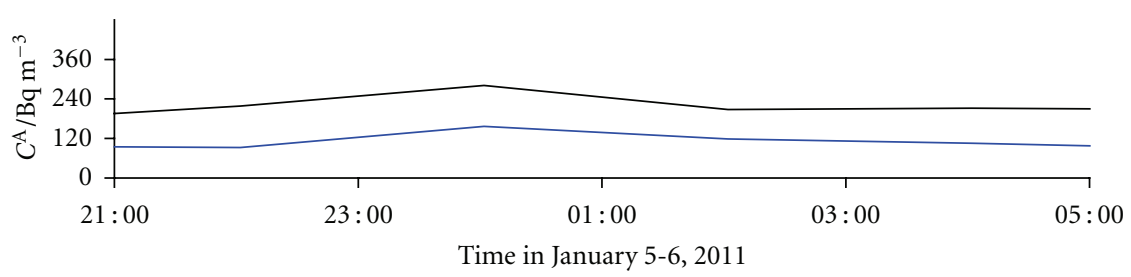

$-C_{\mathrm{Rn}}^{\mathrm{A}}$

$-C_{\mathrm{RnDP}}^{\mathrm{A}}$

(b)

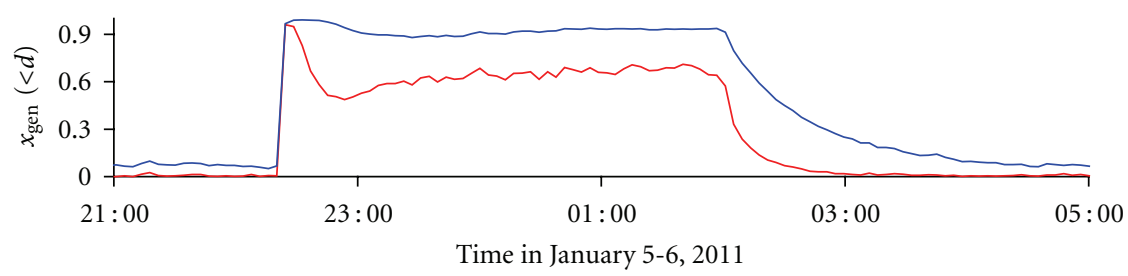

$-d=10 \mathrm{~nm}$

$-d=20 \mathrm{~nm}$
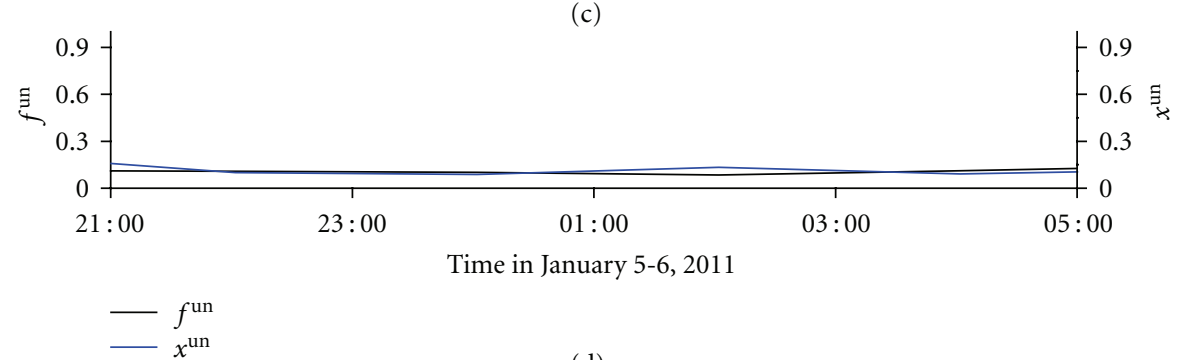

(d)

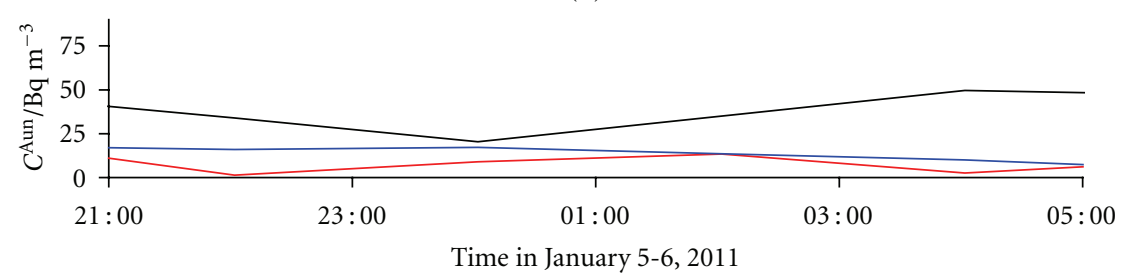

- $C_{218 \mathrm{Po}}$

- $C_{214 \mathrm{~Pb}}$

- $C_{214 \mathrm{Bi}}$

(e)

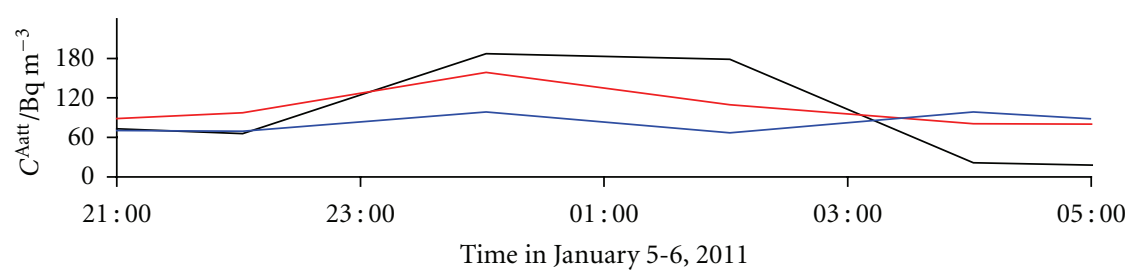

(f)

Figure 19: Continued. 


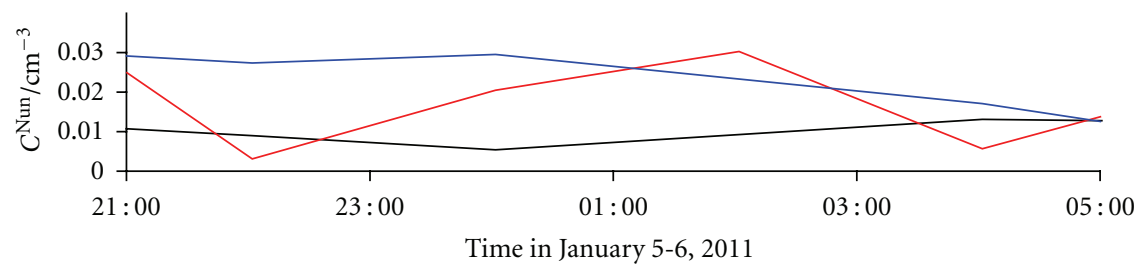

(g)

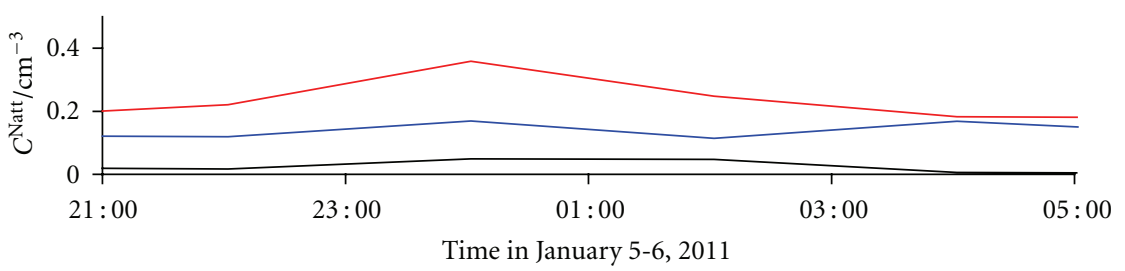

(h)

FIGURE 19: Time run of: (a) total number concentration of general aerosol particles $\left(C_{\mathrm{gen}}^{\mathrm{N}}(\right.$ tot $\left.)\right)$ and geometric mean values of their diameters $\left(d_{\mathrm{GM}}\right)$, (b) activity concentration of radon $\left(C_{\mathrm{Rn}}^{\mathrm{A}}\right)$ and equilibrium equivalent activity concentration of radon decay products $\left(C_{\mathrm{RnDP}}^{\mathrm{A}}\right)$, (c) number fraction of particles smaller than $10 \mathrm{~nm}\left(x_{\text {gen }}(<10)\right)$ and smaller than $20 \mathrm{~nm}\left(x_{\text {gen }}(<20)\right)$, (d) activity fraction of the unattached RnDP $\left(f^{\mathrm{un}}\right)$ and number fraction of the unattached $\operatorname{RnDP}\left(x^{\mathrm{un}}\right),(\mathrm{e})$ activity concentrations of the unattached $\mathrm{RnDP}$ atoms $\left(C_{218}^{\mathrm{Aun}} \mathrm{Po}, C_{214}^{\mathrm{Aun}} \mathrm{Pb}\right.$, and $\left.C_{214 \mathrm{Bi}}^{\mathrm{Aun}}\right)$, (f) activity concentrations of the attached RnDP atoms $\left(C_{218 \text { Po }}^{\text {Aatt }}, C_{214 \mathrm{~Pb}}^{\mathrm{Aatt}}\right.$, and $\left.C_{214 \mathrm{Bi}}^{\mathrm{Aatt}}\right)$, (g) number concentrations of the unattached RnDP atoms $\left(C_{218 \mathrm{Po}}^{\mathrm{Nun}}, C_{214 \mathrm{~Pb}}^{\mathrm{Nun}}\right.$, and $\left.C_{214}^{\mathrm{Nun}}\right)$, and $(\mathrm{h})$ number concentrations of the attached $\mathrm{RnDP}$ atoms $\left.\left(C_{218 \mathrm{Po}}^{\mathrm{Natt}}, C_{214 \mathrm{~Pb}}^{\mathrm{Natt}} \text {, and } C_{214}^{\mathrm{Natt}}\right)_{\mathrm{Bi}}\right)$, in indoor air for the period January 5-6 (period of burning a candle in the kitchen from 22:23 on January 5 to $1: 50$ on January 6).

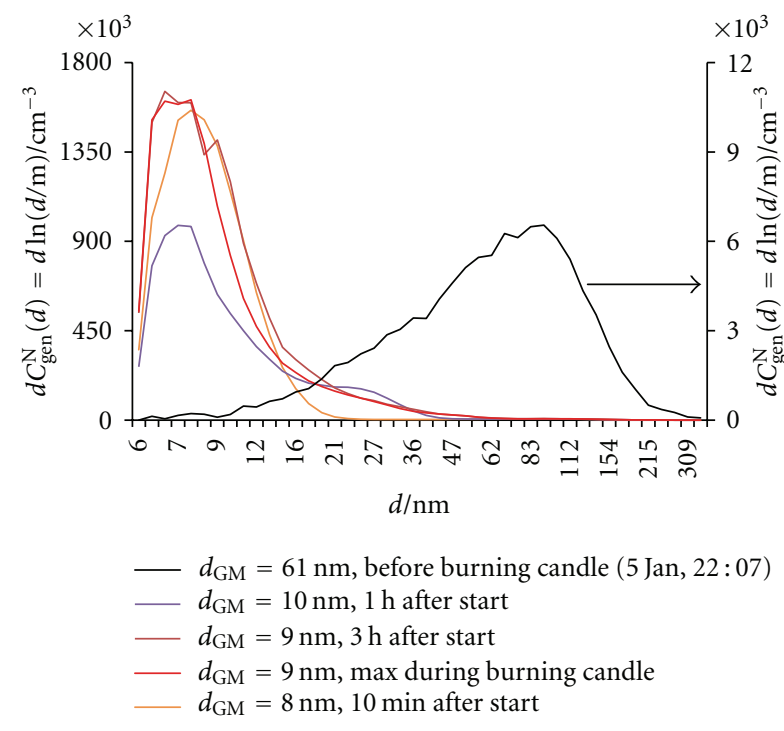

(a)

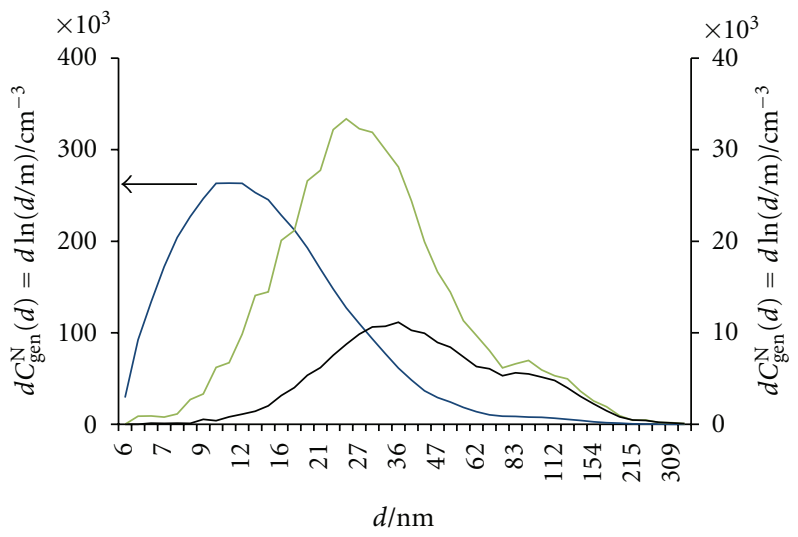

$\begin{aligned}-d_{\mathrm{GM}} & =15 \mathrm{~nm}, 10 \mathrm{~min} \text { after burning } \\ -d_{\mathrm{GM}} & =30 \mathrm{~nm}, 1 \mathrm{~h} \text { after } \\ -d_{\mathrm{GM}} & =44 \mathrm{~nm}, 2 \mathrm{~h} \text { after }\end{aligned}$

(b)

FIGURE 20: Number size distributions $\left(\mathrm{d} C_{\text {gen }}^{\mathrm{N}}(d)=\mathrm{d} \ln (d / \mathrm{m})\right)$ of general aerosol particles in indoor air (a) before and during burning of a candle and (b) after burning a candle.

of smaller size, thus shifting the size distribution shown in Figure 18 toward the left. More than $80 \%$ of the lowered $d_{\mathrm{GM}}$ was contributed by particles smaller than $20 \mathrm{~nm}$ and about $70 \%$ by particles smaller than $10 \mathrm{~nm}$ (Figure $17(\mathrm{c})$ ). RnDP require some time to be created and then attach to aerosol particles [65]. Therefore, even if the SMPS+C and EQF30202 device had the same frequency of analysis, a prompt response of $f^{\text {un }}$ and $x^{\text {un }}$ to the changes in the general aerosol concentration and size distribution may not be anticipated.
The initial conditions were restored more than an hour after the cooking was finished.

3.2.5. Burning a Candle. An enormous $C_{\text {gen }}^{\mathrm{N}}($ tot $)$ peak (reaching $1,320,000 \mathrm{~cm}^{-3}$ ), accompanied by a sudden decrease in $d_{\mathrm{GM}}$, appeared during burning candle from 22:20 on January 5 to $1: 50$ on January 6 (Figure 19(a)). Particles smaller than $10 \mathrm{~nm}$ are produced, as evident from 


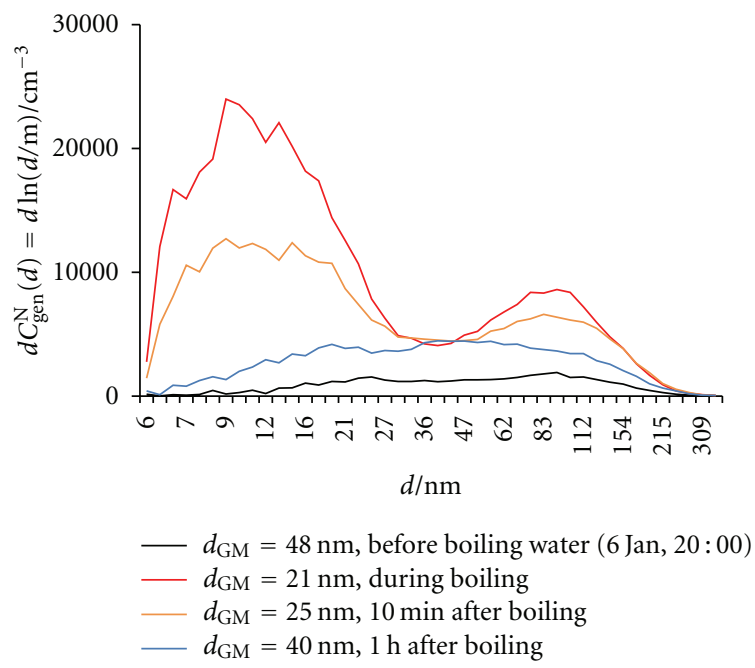

FiguRE 21: Number size distributions $\left(\mathrm{d} C_{\mathrm{gen}}^{\mathrm{N}}(d)=\mathrm{d} \ln (d / \mathrm{m})\right)$ of general aerosol particles in indoor air before, during, and after boiling water.

TABle 1: Minimum and maximum values, geometric means, and geometric standard deviations (except for $R_{s}$ for which arithmetic mean and arithmetic standard deviation are given) for the total number concentration of general aerosol $\left(C_{\mathrm{gen}}^{\mathrm{N}}\right.$ (tot)), geometric mean of number size distribution of general aerosol $\left(d_{\mathrm{GM}}\right)$, number fractions of particles smaller than $10 \mathrm{~nm}\left(x_{\mathrm{gen}}(<10)\right)$ and smaller than $20 \mathrm{~nm}\left(x_{\mathrm{gen}}(<20)\right)$, equilibrium equivalent concentration of radon short-lived decay products $\left(C_{\mathrm{RnDP}}^{\mathrm{A}}\right)$, activity fraction of the unattached radon short-lived decay products $\left(f^{\text {un }}\right)$, barometric pressure $(P)$, air temperature $(T)$, air relative humidity $\left(H_{\text {rel }}\right)$, wind speed $\left(v_{w}\right)$, solar radiation $\left(R_{s}\right)$, and concentrations of aerosol particles smaller than $10 \mu \mathrm{m}\left(C_{\mathrm{PM} 10}\right), \mathrm{SO}_{2}\left(C_{\mathrm{SO}_{2}}\right), \mathrm{NO}_{x}\left(C_{\mathrm{NO}_{x}}\right)$, and $\mathrm{O}_{3}\left(C_{\mathrm{O}_{3}}\right)$ for the entire period of measurements outdoors in May (3 May-6 June) and October (7-11 October, 17-21 October, and 24-26 October).

\begin{tabular}{|c|c|c|c|c|c|c|c|c|}
\hline \multirow{2}{*}{ Parameter } & \multicolumn{4}{|c|}{ May } & \multicolumn{4}{|c|}{ October } \\
\hline & $\min$ & $\max$ & GM & GSD & $\min$ & $\max$ & GM & GSD \\
\hline$C_{\mathrm{gen}}^{\mathrm{N}}($ tot $) / \mathrm{cm}^{-3}$ & 1420 & 75650 & 6830 & 1.69 & 970 & 85930 & 6940 & 1.93 \\
\hline$d_{\mathrm{GM}} / \mathrm{nm}$ & 18 & 124 & 53 & 1.42 & 15 & 133 & 59 & 1.43 \\
\hline$x_{\text {gen }}(<10)$ & & & & & 0.03 & 0.37 & 0.02 & 3.08 \\
\hline$x_{\text {gen }}(<20)$ & 0.03 & 0.78 & 0.12 & 2.47 & 0.03 & 0.79 & 0.09 & 2.75 \\
\hline$C_{\mathrm{RnDP}}^{\mathrm{A}} / \mathrm{Bq} \mathrm{m}^{-3}$ & & & & & 2 & 18 & 6 & 2.05 \\
\hline$f^{\text {un }}$ & & & & & 0.01 & 0.75 & 0.09 & 2.38 \\
\hline $\mathrm{P} / \mathrm{hPa}$ & 963 & 988 & 977 & 1.01 & 970 & 993 & 981 & 1.01 \\
\hline $\mathrm{T} /{ }^{\circ} \mathrm{C}$ & 5 & 28 & 15 & 1.31 & 1 & 16 & 8 & 1.56 \\
\hline$H_{\text {rel }} / \%$ & 21 & 99 & 65 & 1.43 & 42 & 99 & 82 & 1.19 \\
\hline$v_{\mathrm{w}} / \mathrm{m} \mathrm{s}^{-1}$ & 0.1 & 7 & 1.2 & 3.16 & 0.1 & 5 & 0.8 & 2.33 \\
\hline$R_{s} / \mathrm{W} \mathrm{m}^{-2}$ & 1 & 1085 & $198^{*}$ & $266^{* *}$ & 1 & 793 & $78^{*}$ & $145^{* *}$ \\
\hline$C_{\mathrm{PM} 10} / \mu \mathrm{g} \mathrm{m}^{-3}$ & 0.03 & 52 & 13 & 3.22 & 0.03 & 113 & 23 & 3.26 \\
\hline$C_{\mathrm{SO}_{2}} / \mu \mathrm{g} \mathrm{m}^{-3}$ & 0.1 & 8 & 0.7 & 3.40 & 0.1 & 14 & 0.6 & 3.87 \\
\hline$C_{\mathrm{NO}_{x}} / \mu \mathrm{g} \mathrm{m}^{-3}$ & 4 & 129 & 24 & 1.97 & 4 & 209 & 38 & 2.14 \\
\hline$C_{\mathrm{O}_{3}} / \mu \mathrm{g} \mathrm{m}^{-3}$ & 1 & 159 & 42 & 2.60 & 1 & 92 & 14 & 3.22 \\
\hline
\end{tabular}

* Arithmetic mean.

**Arithmetic standard deviation.

Figure 20. Values of $x_{\text {gen }}(<10)$ and $x_{\text {gen }}(<20)$ exceed 0.60 and 0.90 , respectively (Figure 19(c)). This high fraction of small particles should result in high $f^{\text {un }}$ values, but it does not. Considerable changes in individual number concentrations of RnDP, in both unattached (Figure 19(e)) and attached form (Figure 19(f)), are compensated in the final result, leaving $f$ un practically unchanged during the entire period (Figure 19(d)), even though an abrupt decrease was expected based on the inverse $f^{\mathrm{un}}-C_{\mathrm{gen}}^{\mathrm{N}}($ tot $)$ relationship $[40,41]$.
3.2.6. Boiling Water. Before water heating began at 20:00 on January 6, a bimodal, though not well-pronounced, size distribution was observed, with particles grouping at around $25 \mathrm{~nm}$ and $85 \mathrm{~nm}$ (Figure 21). During heating, water emitted particles smaller than $20 \mathrm{~nm}$, but the contribution of larger particles also grew steadily. Smaller particles are probably clusters of water molecules and larger ones of tiny water droplets. At the boiling point, lasting $10 \mathrm{~min}$, a well pronounced bimodal distribution appeared. After boiling 


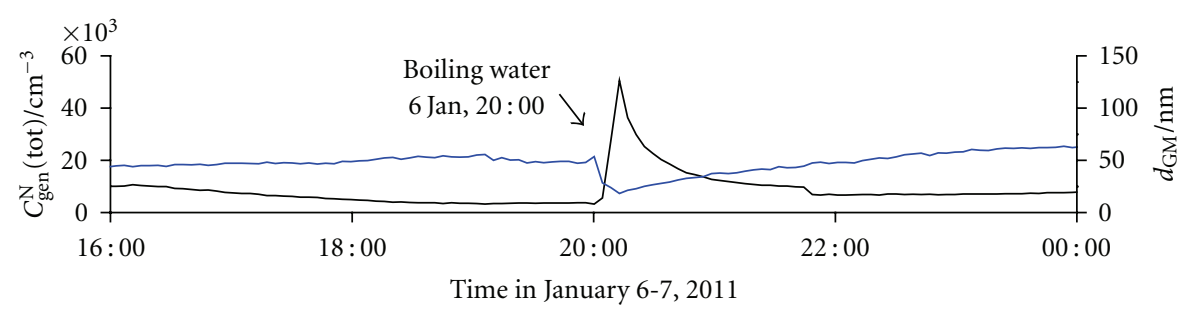

$=C_{\mathrm{gen}}^{\mathrm{N}}($ tot $)$

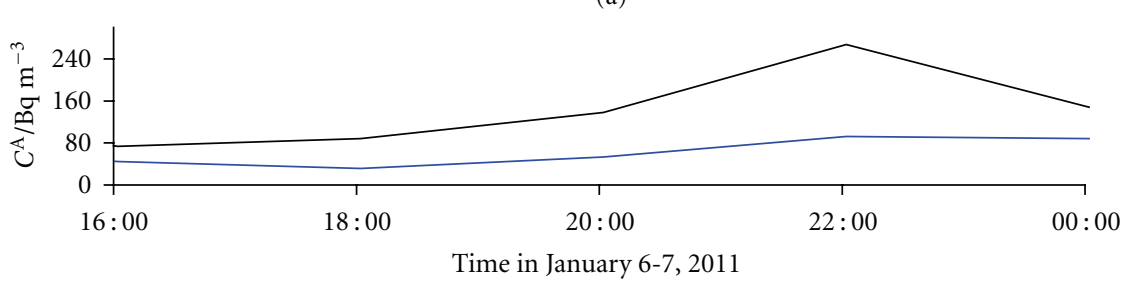

(b)

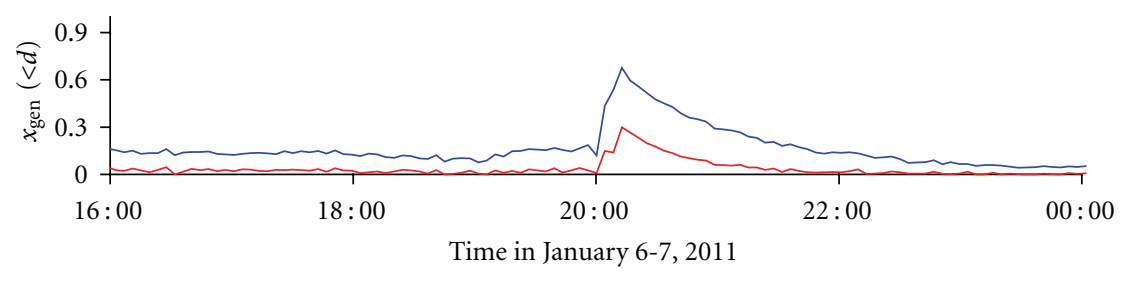

$d=10 \mathrm{~nm}$

$-d=20 \mathrm{~nm}$

(c)
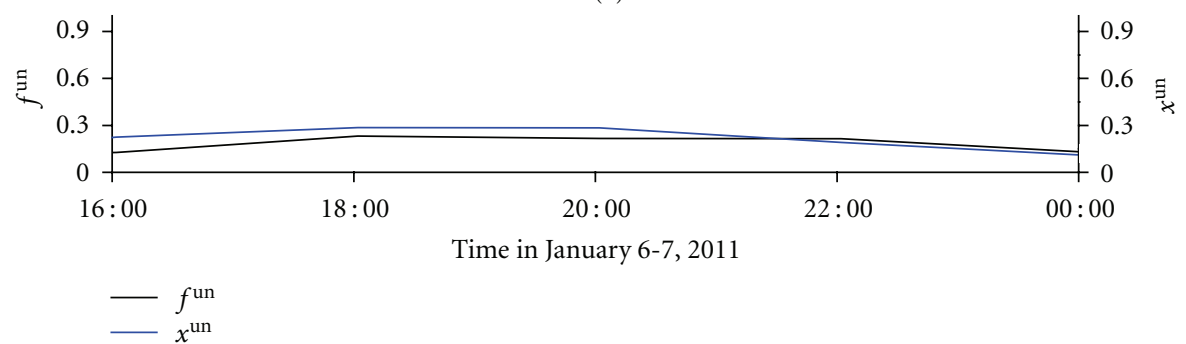

(d)

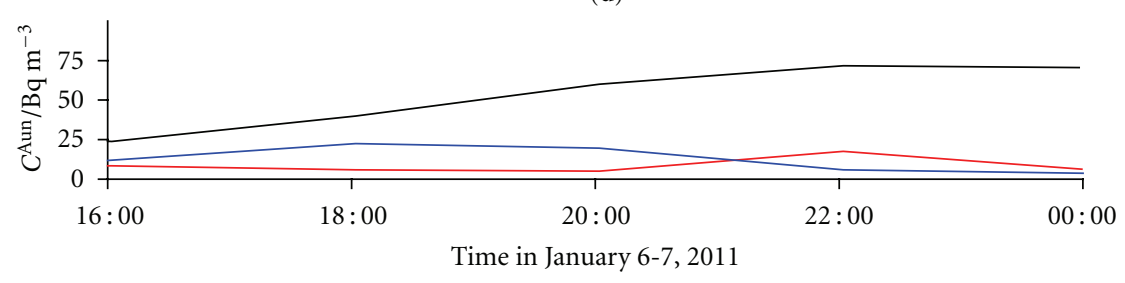

- $C_{218 \mathrm{Po}}$

$-C_{214 \mathrm{~Pb}}$

$-C_{214 \mathrm{Bi}}$

(e)

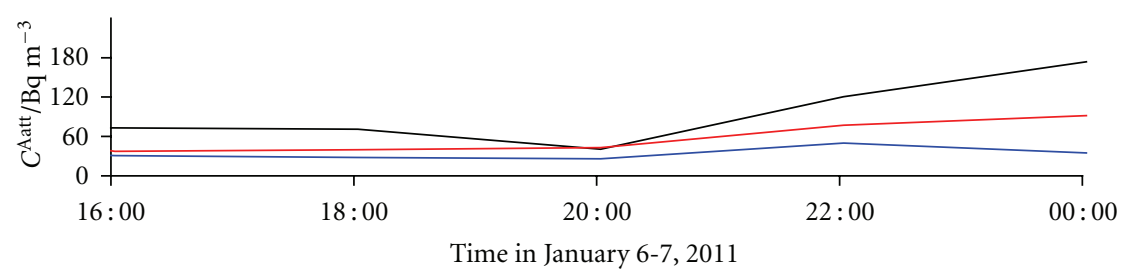

(f)

Figure 22: Continued. 


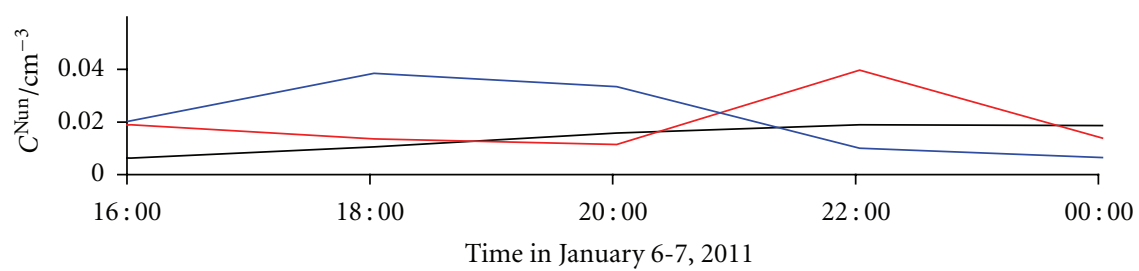

(g)

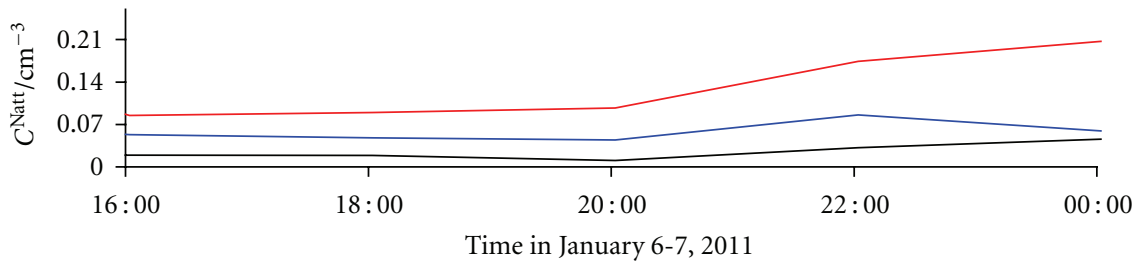

(h)

FIGURE 22: Time run of: (a) total number concentration of general aerosol particles $\left(C_{\mathrm{gen}}^{\mathrm{N}}(\right.$ tot $\left.)\right)$ and geometric mean values of their diameters $\left(d_{\mathrm{GM}}\right),(\mathrm{b})$ activity concentration of radon $\left(C_{\mathrm{Rn}}^{\mathrm{A}}\right)$ and equilibrium equivalent activity concentration of radon decay products $\left(C_{\mathrm{RnDP}}^{\mathrm{A}}\right)$, (c) number fraction of particles smaller than $10 \mathrm{~nm}\left(x_{\text {gen }}(<10)\right)$ and smaller than $20 \mathrm{~nm}\left(x_{\text {gen }}(<20)\right)$, (d) activity fraction of the unattached RnDP $\left(f^{\mathrm{un}}\right)$ and number fraction of the unattached $\mathrm{RnDP}\left(x^{\mathrm{un}}\right),(\mathrm{e})$ activity concentrations of the unattached $\mathrm{RnDP}$ atoms $\left(C_{218}^{\mathrm{Aun}} \mathrm{Po}, C_{214}^{\mathrm{Aun}} \mathrm{Pb}\right.$, and $\left.C_{214 \mathrm{Bi}}^{\text {Aun }}\right)$, (f) activity concentrations of the attached RnDP atoms $\left(C_{218 \mathrm{Po}}^{\text {Aatt }}, C_{214 \mathrm{~Pb}}^{\mathrm{Aatt}}\right.$, and $\left.C_{214 \mathrm{Bi}}^{\text {Aatt }}\right)$, (g) number concentrations of the unattached RnDP atoms $\left(C_{218 \text { Po }}^{\mathrm{Nun}}, C_{214 \mathrm{~Pb}}^{\mathrm{Nun}}\right.$, and $\left.C_{214}^{\mathrm{Nun}}\right)$, and $(\mathrm{h})$ number concentrations of the attached $\mathrm{RnDP}$ atoms $\left(C_{218 \mathrm{Po}}^{\mathrm{Natt}}, C_{214}^{\mathrm{Natt}} \mathrm{Pb}\right.$, and $\left.C_{214}^{\mathrm{Natt}}{ }_{\mathrm{Bi}}\right)$, in indoor air on January 6 (boiling water in the kitchen from 20:00 to 20:12).

TABle 2: Minimum and maximum values, geometric means, and geometric standard deviations for the total number concentration of general aerosol $\left(C_{\mathrm{gen}}^{\mathrm{N}}(\mathrm{tot})\right)$, geometric mean of number size distribution of general aerosol $\left(d_{\mathrm{GM}}\right)$, number fractions of particles smaller than $10 \mathrm{~nm}\left(x_{\text {gen }}(<10)\right)$ and smaller than $20 \mathrm{~nm}\left(x_{\text {gen }}(<20)\right)$, radon activity concentration $\left(C_{\mathrm{Rn}}^{\mathrm{A}}\right)$, equilibrium equivalent concentration of radon short-lived decay products $\left(C_{\mathrm{RnDP}}^{\mathrm{A}}\right)$, equilibrium factor between radon and radon short-lived decay products $(F)$, activity fraction of the unattached radon short-lived decay products $\left(f^{\mathrm{un}}\right)$, and number fraction of the unattached radon short-lived decay products $\left(x^{\mathrm{un}}\right)$, for the entire period of measurements indoors (28-31 October, 21-22 November, and 5-6 January), only when the door and window were closed and without any human activity.

\begin{tabular}{|c|c|c|c|c|}
\hline \multirow{2}{*}{ Parameter } & \multicolumn{4}{|c|}{28 October-6 January } \\
\hline & $\min$ & $\max$ & GM & GSD \\
\hline$C_{\mathrm{gen}}^{\mathrm{N}}($ tot $) / \mathrm{cm}^{-3}$ & 1840 & 13260 & 5120 & 1.50 \\
\hline$d_{\mathrm{GM}} / \mathrm{nm}$ & 22 & 87 & 57 & 1.24 \\
\hline$x_{\text {gen }}(<10)$ & 0.001 & 0.30 & 0.01 & 2.63 \\
\hline$x_{\text {gen }}(<20)$ & 0.004 & 0.59 & 0.08 & 2.08 \\
\hline$C_{\mathrm{Rn}}^{\mathrm{A}} / \mathrm{Bq} \mathrm{m}^{-3}$ & 28 & 834 & 229 & 1.96 \\
\hline$C_{\mathrm{RnDP}}^{\mathrm{A}} / \mathrm{Bq} \mathrm{m}^{-3}$ & 24 & 278 & 101 & 1.85 \\
\hline$F$ & 0.24 & 0.67 & 0.43 & 1.24 \\
\hline$f^{\text {un }}$ & 0.09 & 0.28 & 0.16 & 1.30 \\
\hline$x^{\mathrm{un}}$ & 0.08 & 0.36 & 0.17 & 1.45 \\
\hline
\end{tabular}

was stopped, a reversed situation was observed. Behaviour of the measured parameters during this process is shown in Figure 22. $C_{\text {gen }}^{\mathrm{N}}$ (tot) increased suddenly (Figure 22(a)), as did both $x_{\text {gen }}(<10)$ and $x_{\text {gen }}(<20)$, accompanied by a decrease in $d_{\mathrm{GM}}$ (Figure 22(a)). Because of the small coefficient for ${ }^{218} \mathrm{Po}$ in (1), even a large increase in both its number (Figure 22(e)) and activity concentration (Figure $22(\mathrm{~g})$ ) during boiling did not contribute enough to increase $f^{\text {un }}$ and $x^{\text {un }}$, and, hence, they remained practically unchanged (Figure 22(d)).

As already observed during other activities in previous sections, also here the inverse proportionality between $f$ un and $C_{\text {gen }}^{\mathrm{N}}($ tot $)$ was not observed.
3.3. $f^{\text {un }}-C_{\text {gen }}^{N}$ (tot) Relationship. An inverse proportionality between $f^{\text {un }}$ and $C_{\text {gen }}^{\mathrm{N}}$ (tot) has been observed in a number of cases [40,41], and Porstendörfer [33] proposed the following empirical relationship for it:

$$
f^{\text {un }}=\frac{400}{C_{\text {gen }}^{\mathrm{N}}(\text { tot }) / \mathrm{cm}^{-3}} .
$$

It was also found in the Postojna Cave $[40,45]$. In summer, air in the cave is stagnant, concentration of general aerosols is low, and $f$ un is high. The opposite is true in winter, when inflow of fresh air, caused by the chimney effect, introduces 


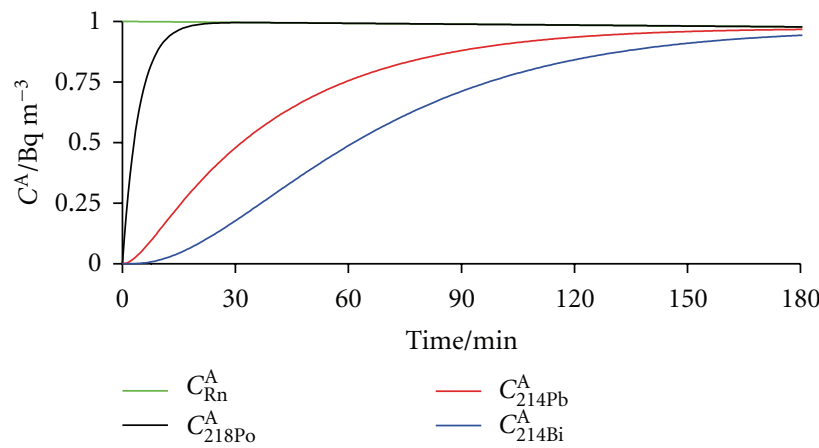

(a)

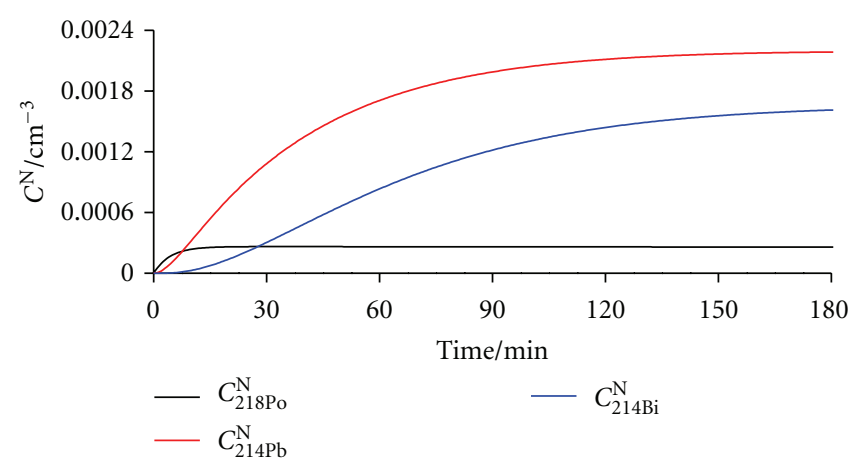

(b)

Figure 23: Growth of ${ }^{218} \mathrm{Po},{ }^{214} \mathrm{~Pb},{ }^{214} \mathrm{Bi}$, and ${ }^{214} \mathrm{Po}$ initiated by $\alpha$-transformation of ${ }^{222} \mathrm{Rn}$ (initial activity concentration of $1 \mathrm{~Bq} \mathrm{~m}^{-3}$, equivalent to 0.477 radon atoms $\mathrm{cm}^{-3}$ ), expressed in: (a) activity concentration and (b) number concentration of RnDP atoms.

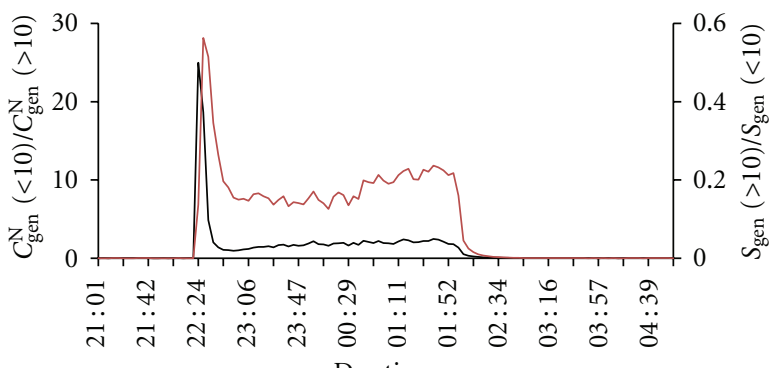

Day time

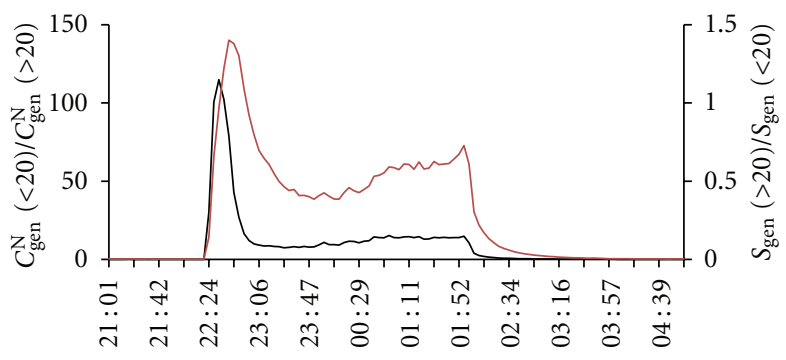

Day time
$-C$

(a)

(b)

FIGURE 24: Conditions of general aerosols during burning of a candle on January 5-6: (a) ratio of the number concentration of aerosol particles smaller than $10 \mathrm{~nm}\left(C_{\text {gen }}^{\mathrm{N}}(<10)\right)$ to that of bigger ones $\left(C_{\mathrm{gen}}^{\mathrm{N}}(>10)\right)$ and ratio of the total surface area of all particles smaller than $10 \mathrm{~nm}\left(S_{\text {gen }}(<10)\right)$ to the total surface area of all particles bigger than $10 \mathrm{~nm}\left(S_{\text {gen }}(>10)\right)$ in a volume unit and (b) ratio of the number concentration of aerosol particles smaller than $20 \mathrm{~nm}\left(C_{\mathrm{gen}}^{\mathrm{N}}(<20)\right)$ to that of bigger ones $\left(C_{\mathrm{gen}}^{\mathrm{N}}(>20)\right)$ and ratio of the total surface area of all particles smaller than $20 \mathrm{~nm}\left(S_{\text {gen }}(<20)\right)$ to the total surface area of all particles bigger than $20 \mathrm{~nm}\left(S_{\text {gen }}(>20)\right)$ in a volume unit.

outside aerosols, and their concentration in the cave is high, resulting in low $f$ un. These are two distinct seasons, separated by weeks or even months. Similarly, higher $f^{\text {un }}$ values were observed in flats near parks with lower aerosol concentration than near roads [47].

In our study, such proportionality was not observed. Changes in number concentration and size distribution of general aerosols were fast, lasting only minutes, or at most two hours (in the case of burning a candle). It is not expected that a change in size distribution will cause an immediate redistribution between unattached and attached RnDP. It will rather influence only the newly born RnDP atoms and clusters. Creation of RnDP atoms by radioactive transformations takes time (Figure 23); also, their neutralization, clustering, and attachment to [65] and detachment from general aerosol particles by recoil are processes with defined values of rate constants. Taking this into account, calculation would show [66] that a time delay of even more than hours [67] necessarily appears between a change in particle size distribution of general aerosols and a change in $f^{\text {un }}$. Therefore, a true dependence of $f^{\text {un }}$ on the changes in general aerosols in our study was masked or even totally obscured. We speculate that most probably this is the main reason for our failure to observe the expected inverse proportionality, and not only the considerable difference in the analysis frequencies of the two devices (once every 4 minutes for SMPS+C and once in two hours for EQF30202). Nevertheless, it would be useful to repeat some measurements using the devices with similar analysis frequencies.

Another reason may be also found in Figure 24, in which ratios of the number concentrations and total surface area of the smaller and larger particles are plotted for the period during candle burning. $C_{\text {gen }}^{\mathrm{N}}(<10)$ is about 2-fold higher than $C_{\text {gen }}^{\mathrm{N}}(>10)$, and the total surface area of smaller particles in a volume unit $\left(S_{\text {gen }}^{\mathrm{N}}(<10)\right)$ is about 5 -fold lower than that of the larger ones $\left(S_{\text {gen }}^{\mathrm{N}}(>10)\right)$ (Figure $\left.24(\mathrm{a})\right)$. In the case of $<20 \mathrm{~nm}$ particles, the situation is as follows (Figure 24(b)): $C_{\mathrm{gen}}^{\mathrm{N}}(<20)$ is about 10 -fold higher than $C_{\mathrm{gen}}^{\mathrm{N}}(>20)$, and the 
total surface area of smaller particles $\left(S_{\text {gen }}^{\mathrm{N}}(<20)\right)$ is about 2fold lower than that of the larger ones $\left(S_{\text {gen }}^{\mathrm{N}}(>20)\right)$. Therefore, a preference of $\mathrm{RnDP}$ atoms (clusters) for association with particles smaller than $20 \mathrm{~nm}$ and smaller than $10 \mathrm{~nm}$, with resulting lower $f^{\text {un }}$ values, may not be expected. It may be concluded that it is the total surface area of the smaller particles that controls the $f^{\text {un }}$ value and neither the total number aerosol concentration nor the number concentration of smaller particles.

\section{Conclusion}

Radon decay products (RnDP) and general aerosols were monitored simultaneously in a basement kitchen and in the courtyard of a farm in a suburban area. In the outdoor air, the total number concentration $\left(C_{\mathrm{gen}}^{\mathrm{N}}(\right.$ tot $\left.)\right)$ of general aerosols varies from $1000 \mathrm{~cm}^{-3}$ to $86,000 \mathrm{~cm}^{-3}$, with two daily maxima, one at around midnight and the other between 8:00 and 16:00. Number size distribution did not show a regular diurnal variation but rather varied from day to day, depending mostly on the solar radiation and intensity of farming equipment use.

In the indoor air, during periods without any human activity and with the window closed, $C_{\text {gen }}^{\mathrm{N}}($ tot $)$ varied from 2000 to $13,000 \mathrm{~cm}^{-3}, d_{\mathrm{GM}}$ from 22 to $87 \mathrm{~nm}, C_{\mathrm{Rn}}^{\mathrm{A}}$ from 28 to $834 \mathrm{~Bq} \mathrm{~m}^{-3}, C_{\mathrm{RnDP}}^{\mathrm{A}}$ from 24 to $278 \mathrm{~Bq} \mathrm{~m}^{-3}$, and $f$ un from 0.09 to 0.28 . $C_{\text {gen }}^{\mathrm{N}}$ (tot) increased substantially during toasting of bread and burning of a candle, reaching $670,000 \mathrm{~cm}^{-3}$ and $1,320,000 \mathrm{~cm}^{-3}$, respectively.

Even these large changes in concentration in indoor air did not change $f^{\text {un }}$ significantly, and the inverse proportionality of the $f^{\mathrm{un}}-C_{\mathrm{gen}}^{\mathrm{N}}$ (tot) relationship was not observed. Thus, even considerable effects of human activity on the general aerosol conditions were not reflected in changes of $f^{\text {un }}$, the important parameter in radon dosimetry. Obviously, not only the number concentration of general aerosols affects $f^{\text {un }}$ but also the particle size distribution. Although during the candle burning the concentration of particles smaller than $10 \mathrm{~nm}$ was several times higher than that of larger ones, in contrast, their total surface area was several times lower than that of the larger ones. Therefore, an enhancement of preferential association of $\mathrm{RnDP}$ atoms or clusters to smaller particles of general aerosols, and thus increasing $f^{\text {un }}$, can hardly be expected. In addition, creation of $\mathrm{RnDP}$ by radioactive transformation and their neutralization, clustering, and association with general aerosol particles are processes with certain values of rate constants. Therefore, the response of $f$ un to the changes in general aerosols is necessarily delayed, and a correct $f^{\text {un }}$ $C_{\text {gen }}^{\mathrm{N}}($ tot $)$ relationship is obscured.

\section{Acknowledgments}

This study was financed by the Slovenian Research Agency within a Research Program P1-0143. The authors thank Professor Ivan Kobal for his careful reading of their paper and constructive remarks.

\section{References}

[1] I. Colbeck, "Introduction to aerosol science," in Physical and Chemical Properties of Aerosols, I. Colbeck, Ed., pp. 5-120, Thomson Science, London, UK, 1998.

[2] U. Pöschl, "Atmospheric aerosols: composition, transformation, climate and health effects," Angewandte Chemie International Edition, vol. 44, no. 46, pp. 7520-7540, 2005.

[3] L. Morawska, Z. Ristovski, E. R. Jayaratne, D. U. Keogh, and X. Ling, "Ambient nano and ultrafine particles from motor vehicle emissions: characteristics, ambient processing and implications on human exposure," Atmospheric Environment, vol. 42, no. 35, pp. 8113-8138, 2008.

[4] P. Kumar, A. Robins, S. Vardoulakis, and R. Britter, "A review of the characteristics of nanoparticles in the urban atmosphere and the prospects for developing regulatory controls," Atmospheric Environment, vol. 44, no. 39, pp. 5035-5052, 2010.

[5] J. P. Shi, D. E. Evans, A. A. Khan, and R. M. Harrison, "Sources and concentration of nanoparticles ( $<10 \mathrm{~nm}$ diameter) in the urban atmosphere," Atmospheric Environment, vol. 35, no. 7, pp. 1193-1202, 2001.

[6] L. Han, G. Zhuang, Y. Sun, and Z. Wang, "Local and non-local sources of airborne particulate pollution at Beijing - the ratio of $\mathrm{Mg} / \mathrm{Al}$ as an element tracer for estimating the contributions of mineral aerosols from outside Beijing," Science in China Series B, vol. 48, no. 3, pp. 253-264, 2005.

[7] E. L. Agus, D. T. Young, J. J. N. Lingard et al., "Factors influencing particle number concentrations, size distributions and modal parameters at a roof-level and roadside site in Leicester, UK," Science of the Total Environment, vol. 386, no. 1-3, pp. 65-82, 2007.

[8] L. Young and G. J. Keeler, "Summertime ultrafine particles in urban and industrial air: Aitken and nucleation mode particle events," Aerosol and Air Quality Research, vol. 7, no. 3, pp. 379402, 2007.

[9] P. R. Buseck and K. Adachi, "Nanoparticles in the atmosphere," Elements, vol. 4, no. 6, pp. 389-394, 2008.

[10] P. Kumar, P. Fennell, and A. Robins, "Comparison of the behaviour of manufactured and other airborne nanoparticles and the consequences for prioritising research and regulation activities," Journal of Nanoparticle Research, vol. 12, no. 5, pp. 1523-1530, 2010.

[11] C. E. Mackay and K. H. Henry, "Environmental fate and transport," in Nanotechnology and the Environment, CRC Press, Taylor \& Francis, Boca Raton, Fla, USA, 2009.

[12] W. Hofmann and L. Koblinger, "Monte Carlo modeling of aerosol deposition in human lungs. Part II: deposition fractions and their sensitivity to parameter variations," Journal of Aerosol Science, vol. 21, no. 5, pp. 675-688, 1990.

[13] B. Alföldy, B. Giechaskiel, W. Hofmann, and Y. Drossinos, "Size-distribution dependent lung deposition of diesel exhaust particles," Journal of Aerosol Science, vol. 40, no. 8, pp. 652663, 2009.

[14] D. Nikezić, B. M. F. Lau, and K. N. Yu, "Comparison of dose conversion factors for radon progeny from the ICRP 66 regional model and an airway tube model of tracheo-bronchial tree," Radiation and Environmental Biophysics, vol. 45, no. 2, pp. 153-157, 2006.

[15] D. Nikezić, B. M. F. Lau, N. Stevanović, and K. N. Yu, "Absorbed dose in target cell nuclei and dose conversion coefficient of radon progeny in the human lung," Journal of Environmental Radioactivity, vol. 89, no. 1, pp. 18-29, 2006.

[16] G. Oberdörster, E. Oberdörster, and J. Oberdörster, "Nanotoxicology: an emerging discipline evolving from studies of 
ultrafine particles," Environmental Health Perspectives, vol. 113, no. 7, pp. 823-839, 2005.

[17] B. Nowack and T. D. Bucheli, "Occurrence, behavior and effects of nanoparticles in the environment," Environmental Pollution, vol. 150, no. 1, pp. 5-22, 2007.

[18] A. Nel, T. Xia, L. Mädler, and N. Li, "Toxic potential of materials at the nanolevel," Science, vol. 311, no. 5761, pp. 622-627, 2006.

[19] A. V. Nero, "Radon and its decay products in indoor air: an overview," in Radon and Its Decay Products in Indoor Air, W. M. Nazaroff and A. V. Nero, Eds., pp. 1-53, John Wiley \& Sons, New York, NY, USA, 1988.

[20] G. Etiope and G. Martinelli, "Migration of carrier and trace gases in the geosphere: an overview," Physics of the Earth and Planetary Interiors, vol. 129, no. 3-4, pp. 185-204, 2002.

[21] K. D. Chu and P. K. Hopke, "Neutralization kinetics for polonium-218," Environmental Science \& Technology, vol. 22, no. 6, pp. 711-717, 1988.

[22] J. Porstendörfer and A. Reineking, "Indoor behaviour and characteristics of radon progeny," Radiation Protection Dosimetry, vol. 45, no. 1-4, pp. 303-311, 1992.

[23] P. K. Hopke, "The initial atmospheric behavior of radon decay products," Journal of Radioanalytical and Nuclear Chemistry, vol. 203, no. 2, pp. 353-375, 1996.

[24] S. D. Goldstein and P. K. Hopke, "Environmental neutralization of polonium-218," Environmental Science and Technology, vol. 19, no. 2, pp. 146-150, 1985.

[25] V. Dankelmann, A. Reineking, and J. Porstendörfer, "Determination of neutralisation rates of ${ }^{218}$ Po ions in air," Radiation Protection Dosimetry, vol. 94, no. 4, pp. 353-357, 2001.

[26] S. D. Schery, Understanding Radioactive Aerosols and Their Measurements, Kluwer Academic Publishers, Dordrecht, The Netherlands, 2001.

[27] P. Pagelkopf and J. Porstendörfer, "Neutralisation rate and the fraction of the positive ${ }^{218}$ Po-clusters in air," Atmospheric Environment, vol. 37, no. 8, pp. 1057-1064, 2003.

[28] C. Papastefanou, "Radioactive aerosols," in Radioactivity in the Environment, M. Baxter, Ed., Elsevier, Amsterdam, The Netherlands, 2008.

[29] K. Fukutsu, Y. Yamada, S. Tokonami, and T. Iida, "Newly designed graded screen array for particle size measurements of unattached radon decay products," Review of Scientific Instruments, vol. 75, no. 3, pp. 783-787, 2004.

[30] K. W. Tu, E. O. Knutson, and A. C. George, "Indoor radon progeny aerosol size measurements in urban, suburban, and rural regions," Aerosol Science and Technology, vol. 15, no. 3, pp. 170-178, 1991.

[31] P. K. Hopke, P. Wasiolek, N. Montassier, A. Cavallo, K. Gadsby, and R. Socolow, "Measurement of activity-weighted size distributions of radon decay products in a normally occupied home," Radiation Protection Dosimetry, vol. 45, no. 1-4, pp. 329-331, 1992.

[32] J. Porstendörfer, "Physical parameters and dose factors of the radon and thoron decay products," Radiation Protection Dosimetry, vol. 94, no. 4, pp. 365-373, 2001.

[33] J. Porstendörfer, "Radon: measurements related to dose," Environment International, vol. 22, no. 1, pp. S563-S583, 1997.

[34] Y. S. Cheng, T. R. Chen, H. C. Yeh et al., "Intercomparison of activity size distribution of thoron progeny and a mixture of radon and thoron progeny," Journal of Environmental Radioactivity, vol. 51, no. 1, pp. 59-78, 2000.

[35] United Nations Scientific Committee on the Effects of Atomic Radiation (UNSCEAR), Sources and Effects of Ionizing Radiation, United Nations Pubns, New York, NY, USA, 2000.
[36] S. Darby, D. Hill, A. Auvinen et al., "Radon in homes and risk of lung cancer: collaborative analysis of individual data from 13 European case-control studies," British Medical Journal, vol. 330, no. 7485, pp. 223-226, 2005.

[37] International Commission on Radiological Protection (ICRP), Protection against Radon-222 at Home and at Work, ICRP Publication 65, Elsevier, Oxford, UK, 1994.

[38] A. Birchall and A. C. James, "Uncertainty analysis of the effective dose per unit exposure from radon progeny and implications for ICRP risk-weighting factors," Radiation Protection Dosimetry, vol. 53, no. 1-4, pp. 133-140, 1994.

[39] J. W. Marsh, A. Birchallt, G. Butterweck et al., "Uncertainty analysis of the weighted equivalent lung dose per unit exposure to radon progeny in the home," Radiation Protection Dosimetry, vol. 102, no. 3, pp. 229-248, 2002.

[40] G. Butterweck, J. Porstendörfer, A. Reineking, and J. Kesten, "Unattached fraction and the aerosol size distribution of the radon progeny in a natural cave and mine atmospheres," Radiation Protection Dosimetry, vol. 45, no. 1-4, pp. 167-170, 1992.

[41] Y. S. Cheng, T. R. Chen, P. T. Wasiolek, and A. van Engen, "Radon and radon progeny in the carlsbad caverns," Aerosol Science and Technology, vol. 26, no. 1, pp. 74-92, 1997.

[42] C. Sainz, L. S. Quindós, I. Fuente, J. Nicolás, and L. Quindós, "Analysis of the main factors affecting the evaluation of the radon dose in workplaces: the case of tourist caves," Journal of Hazardous Materials, vol. 145, no. 3, pp. 368-371, 2007.

[43] L. Thinová and I. Burian, "Effective dose assessment for workers in caves in the Czech Republic: experiments with passive radon detectors," Radiation Protection Dosimetry, vol. 130, no. 1, pp. 48-51, 2008.

[44] J. Vaupotič, "Nanosize radon short-lived decay products in the air of the Postojna Cave," Science of the Total Environment, vol. 393, no. 1, pp. 27-38, 2008.

[45] I. Iskra, N. Kávási, and J. Vaupotič, "Nano aerosols in the Postojna Cave,” Acta Carsologica, vol. 39, no. 3, pp. 523-528, 2010.

[46] K. N. Yu, E. C. M. Young, and K. C. Li, "A survey of radon properties for dwellings for Hong Kong," Radiation Protection Dosimetry, vol. 63, no. 1, pp. 55-62, 1996.

[47] K. N. Yu, E. C. M. Young, and K. C. Li, "A study of factors affecting indoor radon properties," Health Physics, vol. 71, no. 2, pp. 179-184, 1996.

[48] K. N. Yu, E. C. Young, M. J. Stokes, Z. J. Guan, and K. W. Cho, "A survey of radon and thoron progeny for dwellings in Hong Kong," Health Physics, vol. 73, no. 2, pp. 373-377, 1997.

[49] K. N. Yu, T. Cheung, Z. J. Guan, E. C. M. Young, B. W. N. Mui, and Y. Y. Wong, "Concentrations of ${ }^{222} \mathrm{Rn},{ }^{220} \mathrm{Rn}$ and their progeny in residences in Hong Kong," Journal of Environmental Radioactivity, vol. 45, no. 3, pp. 291-308, 1999.

[50] S. Tokonami, T. Matsuzawa, T. Ishikawa, T. Iimoto, H. Yonehara, and Y. Yamada, "Changes in indoor aerosol characteristics and their associated variation on the dose conversion factor due to radon progeny inhalation," Radioisotopes, vol. 52, pp. 285-292, 2003.

[51] K. P. Markov, N. V. Ryabov, and K. N. Stas', "A rapid method for estimating the radiation hazard associated with the presence of radon daughter products in air," Atomic Energy, vol. 12, no. 4, pp. 333-337, 1962.

[52] T. Streil, G. Holfeld, V. Oeser, C. Federsen, and K. Schönfeld, "SARAD EQF 3020: a new microsystem based on monitoring system for the continuous measurement of radon and the attached and unattached fraction of radon progeny," in Proceedings of the IRPA Regional Congress on Regional Congress 
on Radiation Protection in Neighbouring Countries in Central, D. Glavič-Cindro, Ed., pp. 334-341, Portorož, Slovenia, 1996.

[53] C. S. Wen, Fundamentals of Aerosol Dynamics, World Scientific, Singapore, 1996.

[54] M. Shimo and H. Saito, "Size distribution of radon progeny aerosols in indoor and outdoor air," Journal of Environmental Radioactivity, vol. 51, no. 1, pp. 49-57, 2000.

[55] M. Humar, T. Šutej, J. Skvarč, L. Mljač, M. Radež, and R. Ilić, "Indoor and outdoor radon survey in Slovenia by etched track detectors," Radiation Protection Dosimetry, vol. 45, no. 1-4, pp. 549-552, 1992.

[56] C. A. Noble, S. Mukerjee, M. Gonzales et al., "Continuous measurement of fine and ultrafine particulate matter, criteria pollutants and meteorological conditions in urban El Paso, Texas," Atmospheric Environment, vol. 37, no. 6, pp. 827-840, 2003.

[57] Y. Wang, P. K. Hopke, D. C. Chalupa, and M. J. Utell, "Longterm study of urban ultrafine particles and other pollutants," Atmospheric Environment, vol. 45, no. 40, pp. 7672-7680, 2011.

[58] F. Wang, F. Costabileb, H. Li, D. Fang, and I. Alligrini, measurement of ultrafine particle size distribution near Rome," Atmospheric Research, vol. 98, no. 1, pp. 69-77, 2010.

[59] H. Minoura and H. Takekawa, "Observation of number concentrations of atmospheric aerosols and analysis of nanoparticle behavior at an urban background area in Japan," Atmospheric Environment, vol. 39, no. 32, pp. 5806-5816, 2005.

[60] M. Smerajec, A. Gregorič, S. Džeroski, and J. Vaupotič, "Continuous measurements of ultrafine particles at urban background site of Ljubljana," in Proceedings of the 11th European Meeting on Environmental Chemistry (EMEC '11), P. Trebše, M. Petrič, and V. Lavtižar, Eds., p. 237, University Nova Gorica, Portorož, Slovenia, 2010.

[61] M. Kulmala, H. Vehkamäki, T. Petäjä et al., "Formation and growth rates of ultrafine atmospheric particles: a review of observations," Journal of Aerosol Science, vol. 35, no. 2, pp. 143-176, 2004.

[62] T. Hussein, K. Hämeri, M. S. A. Heikkinen, and M. Kulmala, "Indoor and outdoor particle size characterization at a family house in Espoo-Finland," Atmospheric Environment, vol. 39, no. 20, pp. 3697-3709, 2005.

[63] O. Meisenberg and J. Tschiersch, "Online measurement of unattached and total radon and thoron decay products," Applied Radiation and Isotopes, vol. 67, no. 5, pp. 843-848, 2009.

[64] W. Birmili, H. Berresheim, C. Plass-Dülmer et al., "The Hohenpeissenberg aerosol formation experiment (HAFEX): a long-term study including size-resolved aerosol, $\mathrm{H}_{2} \mathrm{SO}_{4}, \mathrm{OH}$, and monoterpenes measurements," Atmospheric Chemistry and Physics, vol. 3, no. 2, pp. 361-376, 2003.

[65] S. Tokonami, "Experimental verification of the attachment theory of radon progeny onto ambient aerosols," Health Physics, vol. 78, no. 1, pp. 74-79, 2000.

[66] D. Nikolopoulos and E. Vogiannis, "Modelling radon progeny concentration variations in thermal spas," Science of the Total Environment, vol. 373, no. 1, pp. 82-93, 2007.

[67] J. Wang, O. Meisenberg, Y. Chen, E. Karg, and J. Tschiersch, "Mitigation of radon and thoron decay products by filtration," Science of the Total Environment, vol. 409, no. 19, pp. 36133619, 2011. 

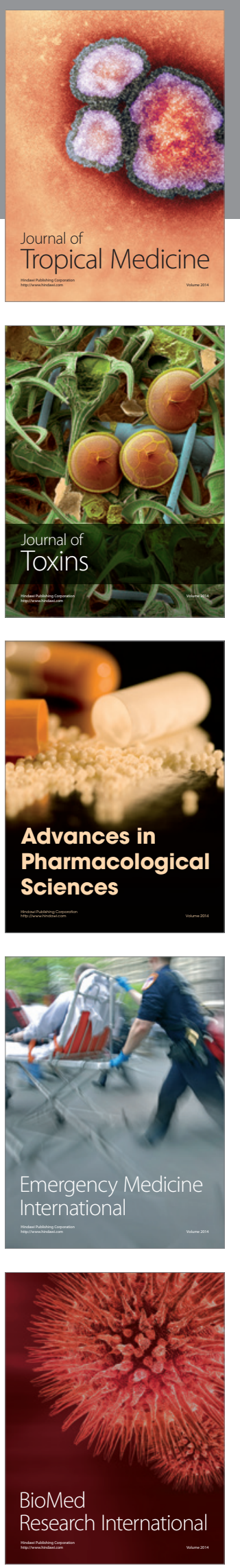
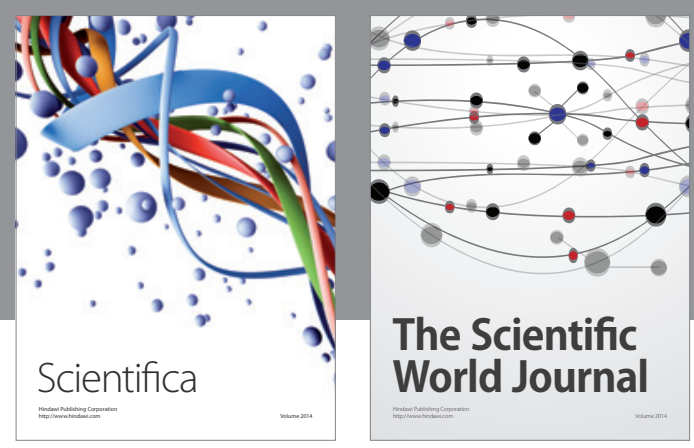

The Scientific World Journal
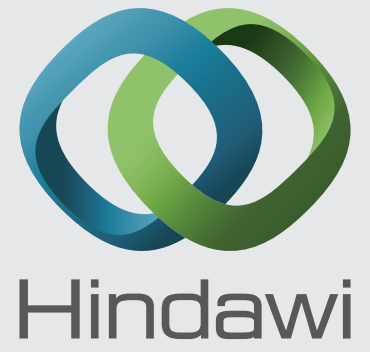

Submit your manuscripts at

http://www.hindawi.com
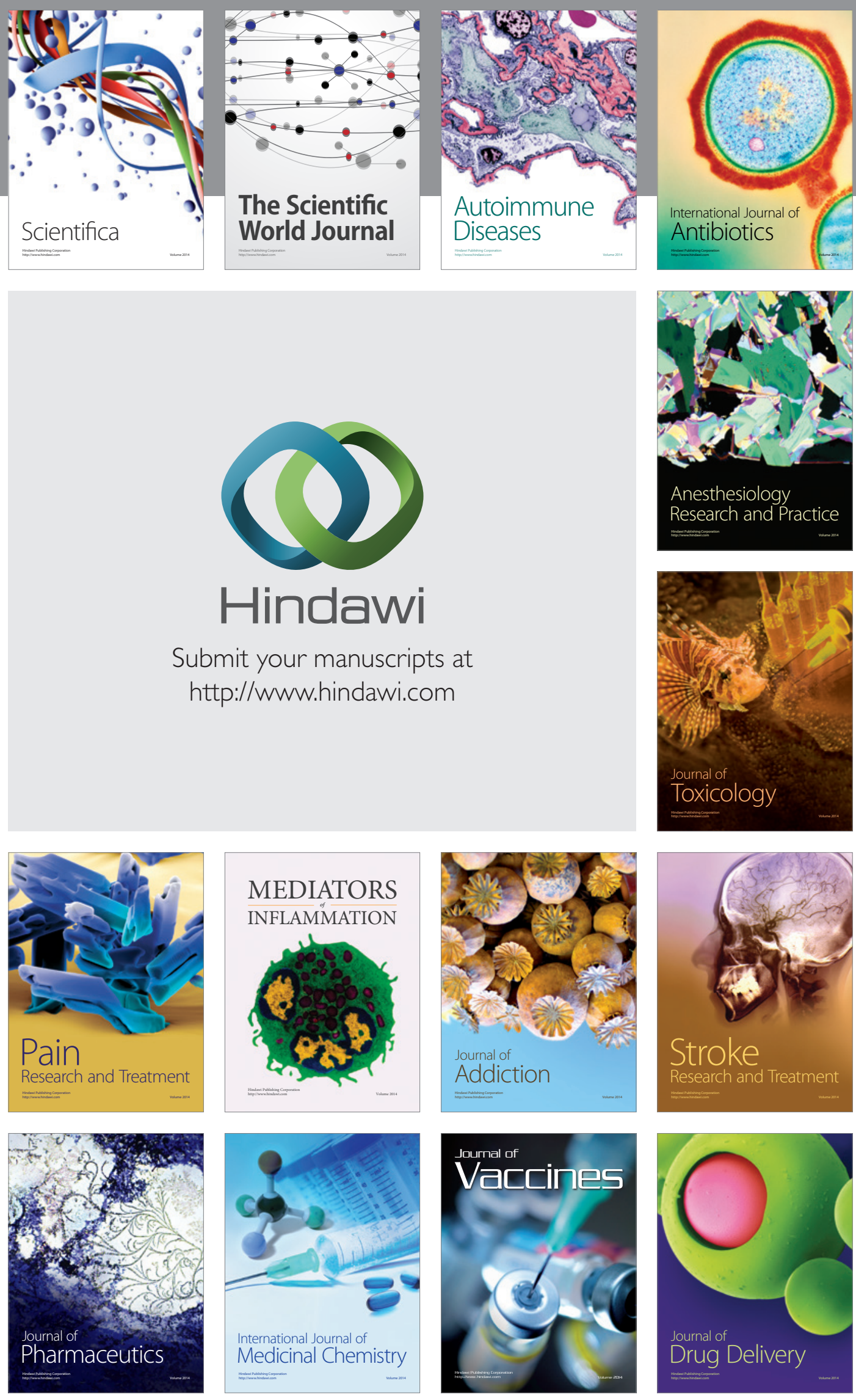